\title{
PRODUTIVIDADE DO Eucalyptus sp. EM FUNÇÃO DO ESTADO NUTRICIONAL E DA FERTILIDADE DO SOLO EM DIFERENTES REGIÕES DO ESTADO DE SÃO PAULO
}

\author{
FÁBIO SGARBI
}

Dissertação apresentada à Escola Superior de Agricultura "Luiz de Queiroz", Universidade de São Paulo, para obtenção do título de Mestre em Recursos Florestais, Área de Concentração: Recursos Florestais, com opção em Manejo de Florestas de Produção.

PIRACICABA

Estado de São Paulo - Brasil

Março - 2002 


\title{
PRODUTIVIDADE DO Eucalyptus sp. EM FUNÇÃO DO ESTADO NUTRICIONAL E DA FERTILIDADE DO SOLO EM DIFERENTES REGIÕES DO ESTADO DE SÃO PAULO
}

\section{FÁBIO SGARBI}

Engenheiro Florestal

Orientador: Prof. Dr. HILTON THADEU ZARATE DO COUTO

\begin{abstract}
Dissertação apresentada à Escola Superior de Agricultura "Luiz de Queiroz", Universidade de São Paulo, para obtenção do título de Mestre em Recursos Florestais, Área de Concentração: Recursos Florestais, com opção em Manejo de Florestas de Produção.
\end{abstract}

PIRACICABA

Estado de São Paulo - Brasil

Março - 2002 
Dados Internacionais de Catalogação na Publicação (CIP) DIVISÃO DE BIBLIOTECA E DOCUMENTAÇÃO - ESALQ/USP

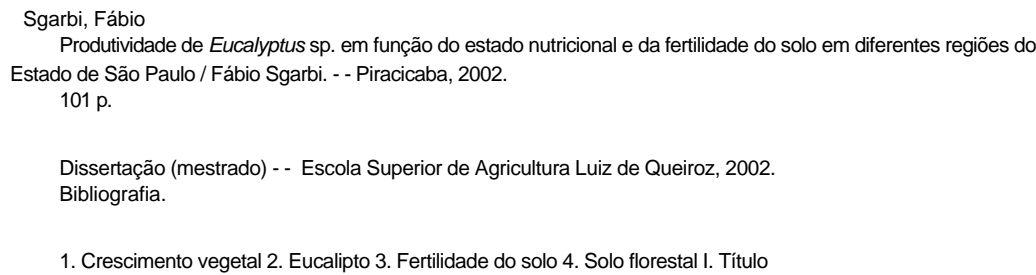

CDD 634.9734

"Permitida a cópia total ou parcial deste documento, desde que citada a fonte - $\mathrm{O}$ autor" 
Dedico este trabalho a minha noiva, Anelise, pelo apoio e compreensão durante toda a execução deste trabalho. 


\section{AGRADECIMENTOS}

Ao Prof. Dr. Hilton Thadeu Zarate do Couto pela orientação dada durante a execução deste trabalho.

Ao Eng. Ftal. Ronaldo Luiz Vaz de Arruda Silveira e ao Biol. Edson Namita Higashi pela orientação técnica, pela parceria nos trabalhos científicos realizados e por todos os ensinamentos que muito irão contribuir em minha vida profissional.

Ao Sr. Fábio Spina França, representando a Siderúrgica Barra Mansa S.A., ao Sr. Walter Jacob, representando a Votorantim Celulose S.A. e ao Sr. Constantino Barros Lordello Neto, representando a Lwarcel Celulose e Papel Ltda., pelo fornecimento dos dados necessários para a realização deste trabalho.

Ao Prof. Dr. Paulo César Sentelhas pela disponibilização das informações necessárias para a realização dos balanços hídricos nas três regiões do Estado de São Paulo.

Ao Tec. Lab. Jeferson, pelo suporte técnico e disponibilidade junto ao Laboratório de Métodos Quantitativos, assim como, pela amizade compartilhada.

A Ana Júlia, Fabiano (Roco), Flávia Capaldi, Juliana (Juá), Laerte, Mario, Paulo (Nelore) e a Tatiana (Sacarose) pelos momentos de dificuldade e de alegria compartilhados juntos.

Ao Carlos Eduardo Pessoa Filho, representando a Monsanto do Brasil Ltda., pelo apoio e compreensão durante a realização deste trabalho. 


\section{SUMÁRIO}

Página

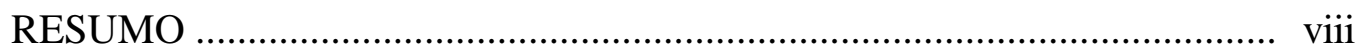

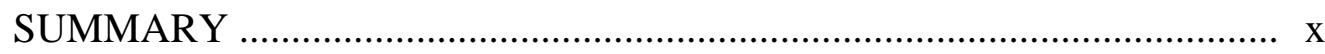

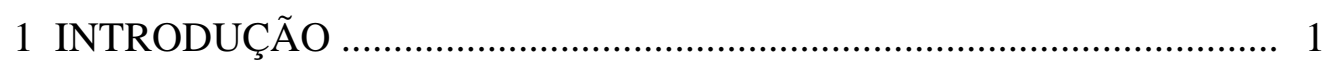

2 REVISÃO DE LITERATURA ..................................................... 2

2.1 Definição de sítio ....................................................................... 2

2.1.1 Avaliação da capacidade produtiva do sítio ...................................... 2

2.1.2 Construção das curvas de índice de sítio ....................................... 2

2.1.3 Método da curva guia ................................................................ 4

2.2 Avaliação do estado nutricional ...................................................... 5

2.2.1 Diagnose foliar ....................................................................... 6

2.2.2 Amostragem de tecido foliar .................................................... 7

2.2.3 Interpretação da análise foliar ................................................. 8

2.3 Avaliação da fertilidade do solo ....................................................... 8

2.3.1 Amostragem de solo ................................................................... 9

2.3.2 Interpretação da análise de solo .................................................. 10

2.4 Relação entre estado nutricional e produtividade de Eucalyptus sp. ...... 11

2.5 Relação entre fertilidade do solo e produtividade esperada ................... 16

2.6 Sistema integrado de diagnose e recomendação (DRIS) ...................... 21

3 MATERIAL E MÉTODOS ............................................................. 24

3.1 Local e área do levantamento ........................................................ 24

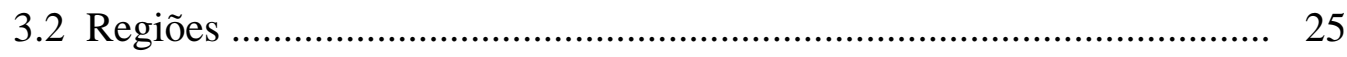

3.2.1 Capão Bonito ......................................................................... 25

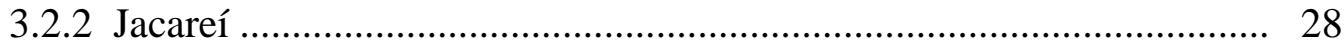


3.2.3 Lençóis Paulista ............................................................................... 29

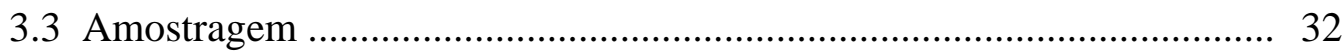

3.3.1 Parcelas ..................................................................................... 32

3.3.2 Amostragem de solos e folhas ………………………………....... 33

3.4 Avaliações ................................................................................ 33

3.4.1 Levantamento pedológico .............................................................. 33

3.4.2 Avaliação do balanço hídrico ……………………………………….... 34

3.4.3 Avaliação da produtividade ............................................................. 34

3.4.4 Análise dos parâmetros químicos de solo e teores foliares de

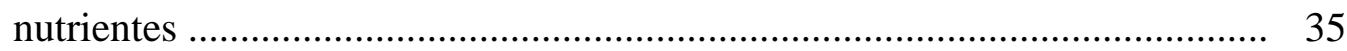

3.4.5 Avaliação do estado nutricional e da fertilidade do solo ....................... 36

3.5 Relação do estado nutricional e da fertilidade do solo com a produtividade .................................................................................... 38

3.6 Sistema integrado de diagnose e recomendação (DRIS) ………………... 40

4 RESULTADOS E DISCUSS ÃO ……………………........................... 41

4.1 Levantamento pedológico ……………………………………………... 41

4.1.1 Capão Bonito ………………………………………………………... 41

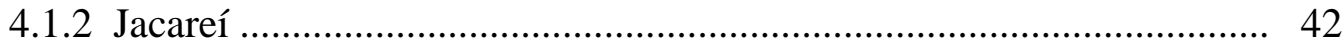

4.1.3 Lençóis Paulista ............................................................................. 43

4.2 Avaliação do balanço hídrico ................................................................ 44

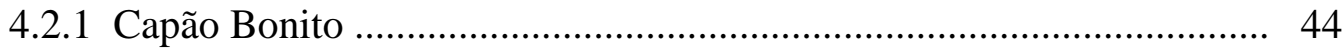

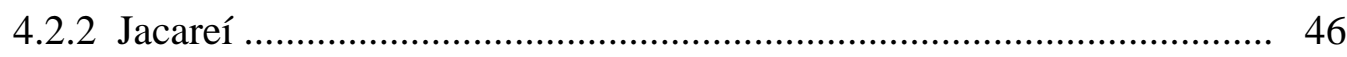

4.2.3 Lençóis Paulista ............................................................................. 48

4.3 Avaliação da produtividade .................................................................... 49

4.3.1 Capão Bonito …………………………………......................... 54

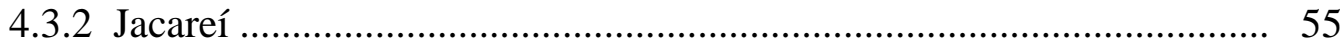

4.3.3 Lençóis Paulista ............................................................................. 56

4.3.4 Todas as regiões .......................................................................... 57

4.4 Avaliação do estado nutricional e da fertilidade do solo .......................... 58

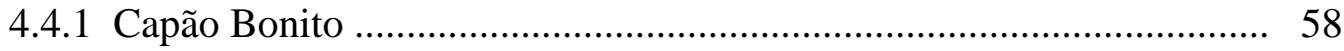




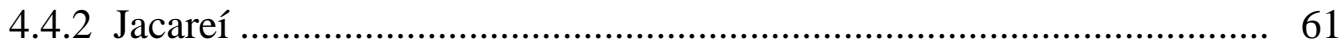

4.4.3 Lençóis Paulista ................................................................................. 62

4.4.4 Todas as regiões ...................................................................... 65

4.5 Relação do estado nutricional e da fertilidade do solo com a

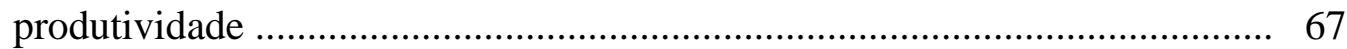

4.5.1 Estado nutricional e produtividade ............................................ 67

4.5.2 Parâmetros químicos do solo e produtividade .................................. 72

4.5.3 Estado nutricional e parâmetros químicos do solo ............................. 73

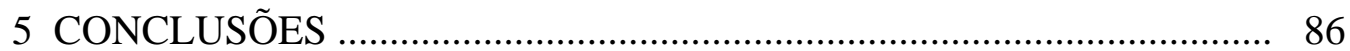

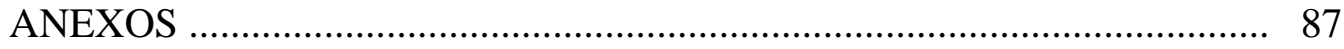

REFERÊNCIAS BIBLIOGRÁFICAS ............................................... 95 


\title{
PRODUTIVIDADE DO Eucalyptus sp. EM FUNÇÃO DO ESTADO NUTRICIONAL E DA FERTILIDADE DO SOLO EM DIFERENTES REGIÕES DO ESTADO DE SÃO PAULO
}

\author{
Autor: FÁBIO SGARBI \\ Orientador: Prof. Dr. HILTON THADEU ZARATE DO COUTO
}

\section{RESUMO}

Grande parte dos plantios de Eucalyptus sp., no Estado de São Paulo, apresentam limitações nutricionais as quais comprometem o crescimento e a sustentabilidade das florestas ao longo dos ciclos. Isso se deve a elevada exportação de nutrientes, durante a colheita da madeira associada a baixa fertilidade dos solos e a insuficiente utilização insumos, nestas áreas. Através de metodologias clássicas, é possível monitorar estes plantios visando a identificação dos nutrientes e dos parâmetros químicos do solo mais limitantes para o crescimento do Eucalyptus sp. Neste estudo, foram levantadas três regiões no Estado de São Paulo (Capão Bonito, Jacareí e Lençóis Paulista), durante os anos de 1997 a 2000. Para tanto, foram amostradas 209 parcelas, 117 talhões e 21 fazendas, totalizando 2.215 ha. As florestas estaram 12 a 45 meses de idade. Em cada talhão, foram locadas parcelas contendo 25 a 50 plantas, nas quais foram realizadas medições de altura das árvores visando a determinação do índice de sítio, assim como, amostragem de folhas e de solo, visando a determinação dos teores foliares dos nutrientes e dos parâmetros químicos do solo. Posteriormente, foi feita a análise dos dados através do método do nível crítico, das análises de correlação e de regressão linear e através do sistema integrado de diagnose e recomendação (DRIS). Verificou-se que os 
nutrientes mais limitantes para o crescimento do Eucalyptus sp. foram: boro, fósforo, nitrogênio e excesso de cobre nas regiões de Capão Bonito e Jacareí; o excesso de manganês, nas regiões de Jacareí e Lençóis Paulista; magnésio, potássio e o excesso de cálcio, na região de Lençóis Paulista. 


\title{
Eucalyptus sp. IN FUNCTION OF NUTRIENT STATUS AND SOIL FERTILITY IN THREE REGIONS OF THE STATE OF SÃO PAULO, BRAZIL
}

\author{
Author: FÁBIO SGARBI \\ Adviser: Prof. Dr. HILTON THADEU ZARATE DO COUTO
}

\section{SUMMARY}

Eucalyptus sp. stands, in the state of São Paulo, Brazil, present some nutrient limitations that can implicate growth and sustainability of the forests in the future. It happens because of high nutrient exportation during timber harvesting and also because of the low soil fertility and insufficient use of fertilizers in these areas. Through classic methodologies, the identification of the limiting nutrients is possible to monitor these stands and to determine the nutrient and the chemical parameters that limiting the growth. It were surveyed three regions of the state of São Paulo (Capão Bonito, Jacareí and Lençóis Paulista), during the years of 1997 to 2000. Data were collected in 209 sample plots, in 117 stands of 21 farms, totalizing 2.215 ha. The ages surveyed varied from 12 to 45 months old. Sample plots had 25 and 50 trees, that we measured total height for site index estimation (base age 7 years). Leaf and soil samples were collected to determine the nutrient content in the leaves and the soil chemical nutrients. Data were analyzed based in the method of the critical level, analyses of correlation and linear regression and through the diagnose and recommendation based on integrated system (DRIS). It was verified that the nutrients that limit Eucalyptus sp. growth were: boron, phosphorus, nitrogen and high copper content in Capão Bonito and Jacareí regions; the high manganese content in Jacareí and Lençóis Paulista regions and high calcium 
content, along with low magnesium and potassium content in the Lençóis Paulista region. 


\section{INTRODUÇÃO}

Os plantios de Eucalyptus sp. apresentam elevada mobilização de nutrientes em função do seu rápido crescimento.

A colheita da madeira, em ciclos que variam de 7 a 21 anos (1 a 3 rotações sucessivas), resultam em grandes exportações de nutrientes, reduzindo consequentemente a disponibilidade dos mesmos para as futuras rotações. Essa situação torna-se ainda mais agravante pelo fato da maioria dos plantios florestais concentrarem em solos de baixa fertilidade natural, como os Latossolos e Argilossolos distróficos ou álicos e os Neossolos Quartzarênicos, e também devido a insuficiente utilização de corretivos e fertilizantes.

Há, desta forma, um déficit nutricional bastante acentuado, principalmente em relação ao nitrogênio, potássio, cálcio, magnésio, enxofre, boro e zinco, podendo com isso, comprometer a produtividade e a sustentabilidade florestal ao longo dos anos.

A avaliação do estado nutricional e da fertilidade do solo, através de algumas metodologias clássicas, como o método do nível crítico, a análise de correlação e de regressão linear e o Sistema Integrado de Diagnose e Recomendação (DRIS), possibilita identificar os nutrientes que podem estar sendo mais limitantes para o crescimento do Eucalyptus sp., sendo possível a realização de adubações corretivas visando tanto a manutenção como o aumento da produtividade florestal.

Este trabalho teve por objetivo identificar os nutrientes mais limitantes para o crescimento do Eucalyptus sp., em três diferentes regiões do Estado de São Paulo. Este objetivo foi atingido através da interpretação dos resultados obtidos pelo método do nível crítico, das análises de correlação e de regressão linear e pelo Sistema Integrado de Diagnose e Recomedação (DRIS). 


\section{REVISÃO DE LITERATURA}

\subsection{Definição de sítio}

Coile (1952), Castanõs (1962) e Spurr (1964) definem "sítio" como sendo uma unidade de área que apresenta características combinadas de solo, topografia e clima, as quais são responsáveis pela determinação da capacidade produtiva do local. As práticas silviculturais como preparo de solo, adubação, controle das plantas daninhas e controle de pragas e doenças também determinam a capacidade produtiva do local e por esta razão devem ser consideradas na definição de "sítio".

Clutter et al. (1983) mencionam que, além dos fatores ambientais, é importante considerar o genótipo para a classificação do sítio. O material genético (espécie, progênie, clone) pode apresentar um elevado crescimento num determinado sítio enquanto em outro não. No entanto, Gonçalves et al. (1990) não encontraram diferenças significativas entre as espécies de E. grandis e E. saligna quando relacionaram a produtividade com as características químicas e físicas dos solos, em diferentes regiões do Estado de São Paulo.

\subsubsection{Avaliação da capacidade produtiva do sítio}

Os métodos existentes para avaliar a capacidade produtiva do sítio, de acordo com Clutter et al. (1983), podem ser classificados como diretos e indiretos.

Os métodos diretos podem se basear na (a) estimativa através de dados históricos de produção, (b) estimativa baseada em dados volumétricos do povoamento e (c) estimativa baseada em dados de altura do povoamento.

Os métodos indiretos, por outro lado, podem se basear na (a) estimativa através da relação histórica entre as espécies, (b) estimativa através das características da vegetação do sub-bosque e (c) estimativa através da topografia, clima e dos fatores edáficos. 
Segundo estes autores, os métodos diretos para avaliação da capacidade produtiva do sítio, geralmente, fornecem estimativas mais precisas quando comparado aos métodos indiretos. A estimativa da capacidade produtiva do sítio através da altura das árvores dominantes e co-dominantes é a mais aceita, sendo comprovado o fato de que sítios mais produtivos resultam em alturas médias mais elevadas (Coile, 1952; Barnes \& Ralston, 1955 e Clutter et al. 1983).

A altura das árvores dominantes e co-dominantes (MHDOM) é definida como sendo a altura média das 100 árvores de maior DAP por hectare, obtidas através de parcelas permanentes ou temporárias (Philip, 1994). Isto se deve a maior facilidade de determinação do DAP em relação a altura total das árvores.

A variável MHDOM é bastante útil nos estudos que relacionam a produtividade com os fatores edáfo-climáticos, pois sofre pouca influência da competição exercida entre os indivíduos que crescem no mesmo sítio. Em outras palavras, esta variável apresenta menor influência da densidade de plantio, ao contrário de outras comumente usadas para a avaliação da produtividade florestal como: incremento médio anual (IMA), incremento corrente anual (ICA), área basal e volume total (Coile, 1952; Golfari, 1971;

Spurr \& Barnes, 1973; Campos \& Turnbull, 1980; Hagglund, 1981 e Clutter et al., 1983).

Gonçalves et al. (1990) verificaram que a utilização do volume sólido de madeira com casca, como variável resposta no modelo, apresentou melhores ajustes quando comparado com o índice de sítio. Os autores, entretanto, concluíram que a utilização do índice de sítio proporcionou estimativas mais realistas quando comparado ao volume sólido de madeira com casca.

\subsubsection{Construção das curvas de índice de sítio}

Muitos métodos de avaliação do potencial produtivo do sítio, baseados na altura média das árvores dominantes, envolvem a utilização das curvas de índice de sítio.

As curvas de índice de sítio são desenvolvidas para uma idade base ou idade índice, sendo a idade de corte ou rotação, a referência mais utilizada (Clutter et al., 1983). 
Clutter et al. (1983) classificaram as equações de índice de sítio de acordo com a natureza das famílias de curvas geradas a partir do modelo: altura $=\mathrm{f}$ (idade). Deste modo, as famílias de curvas podem ser classificadas como: (a) anamórficas, sendo que a altura de uma das curvas é sempre proporcional a altura das demais, numa mesma idade, (b) polimórficas descontínuas, sendo que a proporcionalidade das alturas não se mantém e as curvas não se cruzam dentro do intervalo estabelecido e (c) polimórficas não descontínuas, sendo que a proporcionalidade das alturas não se mantém e as curvas se cruzam dentro do intervalo estabelecido.

Quando se utiliza parcelas temporárias para determinação da relação altura $=\mathrm{f}$ (idade), geralmente é possível obter apenas equações de índice de sítio do tipo anamórficas (Clutter, et al. 1983). Entretanto, diferentes técnicas tem sido utilizadas para se ajustar as curvas de índice de sítio como: (1) método da Curva Guia; (2) método da equação da diferença e (3) método da predição dos parâmetros.

\subsubsection{Método da curva guia}

O método da curva guia é utilizado para equações de índice de sítio do tipo anamórficas. Schumaker ${ }^{1}$, citado por Clutter et al. (1983), propõe o seguinte modelo:

$$
H_{i}=K_{o i} e^{\beta_{1} A^{-1}}
$$

sendo:

$H i=$ altura na idade $\mathrm{A}$ da curva $\mathrm{i}$

$K_{o i}=$ constante da ísima curva

$\beta_{l}=$ constante com valor igual para todas as curvas

1 SCHUMACHER, F.X. A new growth curve and its application to timber yield studies. Journal of Forest. v.37, 819-820, 1939. 
O modelo apresentado anteriormente é normalmente usado na forma logarítmica como:

$$
\begin{gathered}
\ln (H)=\beta_{0}+\beta_{1} A^{-1} \\
\operatorname{ou} \\
\ln (H)=b_{o i}+b_{1} A^{-1}
\end{gathered}
$$

quando o modelo representa um sítio específico

Por definição, $H=\mathrm{S}$ quando $A=A_{B}$ (idade base), portanto:

$$
\begin{gathered}
b_{o i}=\ln (S)-b_{1} A_{B}^{-1} \\
\text { Substituindo (4) em (3), tem-se } \\
\ln (H)=\ln (S)+b_{1}\left(A^{-1}-A_{B}^{-1}\right) \\
\text { ou } \\
\ln (S)=\ln (H)-b_{1}\left(A^{-1}-A_{B}^{-1}\right)
\end{gathered}
$$

O índice de sítio em cada unidade de produção (projeto, horto, talhão) é obtido da seguinte forma: (a) determinação da relação existente entre a idade e a altura das árvores, através da equação (3); (b) substituição do $b_{1}$ obtido na equação (6); (c) substituição do $A_{B}$ pela idade de corte da floresta ou rotação, na equação (6) e (d) determinação do $\mathrm{S}$, em cada unidade de produção, através da equação (6);

\subsection{Avaliação do estado nutricional}

A avaliação do estado nutricional consiste na comparação entre uma amostra, planta ou conjunto de plantas na qual se deseja avaliar o estado nutricional e o padrão, planta ou conjunto de plantas "normais" do ponto de vista nutricional. Uma planta normal é aquela que, ao apresentar quantidades e proporções adequadas dos nutrientes no tecido foliar, resulta em uma alta produtividade (Malavolta et al., 1997). 


\subsubsection{Diagnose foliar}

A diagnose foliar é um método de avaliação do estado nutricional em que se analisam determinadas folhas, em períodos definidos da vida da planta. A utilização da folha para análise dos nutrientes, deve-se ao fato desta refletir melhor o estado nutricional, isto é, responde mais as variações no suprimento de um determinado nutriente, seja pelo solo ou através das adubações. Isso ocorre pelo fato da folha ser o orgão onde ocorrem os processos fisiológicos mais importantes da planta (Malavolta et al., 1997).

O teor dos nutrientes no tecido foliar é o reflexo de um conjunto de fatores que interagem entre si, até o momento da coleta da amostra. A função que descreve a variação dos teores dos nutrientes no tecido foliar, de acordo com Malavolta et al. (1997), é a seguinte:

$$
Y=f(M g, S, C l, P c, P m)
$$

sendo:

Y, o teor do nutriente na folha

Mg, o material genético (espécie, progênie, clone, etc.)

S, o solo, adubo, corretivos e outras entradas de nutrientes no sistema

$\mathrm{Cl}$, as condições climáticas (precipitação, temperatura, luminosidade, etc.)

Pc, as práticas culturais (preparo de solo, espaçamento, controle das plantas daninhas, etc.)

Pm, a ocorrência de pragas e/ou doenças.

Devido à complexidade da função acima, as vezes torna-se necessário a sua simplificação para:

$$
Y=f(S)
$$

Deste modo, considera-se os demais fatores constantes, exceto o apresentado pelo solo, adubo, corretivos e outras entradas de nutrientes no sistema. 
Para que a diagnose foliar possa ser utilizada com sucesso, três premissas básicas devem ser obedecidas. Dentro de certos limites, devem existir relações diretas entre as seguintes variáveis: a) suprimento do nutriente via solo e a produção, ou seja, solos mais férteis devem proporcionar maiores produtividades; b) suprimento do nutriente através do solo e teor foliar, ou seja, a medida que se aumenta o fornecimento do nutriente via solo deve aumentar a concentração do mesmo no tecido foliar; c) teor foliar e produção, ou seja, o aumento da concentração do nutriente no tecido foliar deve proporcionar maiores produtividades (Malavolta et al., 1997).

A diagnose foliar como forma de avaliação do estado nutricional apresenta algumas vantagens como: a) determinação da quantidade de nutrientes que a planta foi capaz de absorver, considerando as condições ambientais a que ela estava submetida; b) identificação dos problemas de deficiências e/ou toxicicidade nutricional nas plantas com ou sem sintomas visuais; c) identificação de interações e antagonismos entre os nutrientes; d) checagem da entrada dos nutrientes na planta após as adubações e outras práticas culturais e e) avaliação de balanços nutricionais. Como desvantagens, a diagnose foliar apresenta: a) custo mais elevado em relação as análises de solo; b) maior rigor durante a amostragem; c) dificuldade de interpretação das concentrações dos nutrientes devido aos efeitos de diluição e/ou concentração e d) menor rendimento operacional durante as amostragens em se tratando de culturas perenes.

\subsubsection{Amostragem do tecido vegetal}

Para a realização da diagnose foliar, Malavolta et al. (1997) sugerem a coleta das duas primeiras folhas completamente desenvolvidas $\left(5^{\mathrm{a}}\right.$ e $\left.6^{\mathrm{a}}\right)$, de ramos situados na região mediana da copa da árvore, em plantios de Eucalyptus sp. Estes autores recomendam também a coleta de 40 a 80 folhas por ha, sendo que o número de árvores amostradas deve ficar em torno de 10 por ha.

De acordo com Silveira et al. (2000b), a amostragem foliar para a avaliação do estado nutricional do Eucalyptus sp. deve ser realizada através da coleta das duas primeiras folhas completamente desenvolvidas ( $3^{\circ}$ e $4^{\circ}$ par $)$, de ramos situados no terço superior da árvore. Os autores sugerem também a coleta de 40 a 80 folhas de 20 árvores 
por ha, devendo esta ser realizada entre os 12 e 18 meses após o plantio, visando correções futuras através das adubações de manutenção.

Bellote \& Silva (2000) recomendam que a amostragem das folhas seja realizada em árvores dominantes, durante o período do verão. Para tanto, estes autores sugerem a coleta de folhas recém maduras $\left(3^{\mathrm{a}}, 4^{\mathrm{a}}, 5^{\mathrm{a}}\right.$ e $6^{\mathrm{a}}$ folha em relação a extremidade mais distante do caule), de ramos situados no meio da copa. As amostras devem ser compostas e conter no mínimo 3 árvores dominantes. Estes autores recomendam a coleta de 10 a 20 amostras compostas, por gleba.

\subsubsection{Interpretação da análise foliar}

A forma mais usual para interpretação da análise foliar baseia-se nos chamados níveis críticos, abaixo dos quais os teores foliares estariam associados a perdas de produtividade. Malavolta et al. (1997) e Silveira et al. (2000b) apresentam algumas tabelas de interpretação, nas quais são apresentadas as faixas dos teores dos nutrientes que estão associadas aos níveis muito baixos, baixos, médios e altos de produtividade.

\subsection{Avaliação da fertilidade do solo}

Raij (1991) refere-se a análise de solo como a única técnica disponível para a avaliação direta da fertilidade do solo, sendo, no entanto, insuficiente para garantir um acompanhamento adequado do estado nutricional das plantas. A existência de nutrientes no solo, mesmo que supostamente em quantidades disponíveis, não garante o suprimento às plantas devido aos inúmeros fatores ambientais que podem influenciar no processo de absorção.

Barros et al. (1990) afirmam que a análise de solos é o método de maior potencialidade para se avaliar a necessidade de adubação, em áreas de implantação florestal. Entretanto, estes mesmos autores citam as desvantagens apresentadas por este método, como sendo: (a) falta de informações básicas quanto à exigência dos nutrientes pelas espécies florestais; (b) falta de dados adequados de correlação para a interpretação dos resultados em termos resposta a fertilizantes; (c) dificuldade de obter amostras 
representativas da zona de exploração radicular das árvores e (d) incerteza quanto à forma ou fração do nutriente a extrair.

Tomé Jr. (1997) conclui que os resultados das análises de solo fornecidos por um determinado extrator só têm validade se os mesmos estiverem associados aos dados de produtividade de uma determinada cultura.

Bellote \& Silva (2000) analisam a potencialidade da análise de solo como método para diagnóstico em programas de monitoramento nutricional, complementarmente à análise foliar.

Podemos destacar, desta forma, algumas vantagens que as análises de solo apresentam em relação as análises foliares como: a) fornecem subsídios para a tomada de decisão antes da implantação da cultura; b) possibilitam a identificação de problemas relacionados a acidez, alcalinidade e salinidade do solo e determinação de medidas corretivas para os mesmos e c) apresentam maior rendimento operacional durante a amostragem quando comparado ao método da diagnose foliar. Como desvantagens, as análises de solo apresentam: a) dificuldade de identificação das zonas radiculares onde ocorrem as maiores taxas de absorção dos nutrientes pelas plantas; b) pouca relação com a capacidade de extração dos nutrientes em se tratando de culturas específicas; c) carência de pesquisas onde se relacionam os parâmetros químicos do solo com a produtividade das culturas.

\subsubsection{Amostragem de solo}

Devido a complexidade da amostragem de solos em áreas de reflorestamento, em função das variações no volume de raízes e da elevada concentração dos nutrientes nas camadas superficiais do solo, devido ao processo de ciclagem, Barros et al. (1990) sugerem que a amostragem de solos deve ser feita nas camadas de 0 a $20 \mathrm{~cm}$ e de 20 a $40 \mathrm{~cm}$ de profundidade, em áreas que apresentam vegetação rasteira. Caso a área esteja coberta por mata ou capoeira fechada, as amostras devem ser coletadas nas profundidades de 0 a $10 \mathrm{~cm}, 10$ a $20 \mathrm{~cm}$ e de 20 a $40 \mathrm{~cm}$.

Embora o sistema radicular do Eucalyptus sp. seja bastante profundo, a camada mais superficial do solo, de acordo com Barros et al. (1986); Gonçalves et al. (1990); 
Melo (1994) e Quadros (1996), é a que melhor explica as variações nos teores dos nutrientes na planta e consequentemente nas variações de produtividade obtidas. As camadas mais profundas do solo, segundo Cardenas (1987) e Correia (1993), não apresentam boas correlações com a produtividade e, por tanto, a sua amostragem deve ser evitada nos levantamentos nutricionais.

Bellote \& Silva (2000), sugerem que a coleta de solos deve ser feita nas profundidades de $0 \mathrm{a} 10 \mathrm{~cm}, 10$ a $20 \mathrm{~cm}$ e 20 a $30 \mathrm{~cm}$, nas proporções de 50, 30 e $20 \%$, respectivamente, a fim de se garantir uma boa representatividade do local.

Raij (1991) sugere a estratificação da área em glebas homogêneas, as quais devem apresentar o mesmo tipo de solo, profundidade e submetida aos mesmos tratos culturais, principalmente com relação as aplicações de fertilizantes e corretivos. Estes autores recomendam a coleta de 15 a 20 amostras simples por gleba, a fim de se obter uma única amostra composta da área. A coleta deve ser feita em "zigue-zague" percorrendo toda a gleba. Nas culturas perenes, estes autores afirmam que a coleta deve ser realizada nas profundidades de 0 a $5 \mathrm{~cm}$ ou 0 a $10 \mathrm{~cm}$ para que se tenha uma maior representatividade da área amostrada.

\subsubsection{Interpretação da análise de solo}

A interpretação dos resultados das análises de solo, assim como para as análises foliares, também se baseiam nos níveis críticos, abaixo dos quais há perdas consideráveis de produtividade. Malavolta et al. (1997), Silveira et al. (1998) e Silveira et al. (1999) apresentam algumas tabelas de interpretação para análises de solo, as quais estabelecem faixas de baixa, média e alta produtividade em função dos níveis dos parâmetros químicos do solo. 


\subsection{Relação entre o estado nutricional e a produtividade do Eucalyptus sp.}

Zakia et al. (1983) estudaram a relação da altura do E. grandis, aos 2,5 anos de idade e do E. saligna, aos 8 anos de idade com a concentração de nitrogênio, fósforo, potássio, cálcio e magnésio nos tecidos foliares. Os autores obtiveram, através da análise de regressão linear, alguns modelos de produtividade, sendo a variável resposta a altura total das árvores e a variável preditora, os teores foliares dos nutrientes (Tabela 1).

Tabela 1. Altura do E. grandis e do E. saligna em função dos teores foliares de alguns macronutrientes.

\begin{tabular}{cc}
\hline Modelo & $\mathbf{r}^{\mathbf{2}}$ \\
\hline E. grandis $(24$ árvores amostradas $)$ & \\
$\mathrm{A}=(1,227-\mathrm{K}) / 0,048$ & 0,94 \\
$\mathrm{~A}=(1,198-\mathrm{Ca}) / 0,055$ & 0,82 \\
$\mathrm{~A}=(0,332-\mathrm{Mg}) / 0,012$ & 0,95 \\
E. saligna $(50$ árvores amostradas $)$ & \\
$\mathrm{A}=(\mathrm{N}-0,077) / 0,025$ & 0,95 \\
$\mathrm{~A}=(\mathrm{P}-0,021) / 0,003$ & 0,98 \\
$\mathrm{~A}=(\mathrm{K}-0,071) / 0,014$ & 0,98 \\
$\mathrm{~A}=(\mathrm{Ca}-0,076) / 0,014$ & 0,96 \\
$\mathrm{~A}=(\mathrm{Mg}+0,016) / 0,006$ & 0,97 \\
\hline
\end{tabular}

N: \% de nitrogênio; P: \% de fósforo; K: \% de potássio; Ca: \% de cálcio; Mg: \% de magnésio; A: Altura (m).

Fonte: Zakia et al. (1983)

Através dos modelos obtidos, os autores verificaram que a altura do E. grandis apresentou uma relação negativa com os teores foliares de magnésio, potássio e cálcio. Isso se deve aos efeitos de diluição do nutriente na planta, pelo fato da taxa de absorção ser muito inferior a taxa de acúmulo de biomassa da planta. Este efeito é um dos maiores incovenientes apresentados pelos métodos que se baseiam na análise isolada dos teores foliares dos nutrientes, visando a avaliação do estado nutricional dos plantios de Eucalyptus sp. 
Para o E. saligna, entretanto, os teores foliares de fósforo, potássio, magnésio, cálcio e nitrogênio estavam associados positivamente com a altura.

Bellote \& Ferreira (1993) relacionaram os teores foliares dos nutrientes com a altura do E. grandis, aos 3 anos de idade, em 15 sítios florestais, distribuídos em 5 municípios do Estado de São Paulo (Mogi-Guaçú, Casa Branca, Itirapina, Itatinga e Angatuba), conforme pode ser observado na Tabela 2. Estes autores verificaram que o nitrogênio, fósforo, potássio, magnésio e enxofre, nestas regiões, apresentaram correlações positivas com o crescimento do E. grandis, enquanto que o cálcio e o boro, apresentaram correlações negativas. A relação inversa entre a altura do E. grandis com os teores foliares de cálcio e boro deve-se a baixa mobilidade de ambos nutrientes na planta, ou seja, a ciclagem dos mesmos das folhas mais velhas para as mais novas é muito reduzida, o que pode ter comprometido a obtenção de relações positivas entre a produtividade e os teores foliares destes nutrientes na planta.

Tabela 2. Correlação (coeficiente de correlação de Pearson) entre a altura do E. grandis e o teor dos nutrientes nas folhas.

\begin{tabular}{|c|c|c|c|c|c|c|c|c|c|c|c|}
\hline Nutriente & $\mathbf{N}$ & $\mathbf{P}$ & $\mathbf{K}$ & $\mathbf{C a}$ & Mg & Al & $\mathbf{S}$ & B & $\mathrm{Fe}$ & Mn & $\mathbf{Z n}$ \\
\hline $\mathrm{r}$ & 0,55 & 0,47 & 0,86 & $-0,28$ & 0,75 & $-0,01$ & 0,40 & $-0,65$ & $-0,20$ & $-0,20$ & 0,35 \\
\hline Signif. & $* * *$ & $* * *$ & $* * *$ & $*$ & $* * *$ & n.s. & $* * *$ & $* * *$ & n.s. & n.s. & n.s. \\
\hline
\end{tabular}

Fonte: Bellote \& Ferreira (1993)

Louw (1997) estudou a relação entre os teores foliares de nitrogênio e fósforo com o índice de sítio do E. grandis, aos 20 anos de idade. Este autor observou uma pequena correlação positiva entre os teores foliares destes nutrientes com a produtividade do $E$. grandis, na região de Mpumalanga Escarpment, África do Sul (Tabela 3). 
Tabela 3. Correlação (coeficiente de correlação de Pearson) entre os teores foliares de nitrogenio e fósforo com o índice de sítio do E. grandis, aos 20 anos de idade.

\begin{tabular}{cc}
\hline Nutriente $\left(\mathbf{g ~ k g}^{-1}\right)$ & Coeficiente de Correlação (r) \\
\hline N & $0,304 * * *$ \\
P & $0,250 * *$ \\
\hline vo ao nível de $1 \%$ de probabilidade; $* * *$ significativo ao nível de $0,1 \%$ de probabilidade.
\end{tabular}

** significativo ao nível de $1 \%$ de probabilidade; *** significativo ao nível de $0,1 \%$ de probabilidade.

Fonte: Louw (1997)

Mushaka (1998) correlacionou a produtividade do E. camaldulensis, com idade entre 1 e 10 anos, obtidas em 27 parcelas na região de Zimbabwe, África do Sul, com os teores de boro, cobre e manganês dos tecidos foliares. Este autor verificou que os teores foliares de boro apresentaram correlações negativas com o DAP e a altura do $E$. camaldulensis, nos diferentes períodos de avaliação. Os teores de manganês e cobre, por outro lado, apresentaram correlações positivas com o DAP e a altura do $E$. camaldulensis, entre 0 e 4 anos de idade e entre 4 e 10 anos de idade, respectivamente (Tabela 4). Estes resultados mostram a importância de se considerar a idade das plantas nos levantamentos nutricionais, principalmente quando se utiliza o método do nível crítico ou as análises de correlação e/ou de regressão linear, uma vez que estas não possibilitam isolar os efeitos do aumento e/ou diminuição da concentração foliar dos nutrientes em função da idade das plantas. 
Tabela 4. Correlação (coeficiente de correlação de Pearson) entre os teores foliares e o DAP e a altura média do E. camaldulensis.

\begin{tabular}{ccc}
\hline Teores foliares $\left(\mathbf{m g ~ k g}^{-1}\right)$ & DAP $(\mathbf{c m})$ & Altura $(\mathbf{m})$ \\
\hline \multicolumn{2}{c}{ Plantios de E. camaldulensis com idade entre 0 a 4 anos } \\
B & $-0,663^{*}$ & $-0,709^{* *}$ \\
$\mathrm{Cu}$ & $0,406 \mathrm{n} . \mathrm{s}$. & $0,523 \mathrm{n} . \mathrm{s}$. \\
$\mathrm{Mn}$ & $0,707^{* *}$ & $0,576^{*}$ \\
\multicolumn{2}{c}{ Plantios de E. camaldulensis com idade entre 4 a 10 anos } \\
$\mathrm{B}$ & $-0,816^{* *}$ & $-0,834^{* *}$ \\
$\mathrm{Cu}$ & $0,629^{*}$ & $0,721^{*}$ \\
$\mathrm{Mn}$ & $0,116 \mathrm{n} . \mathrm{s}$. & $0,147 \mathrm{n} . \mathrm{s}$. \\
\hline
\end{tabular}

n.s. não significativo; * significativo ao nível de 5\% de probabilidade; ** significativo ao nível de $1 \%$ de probabilidade.

Fonte: Mushaka (1998)

Silveira et al. (2000c) ao realizarem um levantamento do estado nutricional em plantios de de Eucalyptus sp., na região sul do Estado da Bahia, observaram correlações positivas entre as concentrações foliares de cálcio e nitrogênio com a produtividade, aos 12 meses de idade (Tabela 5). Estes resultados indicam que os plantios de Eucalyptus sp. com baixos teores foliares destes nutrientes estariam sujeitos a baixas produtividades, contrário aos levantamentos realizados no Estado de São Paulo, onde as limitações de potássio e boro foram as mais comumente encontradas nos plantios de E. grandis (Bellote \& Ferreira, 1993; Silveira et al., 1995b e c, Quadros, 1996). Na região sul do Estado da Bahia, também foram observadas correlações negativas entre o crescimento do Eucalyptus sp. e os teores foliares de manganês (Tabela 6). Os autores observaram que os altos teores foliares deste nutriente poderiam estar prejudicando o crescimento do Eucalyptus sp., nesta região. 
Tabela 5. Correlação (coeficiente de correlação de Pearson) entre as concentrações dos macronutrientes e o volume de madeira de clones de Eucalyptus sp., aos 12 meses de idade, na região sul do Estado Bahia.

\begin{tabular}{|c|c|c|c|c|c|c|}
\hline Clone & $\mathbf{N}$ & $\mathbf{P}$ & $\mathbf{K}$ & $\mathrm{Ca}$ & $\mathbf{M g}$ & $\mathbf{S}$ \\
\hline $\mathrm{A}$ & 0,12 n.s. & $-0,30$ n.s. & $-0,39^{*}$ & $0,84 * *$ & $0,08 \mathrm{n} . \mathrm{s}$ & 0,11 n.s. \\
\hline B & $0,67 * *$ & 0,46n.s. & $0,55^{*}$ & $-0,53^{*}$ & $-0,43$ n.s. & 0,33n.s. \\
\hline $\mathrm{C}$ & $0,21 \mathrm{n} . \mathrm{s}$ & $-0,20$ n.s. & $-0,42 * *$ & $0,48^{* *}$ & $-0,28$ n.s. & 0,18 n.s. \\
\hline D & $0,41^{*}$ & $0,24 \mathrm{n} . \mathrm{s}$ & $0,12 \mathrm{n} . \mathrm{s}$. & $0,54 * *$ & $-0,50 * *$ & $0,40^{*}$ \\
\hline $\mathrm{E}$ & $0,77 * *$ & 0,27 n.s. & 0,03 n.s. & $-0,30$ n.s. & $-0,48$ n.s. & 0,05 n.s. \\
\hline
\end{tabular}

Fonte: Silveira et al. (2000c).

Tabela 6. Correlação (coeficiente de correlação de Pearson) entre as concentrações dos micronutrientes e o volume de madeira de clones de Eucalyptus sp., aos 12 meses de idade, na região sul do Estado da Bahia.

\begin{tabular}{cccccc}
\hline Clone & $\mathbf{B}$ & $\mathbf{C u}$ & $\mathbf{F e}$ & $\mathbf{M n}$ & $\mathbf{Z n}$ \\
\hline A & 0,32 n.s. & $0,16 n . s$. & 0,21 n.s. & 0,09 n.s. & 0,10 n.s. \\
B & $-0,61^{*}$ & $0,37 n . s$. & 0,40 n.s. & 0,41 n.s. & 0,33 n.s. \\
C & 0,17 n.s. & $0,17 n . s$. & 0,29 n.s. & 0,09 n.s. & 0,20 n.s. \\
D & $0,62^{* *}$ & $0,25 n . s$. & 0,28 n.s. & $0,45^{*}$ & $0,37^{*}$ \\
E & 0,29 n.s. & $-0,54$ n.s. & $-0,01$ n.s. & $-0,86^{* *}$ & 0,24 n.s. \\
\hline
\end{tabular}

n.s. não significativo, * significativo ao nível de 5\% de probabilidade; ** significativo ao nível de $1 \%$ de probabilidade.

Fonte: Silveira et al. (2000c).

Sgarbi et al. (2000a) ao realizarem um levantamento do estado nutricional na região de Capão Bonito, verificaram que o cálcio, o magnésio e o boro correlacionaram positivamente com a produtividade do E. grandis e do E. urophyla, sendo estes os nutrientes mais limitantes para o crescimento de ambas espécies, nesta região. $\mathrm{O}$ manganês, por outro lado, correlacionou-se negativamente com a produtividade, mostrando que os elevados teores foliares deste nutriente poderiam estar sendo prejudicial ao desenvolvimento das plantas. (Tabela 7). 
Tabela 7. Correlação (coeficiente de correlação de Pearson) entre os teores foliares de macro e micronutrientes e incremento médio anual do E. grandis e do E. saligna, na região de Capão Bonito.

\begin{tabular}{cccccccccccc}
\hline Nutriente & $\mathbf{N}$ & $\mathbf{P}$ & $\mathbf{K}$ & $\mathbf{C a}$ & $\mathbf{M g}$ & $\mathbf{S}$ & $\mathbf{B}$ & $\mathbf{C u}$ & $\mathbf{F e}$ & $\mathbf{M n}$ & $\mathbf{Z n}$ \\
\hline $\mathrm{r}$ & $-0,26$ & $-0,15$ & $-0,16$ & 0,43 & 0,46 & 0,21 & 0,38 & $-0,63$ & $-0,50$ & $-0,45$ & 0,15 \\
Signif. & n.s. & n.s. & n.s. & $* *$ & $* *$ & n.s. & $* *$ & n.s. & n.s. & $* *$ & n.s.
\end{tabular}

n.s. não significativo; * significativo ao nível de $5 \%$ de probabilidade; $* *$ significativo ao nível de $1 \%$ de probabilidade.

Fonte: Sgarbi et al. (2000a)

Na região de Lençóis Paulista, Sgarbi et al. (2000b) verificaram que as maiores produtividades do E. grandis foram obtidas a medida que se elevou os teores foliares de boro, cobre e ferro. A produtividade, por outro lado, foi reduzida a medida que se elevou os teores foliares de cálcio, manganês e zinco, nos tecidos foliares (Tabela 8).

Tabela 8. Correlação (coeficiente de correlação de Pearson) entre os teores foliares de macro e micronutrientes e o incremento médio anual do E. grandis na região de Lençóis Paulista.

\begin{tabular}{cccccccccccc}
\hline Nutriente & $\mathbf{N}$ & $\mathbf{P}$ & $\mathbf{K}$ & $\mathbf{C a}$ & $\mathbf{M g}$ & $\mathbf{S}$ & $\mathbf{B}$ & $\mathbf{C u}$ & $\mathbf{F e}$ & $\mathbf{M n}$ & $\mathbf{Z n}$ \\
\hline $\mathrm{R}$ & 0,88 & $-0,13$ & 0,11 & $-0,74$ & $-0,17$ & $-0,67$ & 0,40 & 0,33 & 0,59 & $-0,39$ & $-0,30$
\end{tabular}

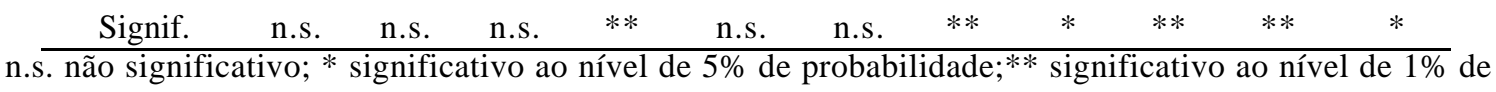
probabilidade.

Fonte: Sgarbi et al. (2000b)

\subsection{Relação entre a fertilidade do solo e a produtividade do Eucalyptus sp.}

Bellote \& Ferreira (1993) também relacionaram os teores dos nutrientes no solo com a produtividade do E. grandis, aos 3 anos de idade, em 15 sítios florestais, distribuídos em 5 municípios do Estado de São Paulo (Mogi-Guaçú, Casa Branca, Itirapina, Itatinga e Angatuba), conforme pode ser observado na Tabela 9. Estes autores 
verificaram correlações positivas apenas entre os teores de fósforo, potássio, magnésio e cálcio com a produtividade do Eucalyptus sp.

Tabela 9. Correlação (coeficiente de correlação de Pearson) entre a altura e o teor dos nutrientes no solo.

\begin{tabular}{cccccc}
\hline Nutriente & $\mathbf{P}$ & $\mathbf{K}$ & $\mathbf{C a}$ & $\mathbf{M g}$ & $\mathbf{S}$ \\
\hline $\mathrm{R}$ & 0,652 & 0,870 & 0,635 & 0,761 & 0,752 \\
Signif. & $* * *$ & $* * *$ & $*$ & $* * *$ & n.s. \\
n.s. não significativo; & $*$ significativo ao nível de $5 \%$ & de probabilidade; & $* * *$ & significativo ao nível de $0,1 \%$ \\
de probabilidade.
\end{tabular}

Fonte: Bellote \& Ferreira (1993)

Zimback et al. (1996) observaram que os parâmetros físicos do solo, no horizonte A, que apresentaram maiores correlações com a produtividade do E. grandis e do $E$. urophylla, nos municípios de Mogi-Guaçú, Conchal e Aguaí foram: densidade do solo, porosidade total e retenção de água à $0,03 \mathrm{MPa}$ e $1,5 \mathrm{MPa}$. Estas características, no entanto, não apresentaram correlações significativas com a produtividade de ambas espécies no horizonte B. Isso mostra a importância do horizonte A nos estudos de correlação entre as características do solo e a produtividade, pois é nesta camada que se concentram a maior parte das raízes finas, as quais são responsáveis pela maior absorção dos nutrientes e consequentemente pela maior produtividade do Eucalyptus sp.

Ainda segundo Zimback et al. (1996), a soma de bases e a saturação por bases obtidos no horizonte A, foram os fatores que apresentaram maior relação com o crescimento do Eucalyptus sp. Os modelos de produtividade obtidos por estes autores estão contidos na Tabela 10. 
Tabela 10. Modelos de produtividade do Eucalyptus sp. em função dos parâmetros químicos e físicos do solo.

\begin{tabular}{cc}
\hline Modelo & Coeficiente de Correlação $(\mathbf{r})$ \\
\hline $\mathrm{Y}=5,65+3762 \mathrm{X}_{1}$ & $0,84^{*}$ \\
$\mathrm{Y}=25,11+1425,59 / \mathrm{X}_{2}$ & $0,83^{*}$ \\
$\mathrm{Ln} \mathrm{Y}=3,61+5,07\left(1 / \mathrm{X}_{3}\right)$ & $0,90^{*}$ \\
$\mathrm{Ln} \mathrm{Y}=3,69+2,66\left(1 / \mathrm{X}_{4}\right)$ & $0,99^{*}$ \\
$\mathrm{Ln} \mathrm{Y}=4,28-0,12\left(1 / \mathrm{X}_{5}\right)$ & $0,86^{*}$ \\
$\mathrm{Y}=33,75+11,46 \ln \left(\mathrm{X}_{6}\right)$ & $0,85^{*}$ \\
\hline $\mathrm{Y}=$ Produtividade $\left(\mathrm{st} \mathrm{ha}^{-1}\right.$ ano $\left.^{-1}\right) ; \mathrm{X} 1=$ Densidade do solo no horizonte A $\left(\mathrm{g} \mathrm{cm}^{-3}\right), \mathrm{X} 2=$ Porosidade total \\
no horizonte A; X3 = Água disponível a 0,03MPa no horizonte A; X4 = Água disponível a 1,50MPa no \\
horizonte A; X5 = Soma de bases no horizonte A; X6 = V\% no horizonte A; * significativo ao nível de 5\% \\
de probabilidade.
\end{tabular}

Fonte: Zimback et al. (1996)

Louw (1997) também estudou a relação entre os parâmetros fisico-químicos dos solos com o índice de sítio do E. grandis, aos 20 anos. Este autor verificou que a umidade e o teor de carbono no solo foram as variáveis que melhor se correlacionaram com a produtividade do E. grandis na região de Mpumalanga Escarpment, África do Sul (Tabela 11). Estes resultados mostraram que o teor de carbono no solo e consequentemente a porcentagem de matéria orgânica explicam, em grande parte, as variações de produtividade, sendo fundamental a sua consideração nos levantamentos nutricionais realizados em plantios de Eucalyptus sp. 
Tabela 11. Correlação (coeficiente de correlação de Pearson) entre os parâmetros físicoquímicos dos solos e os teores dos nutrientes no tecido foliar com o índice de sítio do E. grandis, aos 20 anos.

\begin{tabular}{cc}
\hline Parâmetro & Coeficiente de Correlação (r) \\
\hline Profundidade do solo & $0,616^{* * *}$ \\
$\mathrm{C}(\%)$ no horizonte A & $0,581^{* * *}$ \\
$\mathrm{Mg}\left(\mathrm{mg} \mathrm{kg}^{-1}\right)$ no horizonte B & $-0,304 * * *$ \\
$\mathrm{Ca}\left(\mathrm{mg} \mathrm{kg}^{-1}\right)$ no horizonte B & $-0,271^{* *}$ \\
Argila $(\%)$ no horizonte A & $-0,214 * *$ \\
\hline ignificativo ao nível de 1\% de probabilidade; $* *$ significativo ao nível de $0,1 \%$ de probabilidade.
\end{tabular}

Fonte: Louw (1997)

Mushaka (1998) também correlacionou a produtividade do E. camaldulensis, com idade entre 1 e 10 anos, obtidas em 27 parcelas na região de Zimbabwe, África do Sul, com alguns parâmetros químicos do solo. Este autor não observou correlações significativas entre o $\mathrm{pH}$, os teores de matéria orgânica, fósforo e potássio no solo com a produtividade do E. camaldulensis.

Sgarbi et al. (2000a) verificaram que as maiores produtividades do E. grandis e do E. saligna, na região de Capão Bonito, estavam associadas a solos com maior teor de matéria orgânica, fósforo, potássio, cálcio, magnésio, saturação por bases e com maiores relações de $\mathrm{K} / \mathrm{T}, \mathrm{Ca} / \mathrm{T}$ e $\mathrm{Mg} / \mathrm{T}$, conforme mostra a Tabela 12.

Tabela 12. Correlação (coeficiente de correlação de Pearson) entre os parâmetros químicos do solo, na profundidade de 0 a $10 \mathrm{~cm}$ e o incremento médio anual do E. grandis e do E. saligna na região de Capão Bonito.

\begin{tabular}{cccccccccccc}
\hline Parâmetro & $\mathbf{p H}$ & $\mathbf{M . O}$. & $\mathbf{P}$ & $\mathbf{K}$ & $\mathbf{C a}$ & $\mathbf{M g}$ & $\mathbf{T}$ & $\mathbf{V} \%$ & $\mathbf{K} / \mathbf{T}$ & $\mathbf{C a} / \mathbf{T}$ & $\mathbf{M g} / \mathbf{T}$ \\
\hline r & 0,23 & 0,41 & 0,45 & 0,42 & 0,50 & 0,56 & 0,17 & 0,52 & 0,43 & 0,48 & 0,50 \\
Signif. & n.s. & $* *$ & $* *$ & $* *$ & $* *$ & $* *$ & n.s. & $* *$ & $* *$ & $* *$ & $* *$ \\
\hline
\end{tabular}

n.s. não significativo; $* *$ significativo ao nível de $1 \%$ de probabilidade.

Fonte: Sgarbi et al. (2000a) 
Em relação aos micronutrientes, Sgarbi et al. (2000a) também verificaram que o boro e o manganês foram os nutrientes que apresentaram os maiores coeficientes de correlação com a produtividade do E. grandis e do E. saligna, na região de Capão Bonito (Tabela 13). Embora tenha ocorrido correlações positivas entre o teor de manganês no solo e a produtividade, Sgarbi et al. (2000a) também verificaram uma relação negativa entre os teores foliares deste nutriente com a produtividade, o que explica o efeito prejudicial do manganês no crescimento do Eucalyptus sp.

Tabela 13. Correlação (coeficiente de correlação de Pearson) entre os parâmetros químicos do solo, na profundidade de 0 a $10 \mathrm{~cm}$, e o incremento médio anual do E. grandis e do E. saligna na região de Capão Bonito.

\begin{tabular}{cccccc}
\hline Parâmetro & $\mathbf{B}$ & $\mathbf{C u}$ & $\mathbf{F e}$ & $\mathbf{M n}$ & $\mathbf{Z n}$ \\
\hline $\mathrm{r}$ & 0,70 & 0,25 & 0,38 & 0,63 & 0,09 \\
Signif. & $* *$ & n.s. & $* *$ & $* *$ & n.s. \\
\hline n.s. não significativo;** significativo ao nível de $1 \%$ de probabilidade. & & &
\end{tabular}

n.s. não significativo;** significativo ao nível de $1 \%$ de probabilidade.

Fonte: Sgarbi et al. (2000a)

Sgarbi et al. (2000b) observaram uma estreita relação entre o teor de magnésio, da relação $\mathrm{Mg} / \mathrm{T}$ e do teor de ferro do solo com a produtividade do E. grandis, na região de Lençóis Paulista (Tabelas 14 e 15). Estes resultados mostraram que tanto o magnésio como o ferro, nas áreas que apresentaram baixos teores destes nutrientes no solo, estariam sendo limitantes para o crescimento do E. grandis. 
Tabela 14. Correlação (coeficiente de correlação de Pearson) entre os parâmetros químicos do solo, na profundidade de 0 a $20 \mathrm{~cm}$, e o incremento médio anual do E. grandis na região de Lençóis Paulista.

\begin{tabular}{cccccccccccc}
\hline Parâmetro & $\mathbf{p H}$ & $\mathbf{M . O}$. & $\mathbf{P}$ & $\mathbf{K}$ & $\mathbf{C a}$ & $\mathbf{M g}$ & $\mathbf{T}$ & $\mathbf{V \%}$ & $\mathbf{K} / \mathbf{T}$ & $\mathbf{C a} / \mathbf{T}$ & $\mathbf{M g} / \mathbf{T}$ \\
\hline r & $-0,03$ & 0,19 & 0,08 & 0,25 & 0,02 & 0,35 & 0,14 & 0,01 & 0,24 & $-0,07$ & 0,41 \\
Signif. & n.s. & n.s. & n.s. & n.s. & n.s. & $*$ & n.s. & n.s. & n.s. & n.s. & $* *$ \\
\hline
\end{tabular}

n.s. não significativo; * significativo ao nível de $5 \%$ de probabilidade; ** significativo ao nível de $1 \%$ de probabilidade.

Fonte: Sgarbi et al. (2000b)

Tabela 15. Correlação (coeficiente de correlação de Pearson) entre os parâmetros químicos do solo, na profundidade de 0 a $20 \mathrm{~cm}$, e o incremento médio anual do E. grandis na região de Lençóis Paulista.

\begin{tabular}{cccccc}
\hline Parâmetro & $\mathbf{B}$ & $\mathbf{C u}$ & $\mathbf{F e}$ & Mn & $\mathbf{Z n}$ \\
\hline $\mathrm{r}$ & 0,11 & 0,20 & 0,30 & 0,06 & $-0,06$ \\
Signif. & n.s. & n.s. & $*$ & n.s. & n.s. \\
\hline
\end{tabular}

n.s. não significativo; * significativo ao nível de 5\% de probabilidade.

Fonte: Sgarbi et al. (2000b)

\subsection{Sistema integrado de diagnose e recomendação (DRIS)}

De acordo com Wadt (1996), o Sistema Integrado de Diagnose e Recomendação (DRIS) foi desenvolvido por E.R Beaufils em estudos de avaliação nutricional de Hevea brasiliensis (Beaufils, 1958; 1973), sendo a metodologia, posteriormente dissiminada para outras espécies vegetais (Beaufis, 1973).

O método clássico de interpretação da diagnose foliar consiste na comparação dos resultados obtidos a partir de uma amostra com valores padrões, as quais são obtidas a partir de experimentos em que os demais fatores de produção são mantidos controlados e em níveis supostamente ótimos. De acordo com Bhargava e Chada (1988) estes valores padrões são válidos somente quando as amostras das plantas a serem avaliadas são obtidas nas mesmas condições utilizadas para a determinação da curva de calibração, ou seja, mesmo material genético, idade e local. Além disso, o método clássico de avaliação do estado nutricional permite somente a avaliação isolada dos nutrientes não levando em 
consideração as interações existentes entre eles, as variações nas concentrações dos nutrientes em função da idade e do grau de desenvolvimento da cultura. Quando mais de dois nutrientes encontram-se abaixo dos níveis críticos, por exemplo, o método clássico não informa qual deles é o mais limitante (Malavolta et al. 1997).

De acordo com Wadt (1996), o método DRIS pressupõem que as relações entre dois nutrientes são os melhores indicadores do desequilíbrio nutricional do que simplesmente a utilização da concentração do nutriente (Beaufils ${ }^{2}$ e Jones $^{3}$, citados por Wadt, 1996).

O método DRIS, segundo Malavolta et al. (1997), não indica se um dado nutriente apresenta-se em nível de deficiência ou de toxicicidade, mas qual a ordem de limitação dos mesmos para o desenvolvimento de uma determinada cultura.

A metodologia empregada no sistema DRIS consiste basicamente na:

a) Divisão dos teores dos nutrientes e dos dados de produção em dois grupos distintos, sendo grupo A de baixa produtividade ou amostra e grupo B de alta produtividade ou referência;

b) Determinação do teste de normalidade pelo método do qui-quadrado com o intuito de verificar se os dados de cada grupo apresentam distribuição normal;

c) Determinação da média, do coeficiente de variação e da variância de todas as relações possíveis entre os teores dos nutrientes, em cada grupo. Para se determinar o número possível de relações entre os nutrientes, utiliza-se a fórmula abaixo:

$$
N^{o} \text { relações }=n(n-1),
$$

sendo $n$ o número total de nutrientes a serem avaliados;

d) Determinação da razão entre as variâncias do grupo A e do grupo B, para cada relação entre os nutrientes;

2 BEAUFILS, E.R. Diagnosis and recommendation integrated system (DRIS). Pietermaritzburg: University of Natal, 1973. 132p. (Soil Science Bulletin, 1).

3 JONES, C.A. Proposed modifications of the diagnosis and recommendation integrated system (DRIS) for interpreting plant analyses. Communications in Soil Science and Plant Analysis, v. 12, p. 785-794, 1981. 
e) Seleção das maiores razões obtidas entre as variâncias. Para esta seleção, deve-se considerar as relações onde o nutriente assume a posição do numerador e do denominador;

f) Obtenção dos índices primários com base nas fórmulas que seguem abaixo:

$$
\text { ÍndexX }=f\left(\frac{X}{A}\right)+f\left(\frac{X}{B}\right)+\ldots-f\left(\frac{M}{X}\right)-f\left(\frac{N}{X}\right)-\ldots,
$$

onde:

$$
\begin{gathered}
f\left(\frac{X}{A}\right)=100 \frac{\left.\frac{\frac{X}{A}}{\frac{x}{a}}-1\right]}{C V}, \text { se } \frac{X}{A}>\frac{x}{a}+S_{\frac{\bar{X}}{a}} \\
\left.f\left(\frac{X}{A}\right)=100 \frac{\frac{x}{a}}{C V}\right] \frac{\frac{X}{A}}{C}, \text { se } \frac{X}{A}<\frac{x}{a}-S_{\frac{X}{a}} \\
f\left(\frac{X}{A}\right)=0, \text { se } \frac{x}{a}-S_{\frac{\bar{X}}{a}} \leq \frac{X}{A} \leq \frac{x}{a}+S_{\frac{\bar{x}}{a}} \\
\text { sendo: }
\end{gathered}
$$

$\frac{x}{a}=$ média da relação do grupo $\mathrm{B}$;

$S_{\frac{\bar{X}}{a}}=$ desvio padrão da média;

$C V=$ coeficiente de variação do grupo $\mathrm{B}$;

$\frac{X}{A}=$ relação dos teores dos nutrientes $\mathrm{X}$ e A;

O sinal do índice será positivo se o nutriente cujo índice esta sendo calculado aparecer no numerador da relação $f\left(\frac{X}{A}\right)$, negativo se aparecer no denominador e zero se não aparecer na relação.

Quanto mais negativo forem os índices, mais limitante é o nutriente. 


\section{MATERIAL E MÉTODOS}

\subsection{Local e área do levantamento}

O levantamento abrangeu uma área de aproximadamente 2.215 ha com plantios de Eucalyptus sp., nas regiões de Capão Bonito (48,7\%), Jacareí (16,4\%) e Lençóis Paulista $(34,9 \%)$. As regiões do estudo localizam-se respectivamente na porção sul, litorânea e central do Estado de São Paulo, conforme mostra a Figura 1.

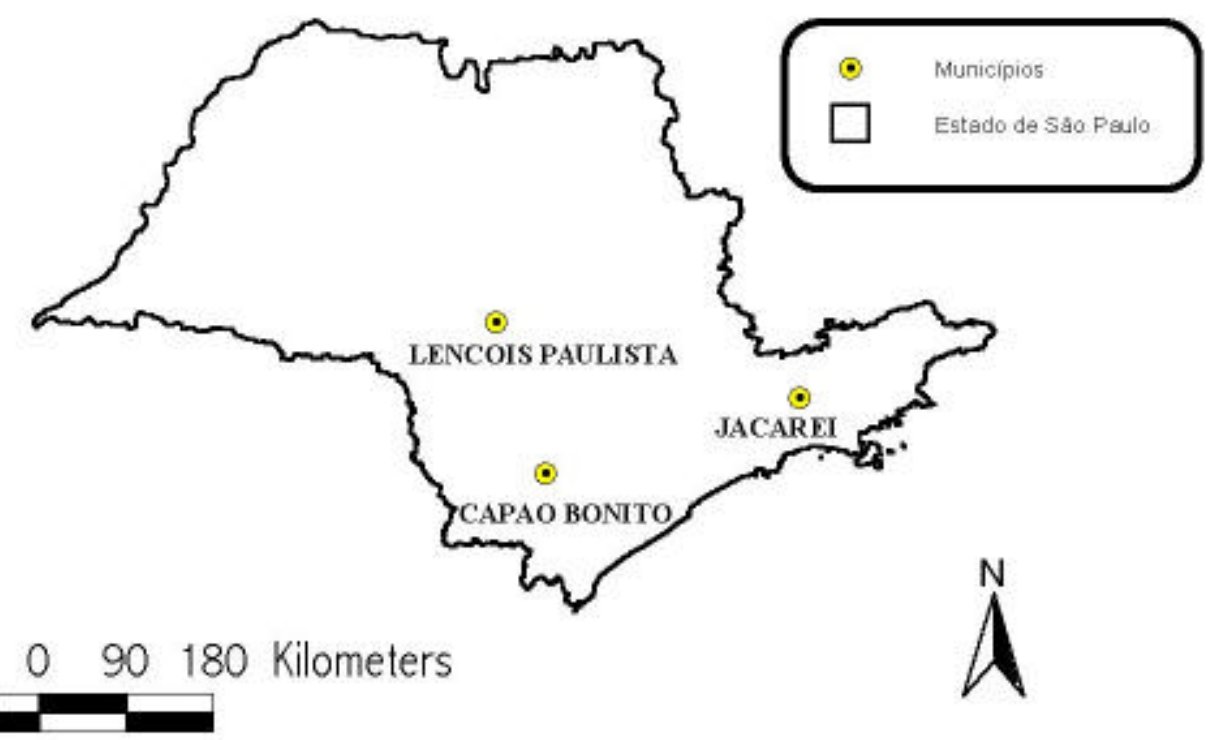

Figura 1 - Posição geográfica dos municípios de Capão Bonito, Jacareí e Lençóis Paulista, no Estado de São Paulo.

O estudo compreendeu 21 fazendas, 117 talhões, 209 parcelas e 13 materiais genéticos, sendo 3 originados por sementes e 10 clones, conforme mostra a Tabela 16. 
Tabela 16. Número de fazendas, talhões, parcelas e materiais genéticos levantados nas diferentes regiões.

\begin{tabular}{|c|c|c|c|c|c|}
\hline \multirow[t]{2}{*}{ Região } & \multirow[t]{2}{*}{ Fazenda } & \multirow[t]{2}{*}{ Talhão } & \multirow[t]{2}{*}{ Parcela } & \multicolumn{2}{|c|}{ Material Genético } \\
\hline & & & & Semente & Clone \\
\hline Capão Bonito & 10 & 61 & 112 & 1 & 6 \\
\hline Jacareí & 4 & 11 & 31 & 1 & 4 \\
\hline Lençóis Paulista & 7 & 45 & 66 & 1 & - \\
\hline Total & 21 & 117 & 209 & 3 & 10 \\
\hline
\end{tabular}

\subsection{Regiões}

\subsubsection{Capão Bonito}

Nesta região, o levantamento abrangeu uma área de aproximadamente 1.080 ha. No período de julho a dezembro de 1997, foram levantados 830 ha distribuídos em 4 fazendas (A, B, C e D), 51 talhões e 2 materiais genéticos propagados por semente. No período de julho a dezembro de 2000, foram levantados aproximadamente 250 ha distribuídos em 4 fazendas $(\mathrm{E}, \mathrm{F}, \mathrm{G}$ e $\mathrm{H}), 10$ talhões e 7 materiais genéticos, sendo 1 propagado por semente e 6 clones (Tabela 17).

A idade das florestas variaram de 12 a 34 meses. A área total dos talhões amostrados variaram de 4,14 a 34,85 ha e o número de parcelas locadas em cada talhão variaram de 1 a 3, dependendo da área do mesmo (Tabela 17). Os espaçamentos de plantio adotados nesta região foram os seguintes: 2,0x1,5m;2,0x2,0m;3,0x3,0m e o $2,7 \times 2,0 \mathrm{~m}$. 
Tabela 17. Informações gerais referentes aos talhões levantados na região de Capão Bonito.

\begin{tabular}{|c|c|c|c|c|c|c|c|c|}
\hline Fazenda & Talhão & $\begin{array}{l}\text { Espécie/ } \\
\text { Clone }\end{array}$ & $\begin{array}{l}\text { Idade } \\
\text { (meses) }\end{array}$ & $\begin{array}{c}\text { Espaçamento } \\
\left(\mathbf{m}^{2}\right)\end{array}$ & $\begin{array}{l}\text { Área } \\
\text { (ha) }\end{array}$ & Parcela & Histórico $^{\mathrm{a}}$ & Adubação $^{\mathbf{b}}$ \\
\hline A & 1 & E. grandis & 28 & $2,5 \times 2,0$ & 8,20 & 1 & 1 & 1 \\
\hline A & 2 & E. grandis & 31 & $2,5 \times 2,0$ & 24,8 & 3 & 2 & 1 \\
\hline $\mathrm{A}$ & 3 & E. grandis & 28 & $2,5 \times 2,0$ & 24,88 & 3 & 2 & 1 \\
\hline A & 4 & E. grandis & 28 & $2,5 \times 2,0$ & 20,41 & 2 & 2 & 1 \\
\hline A & 5 & E. grandis & 28 & $2,5 \times 2,0$ & 29,37 & 3 & 2 & 1 \\
\hline A & 6 & E. grandis & 28 & $2,5 \times 2,0$ & 13,46 & 1 & 2 & 1 \\
\hline A & 7 & E. grandis & 26 & $2,5 \times 2,0$ & 20,36 & 2 & 2 & 1 \\
\hline A & 8 & E. grandis & 26 & $2,5 \times 2,0$ & 27,37 & 3 & 2 & 1 \\
\hline $\mathrm{A}$ & 9 & E. grandis & 26 & $2,5 \times 2,0$ & 18,2 & 2 & 2 & 1 \\
\hline A & 10 & E. grandis & 26 & $2,5 \times 2,0$ & 26,01 & 3 & 2 & 1 \\
\hline A & 11 & E. saligna & 25 & $2,5 \times 2,0$ & 19,42 & 1 & 2 & 1 \\
\hline A & 12 & E. grandis & 25 & $2,5 \times 2,0$ & 12,31 & 1 & 2 & 1 \\
\hline A & 13 & E. grandis & 25 & $2,5 \times 2,0$ & 7,02 & 1 & 2 & 1 \\
\hline A & 14 & E. grandis & 25 & $2,5 \times 2,0$ & 5,5 & 1 & 2 & 1 \\
\hline $\mathrm{A}$ & 15 & E. grandis & 26 & $2,5 \times 2,0$ & 8,38 & 1 & 2 & 1 \\
\hline B & 1 & E. saligna & 32 & $2,5 \times 2,0$ & 7,72 & 1 & - & 1 \\
\hline B & 2 & E. grandis & 32 & $2,5 \times 2,0$ & 8,11 & 1 & - & 1 \\
\hline B & 3 & E. saligna & 34 & $2,5 \times 2,0$ & 7,39 & 1 & - & 1 \\
\hline B & 4 & E. saligna & 34 & $2,5 \times 2,0$ & 8,2 & 1 & - & 1 \\
\hline B & 5 & E. saligna & 32 & $2,5 \times 2,0$ & 4,2 & 1 & - & 1 \\
\hline B & 6 & E. saligna & 34 & $2,5 \times 2,0$ & 12,6 & 1 & - & 1 \\
\hline B & 7 & E. saligna & 32 & $2,5 \times 2,0$ & 12,4 & 1 & - & 1 \\
\hline B & 8 & E. saligna & 32 & $2,5 \times 2,0$ & 13,8 & 1 & - & 1 \\
\hline B & 9 & E. saligna & 32 & $2,5 \times 2,0$ & 14,8 & 1 & - & 1 \\
\hline $\mathrm{C}$ & 1 & E. grandis & 28 & $2,5 \times 2,0$ & 20,94 & 1 & 4 & 1 \\
\hline $\mathrm{C}$ & 2 & E. grandis & 32 & $2,5 \times 2,0$ & 8,04 & 1 & 4 & 1 \\
\hline $\mathrm{C}$ & 3 & E. grandis & 26 & $2,5 \times 2,0$ & 15,26 & 1 & 4 & 1 \\
\hline $\mathrm{C}$ & 4 & E. grandis & 31 & $2,5 \times 2,0$ & 24,85 & 1 & 4 & 1 \\
\hline $\mathrm{D}$ & 1 & E. saligna & 12 & $2,0 \times 1,5$ & 14,37 & 2 & 3 & 1 \\
\hline $\mathrm{D}$ & 2 & E. saligna & 14 & $2,0 \times 1,5$ & 7,09 & 1 & 3 & 1 \\
\hline $\mathrm{D}$ & 3 & E. saligna & 20 & $2,0 \times 1,5$ & 28,83 & 3 & 3 & 1 \\
\hline $\mathrm{D}$ & 4 & E. saligna & 12 & $2,0 \times 1,5$ & 23,89 & 2 & 3 & 1 \\
\hline $\mathrm{D}$ & 5 & E. saligna & 12 & $2,0 \times 1,5$ & 6,68 & 1 & 3 & 1 \\
\hline $\mathrm{D}$ & 6 & E. saligna & 13 & $2,0 \times 1,5$ & 23,81 & 2 & 3 & 1 \\
\hline
\end{tabular}




\begin{tabular}{|c|c|c|c|c|c|c|c|c|}
\hline $\mathrm{D}$ & 7 & E. saligna & 13 & $2,0 \times 1,5$ & 25 & 3 & 3 & 1 \\
\hline $\mathrm{D}$ & 8 & E. saligna & 12 & $2,0 \times 1,5$ & 19,47 & 2 & 3 & 1 \\
\hline $\mathrm{D}$ & 9 & E. saligna & 16 & $2,5 \times 2,0$ & 17,05 & 2 & 3 & 1 \\
\hline $\mathrm{D}$ & 10 & E. saligna & 17 & $2,5 \times 2,0$ & 25,84 & 1 & 3 & 1 \\
\hline $\mathrm{D}$ & 11 & E. saligna & 13 & $2,0 \times 1,5$ & 21,99 & 2 & 3 & 1 \\
\hline $\mathrm{D}$ & 12 & E. saligna & 13 & $2,0 \times 1,5$ & 12,82 & 1 & 3 & 1 \\
\hline $\mathrm{D}$ & 13 & E. saligna & 13 & $2,0 \times 1,5$ & 4,14 & 1 & 3 & 1 \\
\hline $\mathrm{D}$ & 14 & E. saligna & 13 & $2,0 \times 1,5$ & 24,43 & 3 & 3 & 1 \\
\hline $\mathrm{D}$ & 15 & E. saligna & 14 & $2,0 \times 1,5$ & 25,53 & 3 & 3 & 1 \\
\hline $\mathrm{D}$ & 16 & E. saligna & 16 & $2,5 \times 2,0$ & 21,25 & 2 & 3 & 1 \\
\hline $\mathrm{D}$ & 17 & E. saligna & 17 & $2,5 \times 2,0$ & 11,06 & 1 & 3 & 1 \\
\hline $\mathrm{D}$ & 18 & E. saligna & 23 & $2,5 \times 2,0$ & 13,9 & 1 & 3 & 1 \\
\hline $\mathrm{D}$ & 19 & E. saligna & 22 & $2,5 \times 2,0$ & 23,3 & 2 & 3 & 1 \\
\hline $\mathrm{D}$ & 20 & E. saligna & 16 & $2,0 \times 1,5$ & 16,45 & 2 & 3 & 1 \\
\hline $\mathrm{D}$ & 21 & E. saligna & 14 & $2,5 \times 2,0$ & 12,65 & 1 & 3 & 1 \\
\hline $\mathrm{D}$ & 22 & E. saligna & 22 & $2,5 \times 2,0$ & 19,12 & 2 & 3 & 1 \\
\hline $\mathrm{D}$ & 23 & E. saligna & 22 & $2,5 \times 2,0$ & 11,47 & 1 & 3 & 1 \\
\hline $\mathrm{E}$ & 1 & C1 & 23 & $3,0 \times 3,0$ & 9,99 & 3 & 3 & 2 \\
\hline $\mathrm{E}$ & 2 & $\mathrm{C} 1$ & 22 & $3,0 \times 3,0$ & 7,49 & 3 & 3 & 2 \\
\hline $\mathrm{F}$ & 1 & $\mathrm{C} 2$ & 17 & $3,0 \times 3,0$ & - & 3 & 3 & 2 \\
\hline $\mathrm{F}$ & 2 & C3 & 23 & $3,0 \times 3,0$ & 31,4 & 3 & 3 & 2 \\
\hline $\mathrm{F}$ & 3 & $\mathrm{C} 4$ & 18 & $3,0 \times 3,0$ & - & 3 & 3 & 2 \\
\hline $\mathrm{G}$ & 1 & $\mathrm{C} 1$ & 17 & $3,0 \times 3,0$ & - & 3 & 3 & 2 \\
\hline $\mathrm{G}$ & 2 & E. saligna & 22 & $2,7 \times 2,0$ & - & 3 & 3 & 2 \\
\hline $\mathrm{G}$ & 3 & E. saligna & 20 & $2,7 \times 2,0$ & - & 3 & 3 & 2 \\
\hline $\mathrm{H}$ & 1 & C5 & 21 & $3,0 \times 3,0$ & 34,85 & 3 & 3 & 2 \\
\hline $\mathrm{H}$ & 2 & C6 & 21 & $3,0 \times 3,0$ & 29,7 & 3 & 3 & 2 \\
\hline Total & & & & & 948 & 112 & & \\
\hline
\end{tabular}

\section{a) Histórico}

1. Área queimada com posterior cultivo mínimo, coveamento manual, ataque de ferrugem (Puccinia psidii);

2. Gradagem e posterior plantio, ataque de ferrugem (Puccinia psidii);

3. Cultivo mínimo e ocorrência de ferrugem (Puccinia psidii);

4. Pastagem (capim vassoura) com posterior cultivo de tomate e batata, ataque de ferrugem (Puccinia psidii); 


\section{b) Adubação}

1. Adubação de plantio: $180 \mathrm{~kg} \mathrm{ha}^{-1}$ de 04-30-10 + adubação de cobertura aos 6 meses após o plantio: $180 \mathrm{~kg} \mathrm{ha}^{-1}$ de $03-14-18$;

2. Correção do solo: $1000 \mathrm{~kg} \mathrm{ha}^{-1}$ de calcário $(21 \% \mathrm{CaO}+7 \%$ de $\mathrm{MgO})+$ fosfatagem: $250 \mathrm{~kg} \mathrm{ha}^{-1}$ fosfato natural de Araxá $\left(4 \% \mathrm{P}_{2} \mathrm{O}_{5}\right)$ + adubação de plantio: $290 \mathrm{~kg} \mathrm{ha}^{-1}$ de 428-6 + 0,3\% B + adubação de cobertura aos 2 meses após o plantio: $150 \mathrm{~kg} \mathrm{ha}^{-1}$ de 10$05-20+0,3 \%$ de B + adubação de cobertura aos 9 meses após o plantio: $150 \mathrm{~kg} \mathrm{ha}^{-1} \mathrm{de}$ $\mathrm{KCl}+0,5 \%$ de $\mathrm{B}$

\subsubsection{Jacareí}

O levantamento, nesta região, abrangeu uma área de aproximadamente 375 ha, sendo amostradas 6 fazendas (A, B, C, D, E e F) e um total de 11 talhões. Foram amostrados 4 materiais genéticos, sendo 1 originado por semente e 3 clones (Tabela 18). As fazendas B, C e E foram amostradas durante o período de janeiro a julho de 2000, enquanto que as fazendas $\mathrm{A}, \mathrm{D}$, e F foram amostradas no período de agosto a dezembro deste mesmo ano.

A idade das florestas variaram de 18 a 25 meses. A área total dos talhões amostrados variaram de 13,4 a 71,66 ha e o número de parcelas locadas em cada talhão variaram de 1 a 3, dependendo da área do mesmo (Tabela 18). Para os materiais genéticos propagados por semente, o espaçamento adotado foi o 3,0x2,5m e para os clones $3,0 \times 3,0 \mathrm{~m}$. 
Tabela 18. Informações gerais referentes aos talhões levantados na região de Jacareí.

\begin{tabular}{|c|c|c|c|c|c|c|c|}
\hline Fazenda & Talhão & $\begin{array}{c}\text { Espécie/ } \\
\text { Clone }\end{array}$ & $\begin{array}{c}\text { Idade } \\
\text { (meses) }\end{array}$ & $\begin{array}{c}\text { Espaçamento } \\
\left(\mathbf{m}^{2}\right) \\
\end{array}$ & $\begin{array}{c}\text { Área } \\
\text { (ha) }\end{array}$ & Parcela & Adubação $^{a}$ \\
\hline A & 1 & E. grandis & 20 & $3,0 \times 2,5$ & 13,4 & 3 & 1 \\
\hline A & 2 & E. grandis & 20 & $3,0 \times 2,5$ & 23,9 & 3 & 1 \\
\hline $\mathrm{B}$ & 1 & E. grandis & 21 & $3,0 \times 2,5$ & 37,74 & 2 & 1 \\
\hline $\mathrm{C}$ & 1 & J1 & 21 & $3,0 \times 3,0$ & 38,8 & 3 & 1 \\
\hline $\mathrm{D}$ & 1 & E. grandis & 20 & $3,0 \times 2,5$ & 47,27 & 3 & 1 \\
\hline $\mathrm{D}$ & 2 & J1 & 20 & $3,0 \times 3,0$ & 29,97 & 3 & 1 \\
\hline $\mathrm{E}$ & 1 & E. grandis & 21 & $3,0 \times 2,5$ & 47,51 & 1 & 1 \\
\hline $\mathrm{E}$ & 2 & E. grandis & 22 & $3,0 \times 2,5$ & 34,66 & 2 & 1 \\
\hline $\mathrm{E}$ & 3 & $\mathrm{~J} 2$ & 18 & $3,0 \times 3,0$ & - & 3 & 1 \\
\hline $\mathrm{F}$ & 1 & $\mathrm{~J} 3$ & 24 & $3,0 \times 3,0$ & 30,2 & 3 & 1 \\
\hline $\mathrm{F}$ & 2 & $\mathrm{~J} 3$ & 19 & $3,0 \times 3,0$ & 71,66 & 3 & 1 \\
\hline Total & 11 & & & & 375 & 31 & \\
\hline
\end{tabular}

a) Adubação

1. Adubação de plantio: $120 \mathrm{~kg} \mathrm{ha}^{-1}$ de 4-28-6 + adubação de cobertura aos 2 meses após o plantio: $150 \mathrm{~kg} \mathrm{ha}^{-1}$ de $\mathrm{KCl}$.

\subsubsection{Lençóis Paulista}

O levantamento abrangeu uma área de aproximadamente 775 ha, distribuídas em 7 fazendas (A, B, C, D, E, F e G), 45 talhões e apenas 1 material genético propagado por semente (Tabela 19). O levantamento foi realizado durante o período de julho de 1998 a janeiro de 1999. A idade das florestas variaram de 30 a 45 meses. A área total dos talhões amostrados variaram de 5 a 37,7 ha e o número de parcelas locadas em cada talhão variaram de 1 a 3 , dependendo da área do mesmo (Tabela 19). Os espaçamentos utilizados foram 3,25x1,9m; 3,0x1,8m e 3,0x1,9m. 
Tabela 19. Informações gerais referentes aos talhões levantados na região de Lençóis Paulista.

\begin{tabular}{|c|c|c|c|c|c|c|c|c|}
\hline Fazenda & Talhão & $\begin{array}{l}\text { Espécie/ } \\
\text { Clone }\end{array}$ & $\begin{array}{l}\begin{array}{c}\text { Idade } \\
\text { (meses) }\end{array} \\
\end{array}$ & $\begin{array}{c}\text { Espaçamento } \\
\left(\mathbf{m}^{2}\right)\end{array}$ & $\begin{array}{l}\text { Área } \\
\text { (ha) }\end{array}$ & Parcela & Histórico $^{a}$ & Adubação $^{b}$ \\
\hline A & 1 & E. grandis & 44 & $3,25 \times 1,9$ & 26,77 & 2 & 1 & 1 \\
\hline A & 2 & E. grandis & 44 & $3,25 \times 1,9$ & 24,59 & 2 & 1 & 1 \\
\hline A & 3 & E. grandis & 39 & $3,25 \times 1,9$ & 33,55 & 3 & 1 & 1 \\
\hline A & 4 & E. grandis & 45 & $3,0 \times 1,8$ & 30,31 & 3 & 1 & 1 \\
\hline A & 5 & E. grandis & 44 & $3,0 \times 1,8$ & 17,71 & 1 & 1 & 1 \\
\hline A & 6 & E. grandis & 36 & $3,0 \times 1,8$ & 11,40 & 1 & 1 & 1 \\
\hline $\mathrm{B}$ & 1 & E. grandis & 41 & $3,0 \times 1,9$ & 11,00 & 1 & 1 & 1 \\
\hline $\mathrm{B}$ & 2 & E. grandis & 41 & $3,0 \times 1,9$ & - & - & 1 & 1 \\
\hline B & 3 & E. grandis & 44 & $3,0 \times 1,9$ & - & - & 1 & 1 \\
\hline $\mathrm{C}$ & 1 & E. grandis & 36 & $3,0 \times 1,8$ & 37,73 & 3 & 2 & 1 \\
\hline $\mathrm{C}$ & 2 & E. grandis & 41 & $3,0 \times 1,8$ & 9,98 & 1 & 1 & 1 \\
\hline $\mathrm{C}$ & 3 & E. grandis & 41 & $3,0 \times 1,8$ & 10,78 & 1 & 1 & 1 \\
\hline $\mathrm{C}$ & 4 & E. grandis & 41 & $3,0 \times 1,8$ & 8,62 & 1 & 1 & 1 \\
\hline $\mathrm{D}$ & 1 & E. grandis & 37 & $3,0 \times 1,8$ & 25,53 & 2 & 1 & 1 \\
\hline E & 1 & E. grandis & 30 & $3,0 \times 1,9$ & 6,63 & 1 & 3 & 2 \\
\hline E & 2 & E. grandis & 42 & $3,0 \times 1,9$ & 20,00 & 2 & 3 & 2 \\
\hline E & 3 & E. grandis & 42 & $3,0 \times 1,9$ & 12,00 & 1 & 3 & 2 \\
\hline E & 4 & E. grandis & 42 & $3,0 \times 1,9$ & 5,00 & 1 & 4 & 2 \\
\hline E & 5 & E. grandis & 42 & $3,0 \times 1,9$ & 24,00 & 2 & 4 & 2 \\
\hline E & 6 & E. grandis & 42 & $3,0 \times 1,9$ & 15,00 & 1 & 4 & 2 \\
\hline E & 7 & E. grandis & 42 & $3,0 \times 1,9$ & 15,26 & 1 & 4 & 2 \\
\hline E & 8 & E. grandis & 42 & $3,0 \times 1,9$ & 21,00 & 2 & 5 & 2 \\
\hline E & 9 & E. grandis & 41 & $3,0 \times 1,9$ & 16,50 & 1 & 5 & 2 \\
\hline E & 10 & E. grandis & 40 & $3,0 \times 1,9$ & 9,20 & 1 & 5 & 2 \\
\hline $\mathrm{E}$ & 11 & E. grandis & 40 & $3,0 \times 1,9$ & 12,99 & 1 & 5 & 2 \\
\hline $\mathrm{E}$ & 12 & E. grandis & 42 & $3,0 \times 1,9$ & 15,80 & 1 & 5 & 2 \\
\hline E & 13 & E. grandis & 42 & $3,0 \times 1,9$ & 21,76 & 2 & 5 & 2 \\
\hline E & 14 & E. grandis & 42 & $3,0 \times 1,9$ & 20,00 & 2 & 5 & 2 \\
\hline $\mathrm{E}$ & 15 & E. grandis & 42 & $3,0 \times 1,9$ & 22,93 & 2 & 5 & 2 \\
\hline $\mathrm{E}$ & 16 & E. grandis & 41 & $3,0 \times 1,9$ & 20,85 & 2 & 5 & 2 \\
\hline E & 17 & E. grandis & 40 & $3,0 \times 1,9$ & 13,72 & 1 & 5 & 2 \\
\hline E & 18 & E. grandis & 40 & $3,0 \times 1,9$ & 16,00 & 1 & 5 & 2 \\
\hline E & 19 & E. grandis & 40 & $3,0 \times 1,9$ & 8,00 & 1 & 5 & 2 \\
\hline $\mathrm{E}$ & 20 & E. grandis & 40 & $3,0 \times 1,9$ & 9,20 & 1 & 5 & 2 \\
\hline $\mathrm{E}$ & 21 & E. grandis & 40 & $3,0 \times 1,9$ & 16,70 & 1 & 5 & 2 \\
\hline
\end{tabular}




\begin{tabular}{ccccccccc} 
E & 22 & E. grandis & 41 & $3,0 \times 1,9$ & 23,69 & 2 & 5 & 2 \\
E & 23 & E. grandis & 41 & $3,0 \times 1,9$ & 27,00 & 3 & 5 & 2 \\
F & 1 & E. grandis & 36 & $3,0 \times 1,8$ & 18,15 & 2 & 6 & 1 \\
F & 2 & E. grandis & 36 & $3,0 \times 1,8$ & 15,04 & 1 & 6 & 1 \\
F & 3 & E. grandis & 36 & $3,0 \times 1,8$ & 15,00 & 1 & 6 & 1 \\
F & 4 & E. grandis & 36 & $3,0 \times 1,8$ & 15,00 & 1 & 6 & 1 \\
G & 1 & E. grandis & 40 & $3,0 \times 1,9$ & 30,81 & 3 & 1 & 1 \\
G & 2 & E. grandis & 40 & $3,0 \times 1,9$ & 23,57 & 2 & 1 & 1 \\
G & 3 & E. grandis & 40 & $3,0 \times 1,9$ & 15,47 & 1 & 1 & 1 \\
G & 4 & E. grandis & 39 & $3,0 \times 1,8$ & 14,43 & 1 & 1 & 1 \\
Total & 45 & & & & 769 & 66 & & 1 \\
\hline
\end{tabular}

\section{a) Histórico}

1. Área de reforma de eucalipto;

2. Área de reforma de eucalipto com queima;

3. Incêndio com posterior desmatamento;

4. Área desmatada;

5. Área de reforma de pinus;

6. Área de pastagem

\section{b) Adubação}

1. Correção: 3000 a $6000 \mathrm{~kg} \mathrm{ha}^{-1}$ de lama cal*, em área total, sem incorporação $+400 \mathrm{~kg}$ $\mathrm{ha}^{-1}$ de fosfato natural em área total + adubação de plantio: $150 \mathrm{~kg} \mathrm{ha}^{-1}$ de 06-30-06 no sulco;

2. Correção: 3000 a $6000 \mathrm{~kg} \mathrm{ha}^{-1}$ de lama cal*, em área total, sem incorporação $+400 \mathrm{~kg}$ $\mathrm{ha}^{-1}$ de fosfato natural em área total + adubação de plantio: $150 \mathrm{~kg} \mathrm{ha}^{-1}$ de 06-30-06 no sulco + adubação de cobertura aos 3 meses após o plantio: $200 \mathrm{~kg} \mathrm{ha}^{-1}$ de 10-00-10 + adubação de cobertura aos 4 meses após o plantio: $200 \mathrm{~kg} \mathrm{ha}^{-1}$ de 10-00-10 + adubação de cobertura aos 24 meses após o plantio: $300 \mathrm{~kg} \mathrm{ha}^{-1}$ de 08-05-18; 
*Composição fisico - química da lama cal

\begin{tabular}{ccccccccc}
\hline $\begin{array}{c}\text { Umidade } \\
\%\end{array}$ & $\mathbf{S}$ & $\mathbf{C a O}$ & $\begin{array}{c}\mathbf{M g O} \\
\mathrm{g} \mathrm{kg}^{-1}\end{array}$ & $\mathbf{N a}$ & $\mathbf{K}$ & $\mathbf{B}$ & $\mathbf{F e}$ & $\mathbf{Z n}$ \\
\hline 39,2 & 0,22 & 54,6 & 1,7 & 1,53 & 41,9 & $<5$ & 480 & 13,2 \\
\hline
\end{tabular}

\subsection{Amostragem}

\subsubsection{Parcelas}

Nas três regiões, foram selecionadas áreas que visualmente apresentassem baixa, média e alta produtividade.

No levantamento realizado em Capão Bonito, no período de julho a dezembro de 1997, foram locadas parcelas de 25 plantas $(5 \times 5)$ em cada talhão. Todas as plantas da parcela foram consideradas úteis para as avaliações. A intensidade amostral adotada foi de 1 parcela para cada 10 ha. Ainda na região de Capão Bonito, no período de julho a dezembro de 2000, foram locadas parcelas de 50 plantas (5x10) em cada talhão. Nestas, foram consideradas apenas as 10 plantas do sentido diagonal da parcela como úteis para as avaliações. A intensidade amostral, neste caso, foi de 1 parcela para cada 3,7 ha. Ao considerar os dois períodos de amostragem, na região de Capão Bonito (1997 e 2000), obteve-se uma intensidade amostral de 1 parcela para cada 9,6 ha.

Na região de Jacareí, também foram locadas parcelas de 50 plantas (5x10) para cada um dos talhões levantados. Neste caso, também foram consideradas somente as 10 plantas do sentido diagonal da parcela como úteis para as avaliações. A intensidade amostral, nesta região, foi de 1 parcela para cada 11,6 ha.

Foram locadas, na região de Lençóis Paulista, parcelas de 49 plantas (7x7) em cada talhão. Todas as plantas da parcela foram consideradas úteis para as avaliações. Nesta região, a intensidade amostral foi de 1 parcela para cada 11,6 ha.

\subsubsection{Amostragem de solos e folhas}

Em cada parcela, foram coletadas amostras de solo em 5 pontos e em 2 profundidades $(0$ a $10 \mathrm{~cm}$ e 10 a $30 \mathrm{~cm}$ ). As amostras de solo foram retiradas na entrelinha de plantio, entre as árvores que tiveram a altura medida. Os 5 pontos amostrados foram reunidos para que se obtivesse uma única amostra composta do talhão. 
Deste modo, cada talhão forneceu 2 amostras compostas, as quais corresponderam as 2 profundidades amostradas. As duas amostras de cada talhão, em seguida, foram misturadas (60\% na profundidade de $0 \mathrm{a} 10 \mathrm{~cm}$ e $40 \%$ na profundidade de 10 a $30 \mathrm{~cm}$ ) a fim de se obter apenas 1 amostra que representasse todo o talhão.

Amostraram-se as folhas diagnóstico situadas na $5^{\circ}$ a $8^{\circ}$ inserção $\left(3^{\circ}\right.$ e $4^{\circ}$ par de folhas a partir do ápice dos ramos), das árvores que tiveram a altura medida. Foram amostrados quatro ramos, os quais estavam distribuídos nos quatro quadrantes $(\mathrm{N}, \mathrm{S}, \mathrm{L}$ e O) e localizados no terço médio superior da copa, conforme sugerido por Silveira (2000b). As amostras foliares obtidas em cada uma das árvores foram reunidas para que se obtivesse uma única amostra da parcela. Posteriormente, as amostras de cada parcela foram misturadas para que se obtivesse uma única amostra composta do talhão.

\subsection{Avaliações}

\subsubsection{Levantamento pedológico}

Foi realizado um macro levantamento pedológico com o intuito de se conhecer os solos predominantes em cada uma das regiões estudadas. Inicialmente foi locado no mapa pedológico do Estado de São Paulo (escala $\cong 1: 330.000$ ), conforme apresentado por Oliveira et al. (1999), os municípios de Capão Bonito, Jacareí e Lençóis Paulista. Em seguida, foi traçado uma circunferência com aproximadamente $35 \mathrm{~km}$ de raio, a partir de cada um dos municípios estudados. Cada circunferência demarcada no mapa apresentou aproximadamente 385.000 ha. Posteriormente, foi realizada a digitalização das regiões delimitadas para que se pudesse determinar a área de ocorrência dos principais tipos de solos. A determinação da área para cada tipo de solo foi realizada com o auxílio do software ArcView 3.2 ${ }^{1}$. Finalmente, foi feita a classificação dos mesmos com base na legenda apresentada pelo mapa pedológico do Estado de São Paulo (Oliveira et al. 1999).

\footnotetext{
${ }^{1}$ ESRI. ArcView GIS. Redlands: Environmental System Research Institute, 1996. 350p.
} 


\subsubsection{Avaliação do balanço hídrico}

Obteve-se os balanços hídricos, de cada uma das regiões estudadas, com base no trabalho de Sentelhas et al. (1999), para que se pudesse compreender como os fatores de ordem nutricional poderiam estar sendo influenciados pelas condições climáticas das diferentes regiões. A disponibilidade de água no sistema é fundamental para que a planta possa extrair os nutrientes do solo, principalmente em se tratando daqueles absorvidos pelo mecanismo de fluxo de massa, como é o caso do nitrogênio e o enxofre. De qualquer forma, a planta só será capaz de absorver os nutrientes se os mesmos estiverem disponíveis na solução do solo.

O balanço hídrico foi obtido através dos dados de latitude, longitude, altitude, temperatura e precipitação média mensal de cada uma das regiões. Foram realizados gráficos através de dados históricos e através dos dados correspondentes ao período do plantio até a coleta das amostras de folha e solo em todos os povoamentos de Eucalyptus sp. amostrados. Para a região de Capão Bonito, foram utilizados os dados fornecidos pelo IAC, referentes ao período de 1978 a 1990 e de 1995 a 2000. Para a região de Jacareí, foram utilizados os dados fornecidos pelo DAEE e pela Estação do Aeroporto de São José dos Campos, referentes ao período de 1941 a 1970 e de 1999 e 2000, respectivamente. Para a região de Lençóis Paulista, foram utilizados as informações do

município de São Manoel. Para tanto, utilizou-se os dados fornecidos pelo DAEE e UNESP/Botucatu, referentes ao período de 1941 a 1970 e de 1998 a 1999, respectivamente.

\subsubsection{Avaliação da produtividade}

O índice de sítio (IS) foi obtido através dos dados de altura obtidos nas parcelas de cada talhão. Para tanto, determinou-se a altura de todas as árvores úteis da parcela e em seguida a altura média das árvores dominantes e codominantes. Para isto, considerou-se as 100 árvores de maior altura por ha. Nas parcelas que apresentavam 25 plantas úteis, foram consideradas como dominantes as 4 maiores árvores da parcela, enquanto que nas parcelas que apresentavam 49 e 50 plantas úteis, foram consideradas as 8 árvores de maior altura. 
O método utilizado para a obtenção do índice de sítio foi o método da curva guia. O modelo utilizado foi o log-recíproco de Shumacher (1939).

Para obter o índice de sítio em cada uma dos talhões, procedeu-se da seguinte maneira: (a) Determinou-se a relação existente entre a idade e a altura das árvore em cada talhão, através da equação (1).

$$
\ln (H)=b_{o i}+b_{1} A^{-1}
$$

Para tanto, selecionou-se aleatóriamente 11 talhões em cada uma das regiões. A relação entre a idade e a altura obtida foi a seguinte $\ln (\mathrm{H})=3,5166-25,8958 \mathrm{~A}^{-1}$; (b) Substituiu-se o $b_{l}$ obtido, na equação (2).

$$
\ln (S)=\ln (H)-b_{1}\left(A^{-1}-A_{B}^{-1}\right)
$$

(c) Substituiu-se o $A_{B}$ por 84 (7 anos x 12 meses), na equação (2) e Determinou-se o $\mathrm{S}$, em cada um dos talhões, também através da equação (2);

\subsubsection{Análise dos parâmetros químicos do solo e teores foliares dos nutrientes}

Após a coleta, as amostras de solos e de folhas foram enviadas ao Departamento de Solos e Nutrição de Plantas da ESALQ/USP, para posterior análise.

Nas amostras de solo, determinou-se o $\mathrm{pH}$ em $\mathrm{CaCh}$ pelo método potenciométrico, a \% de M.O. e o teor de P-resina pelo método colorimétrico, o teor de K pelo método fotométrico, os teores de $\mathrm{Ca}$ e $\mathrm{Mg}$ pelo método espectofotométrico, o teor de $\mathrm{H}+\mathrm{Al}$ pelo

método potenciométrico, a soma de bases ( $\mathrm{SB}$ ) através da fórmula: $\mathrm{SB}=\mathrm{K}+\mathrm{Mg}+\mathrm{Ca}$, a capacidade de troca catiônica $(\mathrm{T})$ através da fórmula: $\mathrm{T}=[\mathrm{SB}+(\mathrm{H}+\mathrm{Al})]$, a saturação de bases $(\mathrm{V} \%)$ pela fórmula: $\mathrm{V} \%=[(\mathrm{SB} / \mathrm{T}) \times 100]$ e os teores de $\mathrm{B}, \mathrm{Cu}, \mathrm{Fe}, \mathrm{Mn}$ e Zn pelo método espectrofotométrico, segundo Raij, et al. (1991).

As amostras foliares secas e moídas, foram digeridas em ácido nítrico-perclórico (P, K, Ca, Mg, S, Cu, Fe, Mn e Zn) e sulfúrico (N) para a obtenção dos extratos, visando a determinação dos macro e micronutrientes, conforme metodologia sugerida por 
Malavolta et al. (1997). A determinação do $\mathrm{P}$ foi realizada pelo método da colorimetria de molibdato-vanadato; $\mathrm{K}$ por fotometria de chama; $\mathrm{Ca}, \mathrm{Mg}, \mathrm{Cu}, \mathrm{Fe}, \mathrm{Mn}$ e $\mathrm{Zn}$ por espectrometria de absorção atômica; S por turbidimetria de suspensão de sulfato de bário; B por colorimetria de azometina. As determinações de nitrogênio foram feitas através do método micro Kjeldahl.

\subsubsection{Avaliação do estado nutricional e da fertilidade do solo}

Após a análise química do solo e das folhas, procurou-se identificar a porcentagem das áreas que apresentavam níveis baixos, médios e altos dos parâmetros químicos do solo e níveis muito baixos, baixos, médios e altos dos nutrientes nos tecidos foliares, com base nos trabalhos realizados por Malavolta et al. (1997) e Silveira et al. (1998) e (1999). (Tabelas 20 e 21). 
Tabela 20. Classificação dos parâmetros químicos do solo em níveis baixos, médios e altos.

\begin{tabular}{ccccc}
\hline Parâmetro & Unidade & Baixo & $\begin{array}{c}\text { Nível } \\
\text { Médio }\end{array}$ & Alto \\
\hline $\mathrm{PH}$ & - & $<3,9$ & $3,9-5$ & $>5,0$ \\
$\mathrm{M} . \mathrm{O}$. & $\mathrm{g} \mathrm{dm}^{-3}$ & $<15$ & $15-40$ & $>40$ \\
$\mathrm{P}$ & $\mathrm{mg} \mathrm{dm}^{-3}$ & $<5$ & $5-8$ & $>8$ \\
$\mathrm{~K}$ & & $<1$ & $1-1,5$ & $>1,5$ \\
$\mathrm{Mg}$ & & 2,5 & $8,5-4$ & $>4$ \\
$\mathrm{Ca}$ & $\mathrm{mmolc} \mathrm{dm}^{-3}$ & $<8$ & $8-12$ & $>12$ \\
$\mathrm{SB}$ & & $<11,5$ & $11,5-17,5$ & $>17,5$ \\
$\mathrm{~T}$ & & $<110$ & $110-190$ & $>190$ \\
$\mathrm{~V} \%$ & & $<10$ & $10-30$ & $>30$ \\
$\mathrm{~K} / \mathrm{T}$ & $\%$ & $<1$ & $1-3$ & $>3$ \\
$\mathrm{Mg} / \mathrm{T}$ & & $<4$ & $4-10$ & $>10$ \\
$\mathrm{Ca} / \mathrm{T}$ & & $<5$ & $5-15$ & $>0,4$ \\
$\mathrm{~B}$ & & $<0,2$ & $0,2-0,4$ & $>0,5$ \\
$\mathrm{Cu}$ & & $<0,3$ & $0,3-0,5$ & $>25$ \\
$\mathrm{Fe}$ & $\mathrm{mg} \mathrm{dm}{ }^{-3}$ & $<15$ & $15-25$ & $>5$ \\
$\mathrm{Mn}$ & & $<0,5$ & $0,5-5$ & $>0,5$ \\
$\mathrm{Zn}$ & & $<0,25$ & $0,25-0,5$ & \\
\hline $\mathrm{F}$
\end{tabular}

Fonte: Silveira et al. (1998) e (1999) 
Tabela 21. Classificação dos teores dos nutrientes no tecido foliar em níveis muito baixos, baixos, médios e altos.

\begin{tabular}{|c|c|c|c|c|c|}
\hline \multirow[t]{2}{*}{ Nutriente } & \multirow[t]{2}{*}{ Unidade } & \multicolumn{4}{|c|}{ Nível } \\
\hline & & Muito Baixo & Baixo & Médio & Alto \\
\hline $\mathbf{N}$ & & $<14$ & $14-17$ & $17-24$ & $>24$ \\
\hline $\mathrm{P}$ & & $<0,7$ & $0,7-1,0$ & $1,0-1,5$ & $>1,5$ \\
\hline $\mathrm{K}$ & $\mathrm{g} \mathrm{kg}^{-1}$ & $<5$ & $5-7$ & $7-10$ & $>10$ \\
\hline $\mathrm{Ca}$ & & $<3$ & $3-5$ & $5-10$ & $>10$ \\
\hline $\mathrm{Mg}$ & & $<1$ & $1-2$ & $2-3$ & $>3$ \\
\hline $\mathrm{S}$ & & $<0,8$ & $0,8-1,4$ & $1,4-2$ & $>2$ \\
\hline B & & $<17$ & $17-27$ & $27-40$ & $>40$ \\
\hline $\mathrm{Cu}$ & & $<3$ & $3-6$ & $6-10$ & $>10$ \\
\hline $\mathrm{Fe}$ & $\mathrm{mg} \mathrm{kg}^{-1}$ & $<40$ & $40-69$ & $69-150$ & $>150$ \\
\hline $\mathrm{Mn}$ & & $<100$ & $100-200$ & $200-850$ & $>850$ \\
\hline $\mathrm{Zn}$ & & $<10$ & $10-15$ & $15-30$ & $>30$ \\
\hline
\end{tabular}

Fonte: Malavolta et al. (1997) e Silveira et al. (1998) e (1999)

\subsection{Relação do estado nutricional e da fertilidade do solo com a produtividade}

Visando uma maior compreensão das relações entre os teores foliares dos nutrientes e a produtividade, entre os parâmetros químicos do solo e a produtividade e entre os parâmetros químicos do solo com os teores foliares dos nutrientes, foram realizadas as seguintes análises estatísicas:

a) Análise de variância e teste de comparação de médias do índice de sítio entre as regiões;

b) Análise de variância e teste de comparação de médias do índice de sítio entre as fazendas, nas diferentes regiões;

c) Teste de comparação de médias dos parâmetros químicos do solo entre as regiões;

d) Teste de comparação de médias dos parâmetros químicos do solo entre as fazendas, nas diferentes regiões;

e) Teste de comparação de médias dos teores foliares dos nutrientes entre as regiões;

f) Teste de comparação de médias dos teores foliares dos nutrientes entre as fazendas, nas diferentes regiões; 
g) Análise de correlação e regressão linear entre os teores foliares dos nutrientes e o índice de sítio, em cada região separadamente;

h) Análise de correlação e regressão linear entre os teores foliares dos nutrientes e o índice de sítio, em todas as regiões;

i) Análise de correlação e regressão linear entre os parâmetros químicos do solo e o índice de sítio, em cada região separadamente;

j) Análise de correlação e regressão linear entre os parâmetros químicos do solo e o índice de sítio, em todas as regiões;

1) Análise de correlação e regressão linear entre os teores foliares dos nutrientes e os parâmetros químicos do solo, em cada região separadamente;

m) Análise de correlação e regressão linear entre os teores foliares dos nutrientes e os parâmetros químicos do solo, em todas as regiões;

Todas as análises estatísticas foram realizadas como o auxílio do Software SAS $6.0^{2}$

Foi utilizado o coeficiente de correlação de Pearson, nas análises de correlação. Os critérios de seleção adotados foram os seguintes: (a) coeficiente de correlação superior a 0,5 e (b) nível de significância não superior a 5\%, para rejeição da hipótese nula, ou seja, de que o coeficiente de correlação de Pearson seja igual a 0.

Foram testados modelos lineares e quadráticos nas análises de regressão linear. Os critérios de seleção adotados foram os seguintes: (a) análise gráfica dos resíduos, com o intuito de avaliar se há distribuição aleatória dos mesmos em relação a variável resposta; (b) nível de significância não superior a 5\% para rejeição da hipótese de nulidade do modelo, ou seja, de que todos os parâmetros calculados $\left(b_{o}, b_{1}\right.$ e $\left.b_{2}\right)$ sejam iguais a zero; (c) nível de significância não superior a 5\% para rejeição da hipótese nula, do teste $\mathrm{T}$ calculado, para cada parâmetro, ou seja, de que cada um seja igual a zero e (d) coeficiente de determinação superior a 0,25 .

${ }^{2}$ SAS INSTIUTE. SAS/STAT TIM guide for personal computers: version 6.. Cary, 1987. 1028p. 


\subsection{Sistema integrado de diagnose e recomendação (DRIS)}

Utilizou-se o Sistema Integrado de Diagnose e Recomendação (DRIS) visando identificar os nutrientes que poderiam estar limitando o crescimento do Eucalyptus sp., em todas as fazendas, nas regiões de Capão Bonito, Jacareí e Lençóis Paulista.

Para tanto, foi utilizado o software DRIS ${ }^{3}$ visando facilitar a obtenção dos índices primários de cada nutriente. Nesta versão, as normas, ou seja, o conjunto de dados relativos aos teores dos nutrientes de plantios de Eucalyptus sp. que apresentam elevada produtividade, já estão inseridas no sistema.

\footnotetext{
${ }^{3}$ Software DRIS versão 1,61 meta@ osite.com.br
} 


\section{RESULTADOS E DISCUSSÃO}

\subsection{Levantamento pedológico}

\subsubsection{Capão Bonito}

Nas proximidades do município de Capão Bonito, verificou-se haver um maior predomínio do Latossolo Vermelho associado ao Argilossolo Vermelho-Amarelo, conforme pode ser observado na Figura 2. Este tipo de solo ocorre em aproximadamente $36 \%$ da área total levantada (Anexo I). Acima deste solo, observou-se uma mancha bastante representativa do Argissolo Vermelho-Amarelo, representando $11 \%$ da área total levantada. Abaixo, observou-se a ocorrência do Latossolo Vermelho-Amarelo associado ao Argilossolo Vermelho-Amarelo e representando $10 \%$ da área total levantada. Outro solo de ocorrência relativamente alta (13\%) foi o Cambissolo Háplico, localizado na porção inferior do mapa.

Verificou-se, desta forma, que a ordem de ocorrência dos principais tipos de solos, na região de Capão Bonito, é a seguinte: Latossolos > Argilossolos = Cambissolos. 


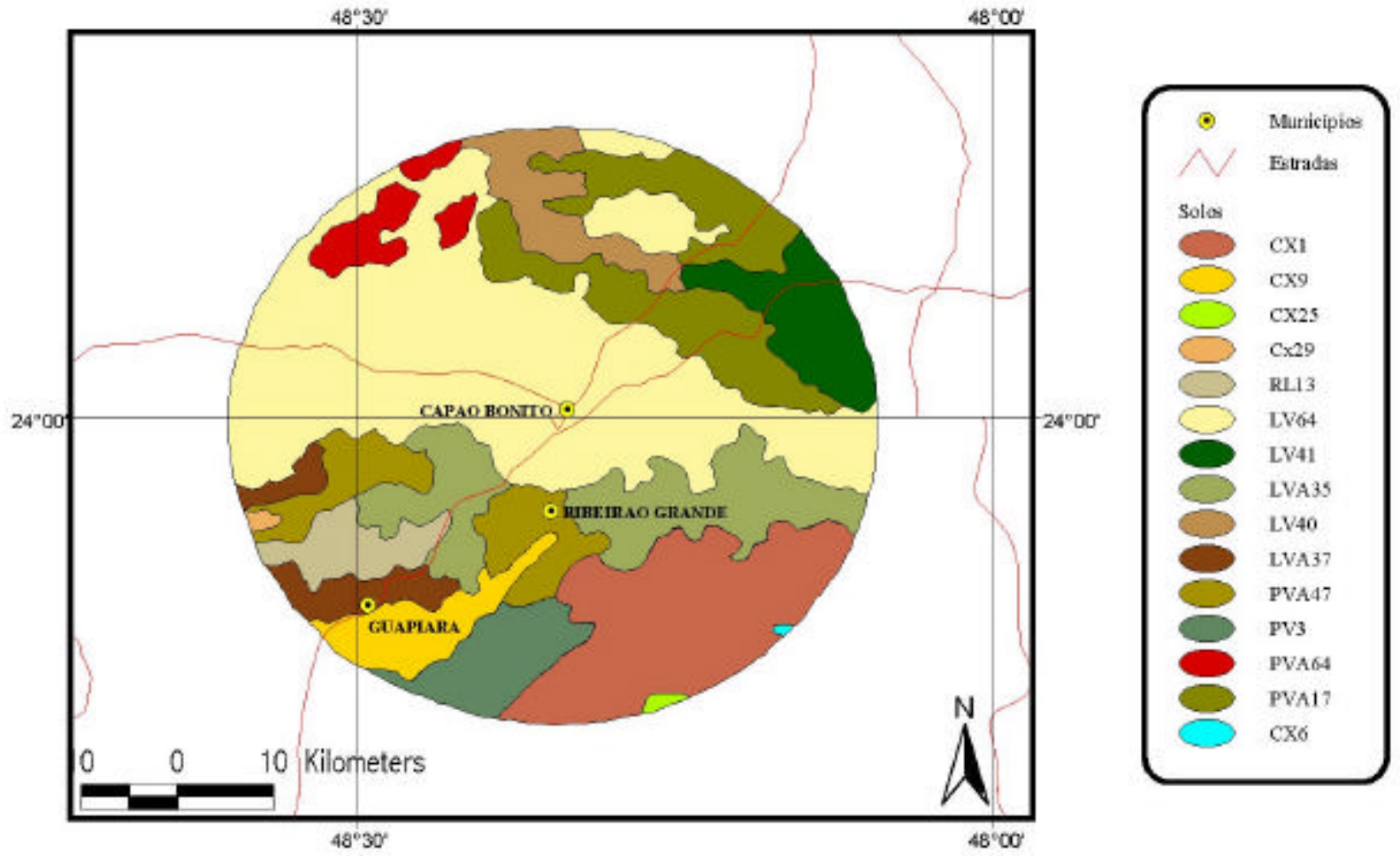

Figura 2 - Principais tipos de solos encontrados na região de Capão Bonito.

\subsubsection{Jacareí}

Na região de Jacareí, observou-se uma predominância do solo Argilosso VermelhoAmarelo associado ao Latossolo Vermelho-Amarelo. Este tipo de solo ocorre em aproximadamente $30 \%$ da área total levantada e está localizado na porção esquerda do mapa (Figura 3 e Anexo II). Próximo ao município de Jacareí, observou-se a ocorrência do Argilosso Vermelho-Amarelo associado ao Argilossolo Vermelho-Amarelo. Este tipo de solo ocorre em aproximadamente $14 \%$ da área total levantada. Abaixo, encontra-se um outro tipo de Argilosso Vermelho-Amarelo em aproximadamente 18\% da área total levantada. 
Verificou-se, desta forma, que os Argilossolos são os solos de maior predominância na região de Jacareí.
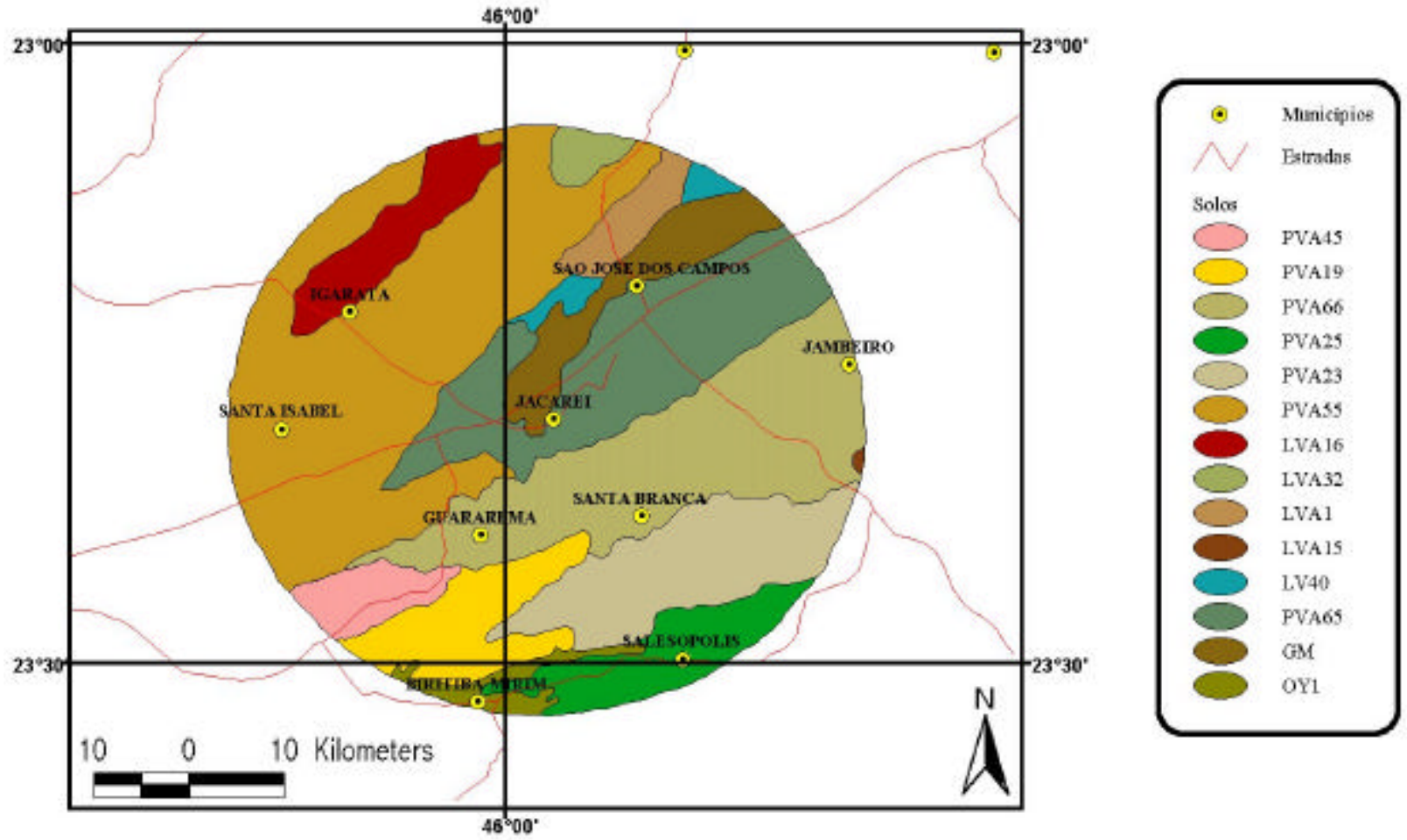

Figura 3 - Principais tipos de solos encontrados na região de Jacareí.

\subsubsection{Lençóis Paulista}

$\mathrm{Na}$ região de Lençóis Paulista, verificou-se uma maior ocorrência do Latossolo Vermelho associado ao Latossolo Vermelho-Amarelo. Este tipo de solo compreende 47\% da área total levantada (Anexo III, Tabela 24) e localiza-se na porção esquerda do mapa (Figura 4). Um outro tipo de solo, representando $29 \%$ da área total levantada e localizado na porção direita do mapa, é o Latossolo Vermelho. 
De acordo com estes resultados, verificou-se que, na região de Lençóis Paulista, há uma predominância de Latossolos em relação aos outros tipos de solos.
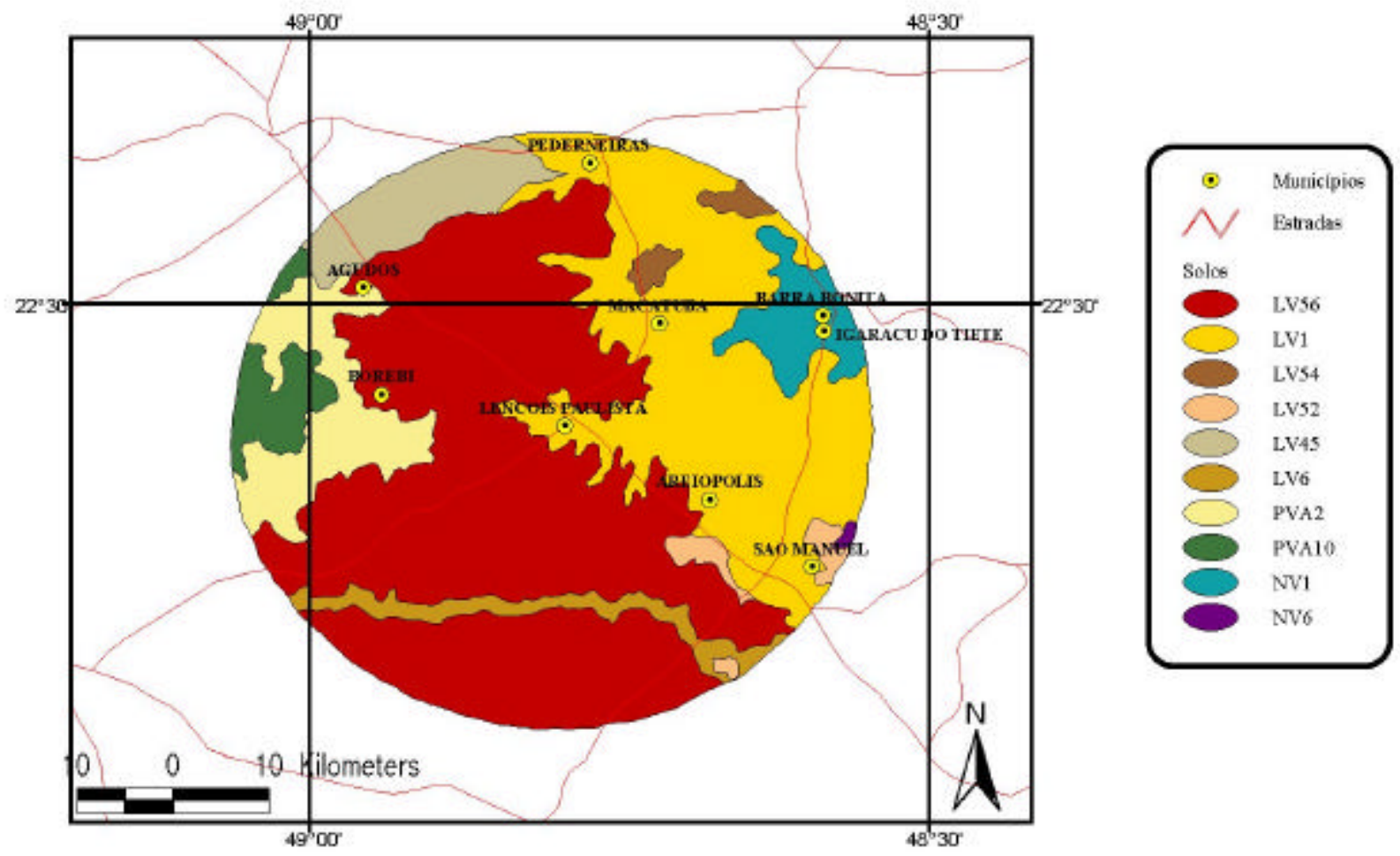

Figura 4 - Principais tipos de solos encontrados na região de Lençóis Paulista.

\subsection{Avaliação do balanço hídrico}

\subsubsection{Capão Bonito}

As Figuras 5 e 6 apresentam o balanço hídrico da região de Capão Bonito, com base nos dados históricos de temperatura média e precipitação mensal, dos anos de 1978 a 1990 e de 1995 a 2000, respectivamente.

A temperatura média e a precipitação mensal, da região de Capão Bonito, com base nos dados históricos de 1978 a 1990, foram respectivamente de 20,1 ${ }^{\circ} \mathrm{C}$ e $1210 \mathrm{~mm}$. De 
acordo com a Figura 5, verificou-se que não há longos períodos de déficit hídrico nesta região.

A Figura 6 mostra que durante os anos de 1995 a 2000, houve uma pequena redução na temperatura média e um aumento da precipitação, as quais foram respectivamente de $19,6^{\circ} \mathrm{C}$ e $1378,5 \mathrm{~mm}^{2}$ ano $^{-1}$. O déficit hídrico teve um aumento durante este período, chegando a 4,8 mm ano ${ }^{-1}$, o que pode estar associado a redução da precipitação em 48\%, no mês de maio.

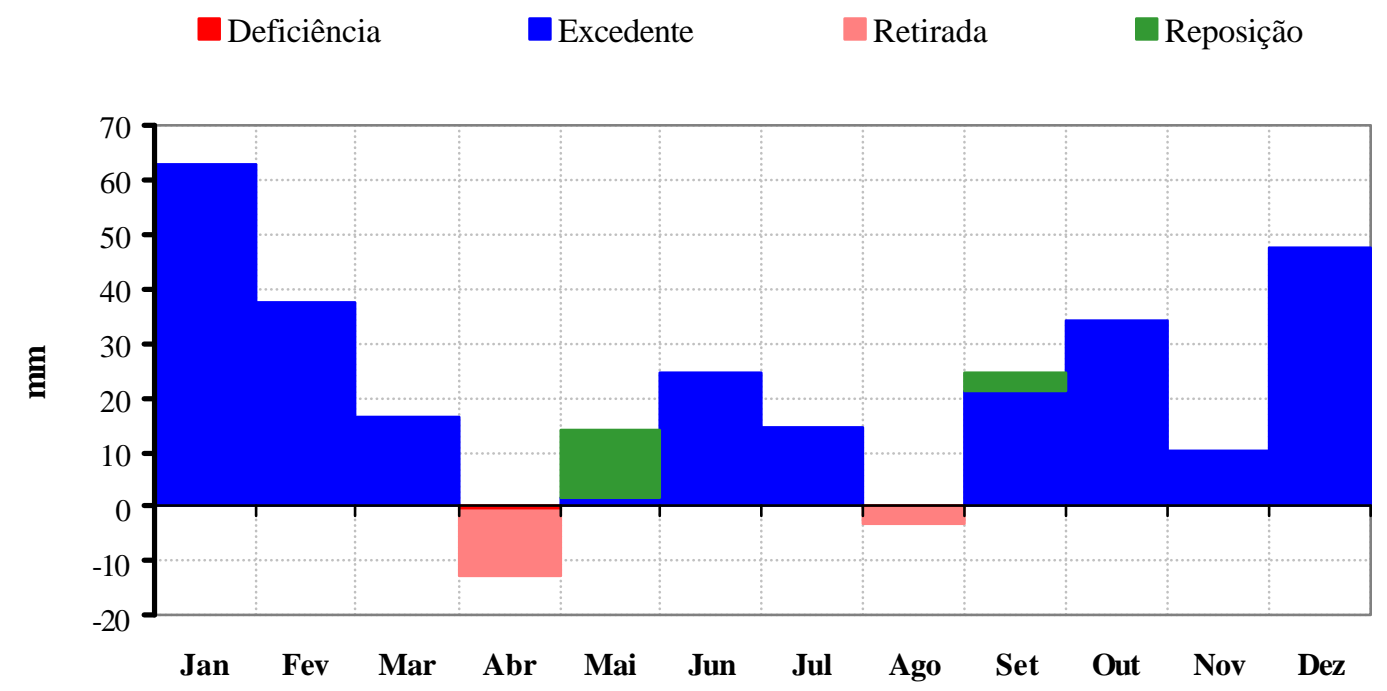

Figura 5 - Balanço hídrico da região de Capão Bonito, referente aos anos de 1978 a 1990. 


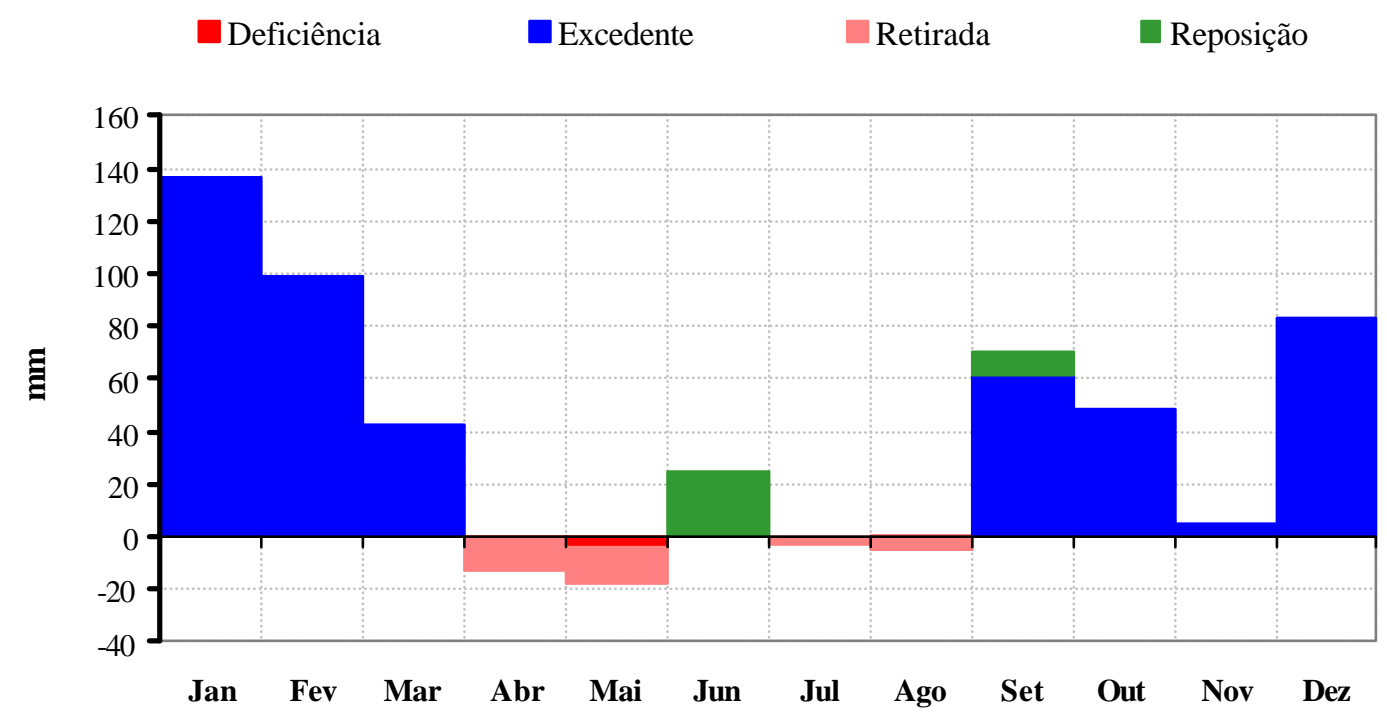

Figura 6 - Balanço hídrico da região de Capão Bonito, referente aos anos de 1995 a 2000.

\subsubsection{Jacareí}

As Figuras 7 e 8 apresentam o balanço hídrico da região de Jacareí, com base nos dados históricos de temperatura média e precipitação mensal, dos anos de 1941 a 1970 e de 1999 a 2000, respectivamente.

A temperatura média e a precipitação mensal, da região de Jacareí, com base nos dados históricos de 1941 a 1970, foram respectivamente de $21,4^{\circ} \mathrm{C}$ e $1239 \mathrm{~mm}$. De acordo com a Figura 7, verificou-se que um longo período de déficit hídrico na região de Jacareí, ocorrendo entre os meses abril a setembro. Entretanto, a maior intensidade do déficit hídrico ocorre entre os meses de julho a setembro, chegando a $37,9 \mathrm{~mm}$ ano $^{-1}$.

A Figura 8, indica que durante os anos de 1999 a 2000, houve uma pequena redução da precipitação média durante os meses de março a novembro, quando comparado com a série histórica de 1941 a 1970, embora a precipitação total tenha sido superior a esta. A menor uniformidade de distribuição das chuvas ao longo do ano, ocasionou um aumento 
bastante significativo do déficit hídrico, durante os anos de 1999 e 2000, o qual atingiu 111,1 $\mathrm{mm} \mathrm{ano}^{-1}$.

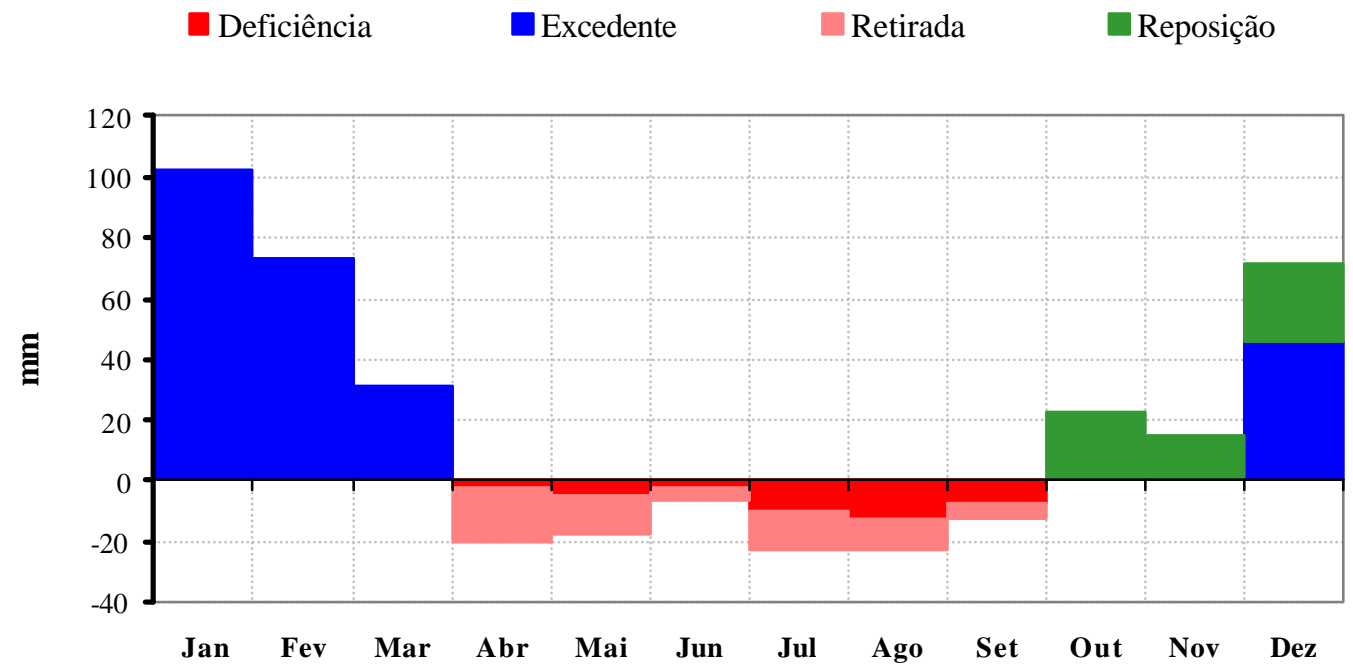

Figura 7 - Balanço hídrico da região de Jacareí, referente aos anos de 1941 a 1970.

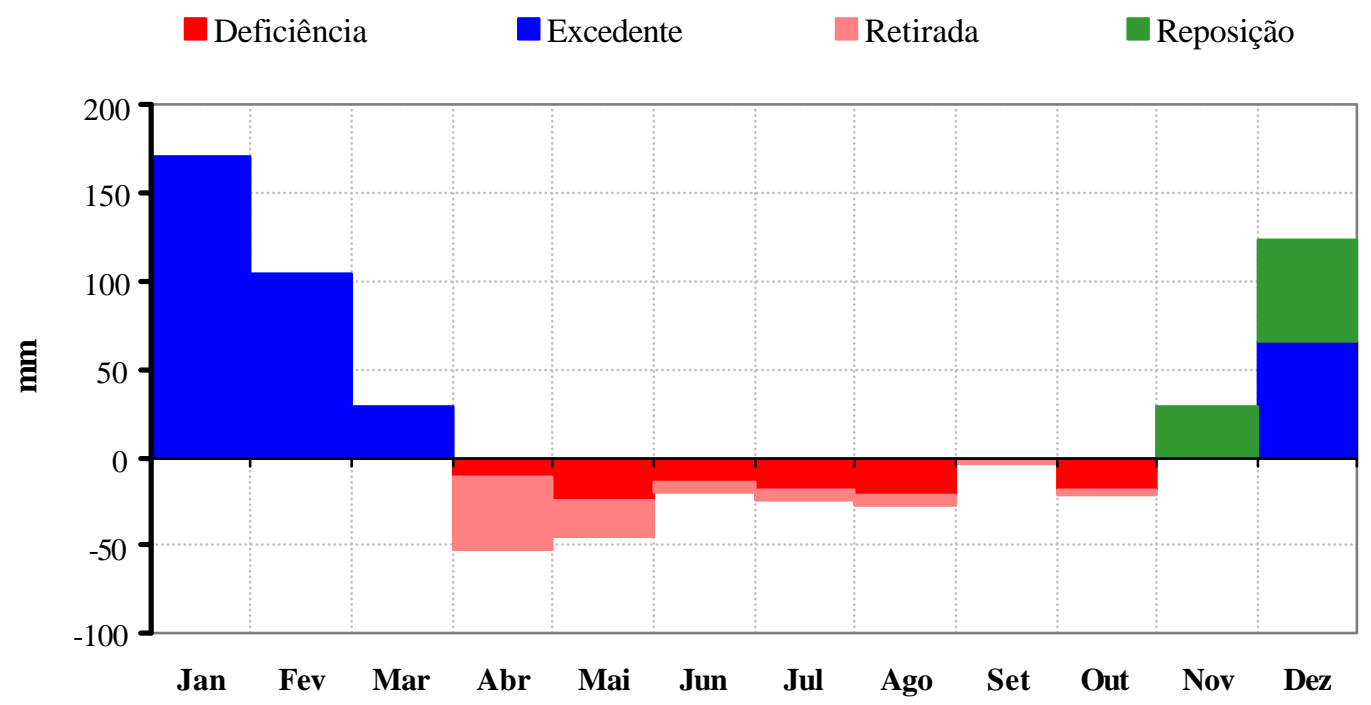

Figura 8 - Balanço hídrico da região de Jacareí, referente aos anos de 1999 a 2000. 


\subsubsection{Lençóis Paulista}

As Figuras 9 e 10 apresentam o balanço hídrico da região de Lençóis Paulista, com base nos dados históricos de temperatura média e precipitação mensal, dos anos de 1941 a 1970 e de 1998 a 1999, respectivamente.

A temperatura média e a precipitação mensal, da região de Lençóis Paulista, com base nos dados históricos de 1941 a 1970, foram respectivamente de $21^{\circ} \mathrm{C}$ e $1369 \mathrm{~mm}$. De acordo com a Figura 9, verificou-se que os meses de agosto e setembro apresentaram déficit hídrico, cuja intensidade chegou a $17,4 \mathrm{~mm}^{\mathrm{ano}}{ }^{-1}$.

A Figura 10 indica que durante os anos de 1998 a 1999, houve uma redução atípica de $48 \%$ nos índices pluviométricos, entre os meses de outubro e novembro. Isso ocasionou um déficit hídrico de 12,2 mm no mês de novembro, levando a um aumento do déficit hídrico anual para $30,6 \mathrm{~mm}$.

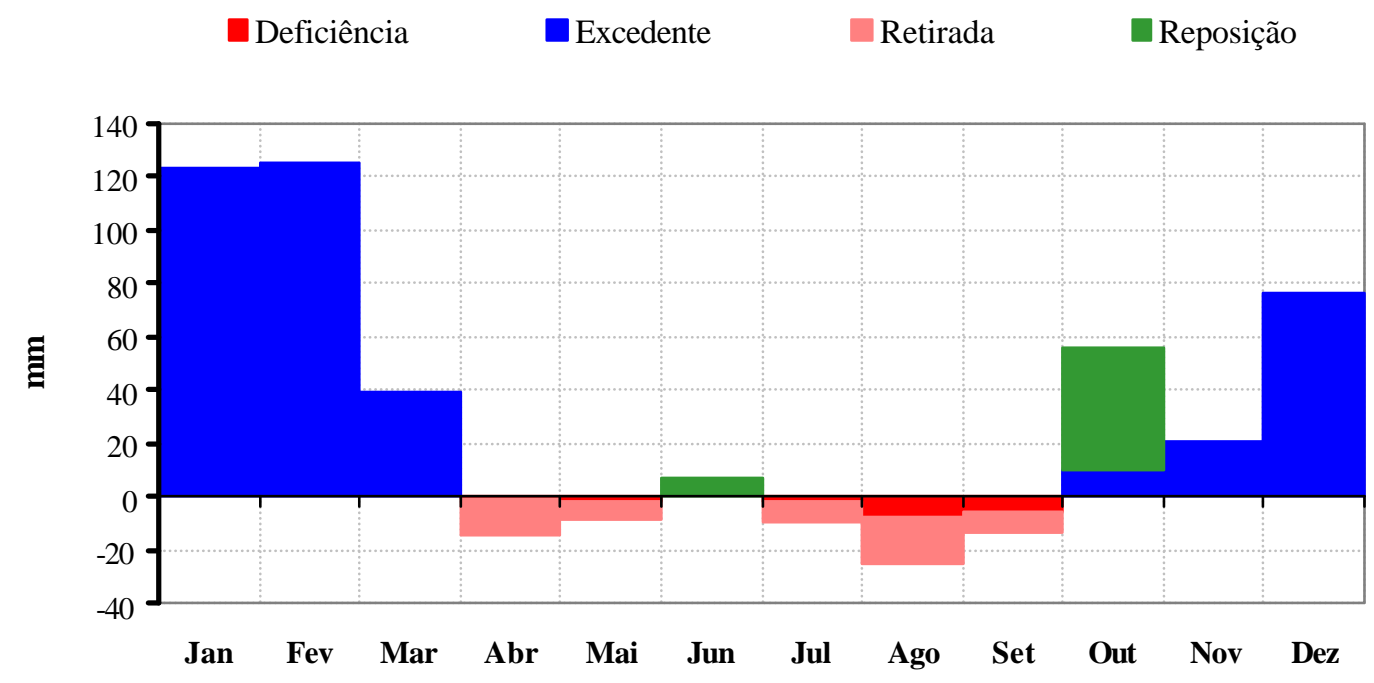

Figura 9 - Balanço hídrico da região de Lençóis Paulista, referente aos anos de 1941 a 1970. 


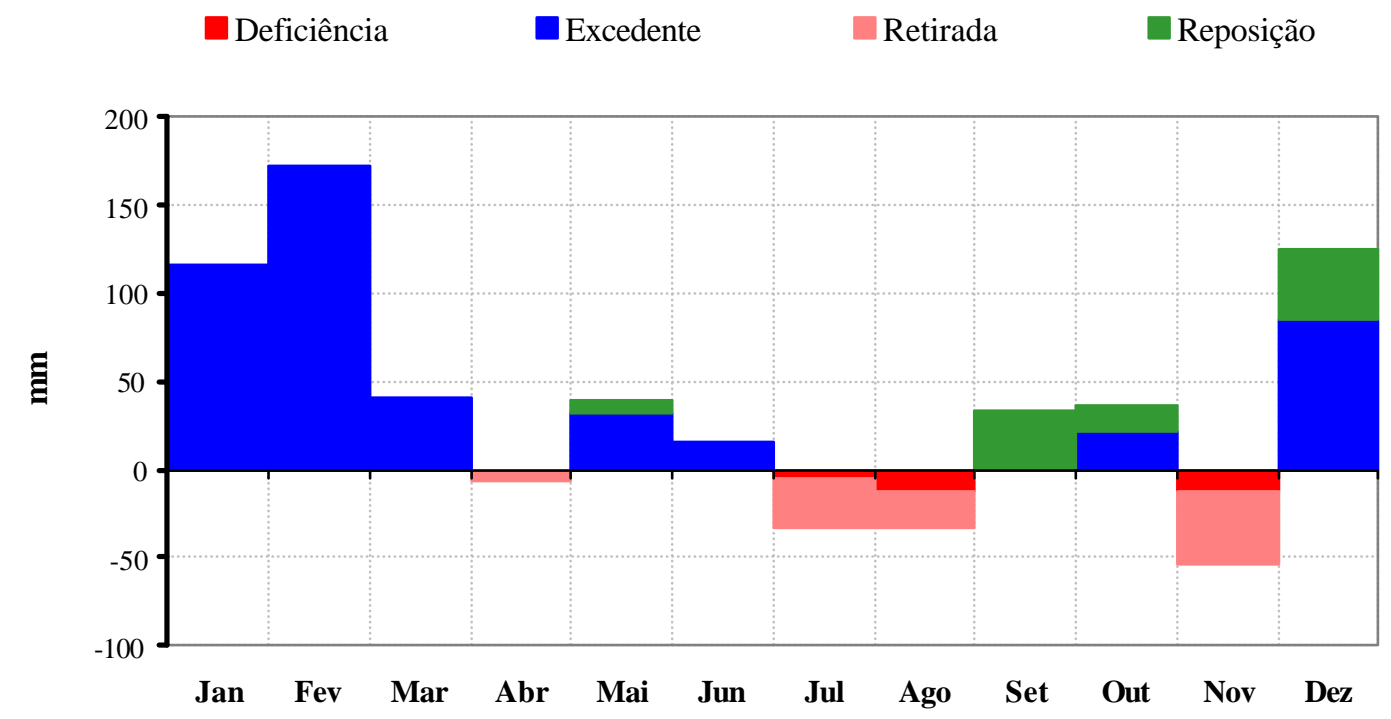

Figura 10 - Balanço hídrico da região de Lençóis Paulista, referente aos anos de 1998 a 1999.

\subsection{Avaliação da Produtividade}

Os índices de sítio (IS) na idade base de 84 meses, obtidos através da altura média das árvores dominantes (MHDOM) de cada talhão, nas diferentes regiões estudadas, estão apresentados nas Tabelas 22, 23 e 24. 
Tabela 22. Avaliação da produtividade dos talhões na região de Capão Bonito.

\begin{tabular}{|c|c|c|c|c|c|c|c|}
\hline Fazenda & Talhão & $\begin{array}{c}\text { Espécie/ } \\
\text { Clone }\end{array}$ & $\begin{array}{c}\text { Idade } \\
\text { (meses) }\end{array}$ & $\begin{array}{c}\text { Espaçamento } \\
\left(\mathbf{m}^{2}\right)\end{array}$ & $\begin{array}{c}\text { Área } \\
\text { (ha) }\end{array}$ & $\begin{array}{c}\text { MHDOM } \\
(\mathbf{m}) \\
\end{array}$ & $\begin{array}{c}\text { IS } \\
(\mathbf{m})\end{array}$ \\
\hline A & 1 & E. grandis & 28 & $2,5 \times 2,0$ & 8,20 & 15,31 & 28,4 \\
\hline A & 2 & E. grandis & 31 & $2,5 \times 2,0$ & 24,8 & 16,00 & 27,1 \\
\hline A & 3 & E. grandis & 28 & $2,5 \times 2,0$ & 24,88 & 14,83 & 27,5 \\
\hline $\mathrm{A}$ & 4 & E. grandis & 28 & $2,5 \times 2,0$ & 20,41 & 16,25 & 30,1 \\
\hline A & 5 & E. grandis & 28 & $2,5 \times 2,0$ & 29,37 & 15,67 & 29,0 \\
\hline A & 6 & E. grandis & 28 & $2,5 \times 2,0$ & 13,46 & 14,50 & 26,9 \\
\hline A & 7 & E. grandis & 26 & $2,5 \times 2,0$ & 20,36 & 14,00 & 27,8 \\
\hline A & 8 & E. grandis & 26 & $2,5 \times 2,0$ & 27,37 & 15,00 & 29,8 \\
\hline A & 9 & E. grandis & 26 & $2,5 \times 2,0$ & 18,2 & 14,25 & 28,3 \\
\hline A & 10 & E. grandis & 26 & $2,5 \times 2,0$ & 26,01 & 12,83 & 25,5 \\
\hline A & 11 & E. saligna & 25 & $2,5 \times 2,0$ & 19,42 & 13,50 & 27,9 \\
\hline A & 12 & E. grandis & 25 & $2,5 \times 2,0$ & 12,31 & 13,00 & 26,9 \\
\hline A & 13 & E. grandis & 25 & $2,5 \times 2,0$ & 7,02 & 13,50 & 27,9 \\
\hline A & 14 & E. grandis & 25 & $2,5 \times 2,0$ & 5,5 & 13,50 & 27,9 \\
\hline A & 15 & E. grandis & 26 & $2,5 \times 2,0$ & 8,38 & 12,50 & 24,9 \\
\hline B & 1 & E. saligna & 32 & $2,5 \times 2,0$ & 7,72 & 13,50 & 21,2 \\
\hline B & 2 & E. grandis & 32 & $2,5 \times 2,0$ & 8,11 & 16,00 & 25,2 \\
\hline $\mathrm{B}$ & 3 & E. saligna & 34 & $2,5 \times 2,0$ & 7,39 & 15,50 & 25,6 \\
\hline $\mathrm{B}$ & 4 & E. saligna & 34 & $2,5 \times 2,0$ & 8,2 & 16,50 & 26,0 \\
\hline B & 5 & E. saligna & 32 & $2,5 \times 2,0$ & 4,2 & 14,50 & 23,9 \\
\hline B & 6 & E. saligna & 34 & $2,5 \times 2,0$ & 12,6 & 15,25 & 25,2 \\
\hline B & 7 & E. saligna & 32 & $2,5 \times 2,0$ & 12,4 & 14,00 & 23,1 \\
\hline B & 8 & E. saligna & 32 & $2,5 \times 2,0$ & 13,8 & 18,50 & 30,5 \\
\hline B & 9 & E. saligna & 32 & $2,5 \times 2,0$ & 14,8 & 16,75 & 27,6 \\
\hline $\mathrm{C}$ & 1 & E. grandis & 28 & $2,5 \times 2,0$ & 20,94 & 15,75 & 29,2 \\
\hline $\mathrm{C}$ & 2 & E. grandis & 32 & $2,5 \times 2,0$ & 8,04 & 17,00 & 28,1 \\
\hline $\mathrm{C}$ & 3 & E. grandis & 26 & $2,5 \times 2,0$ & 15,26 & 14,50 & 28,8 \\
\hline $\mathrm{C}$ & 4 & E. grandis & 31 & $2,5 \times 2,0$ & 24,85 & 16,00 & 27,1 \\
\hline $\mathrm{D}$ & 1 & E. saligna & 12 & $2,0 \times 1,5$ & 14,37 & 4,00 & 25,4 \\
\hline $\mathrm{D}$ & 2 & E. saligna & 14 & $2,0 \times 1,5$ & 7,09 & 5,00 & 23,4 \\
\hline $\mathrm{D}$ & 3 & E. saligna & 20 & $2,0 \times 1,5$ & 28,83 & 9,33 & 25,0 \\
\hline $\mathrm{D}$ & 4 & E. saligna & 12 & $2,0 \times 1,5$ & 23,89 & 3,25 & 20,7 \\
\hline $\mathrm{D}$ & 5 & E. saligna & 12 & $2,0 \times 1,5$ & 6,68 & 4,00 & 25,4 \\
\hline $\mathrm{D}$ & 6 & E. saligna & 13 & $2,0 \times 1,5$ & 23,81 & 4,25 & 22,9 \\
\hline
\end{tabular}




\begin{tabular}{|c|c|c|c|c|c|c|c|}
\hline $\mathrm{D}$ & 7 & E. saligna & 13 & $2,0 \times 1,5$ & 25 & 4,83 & 26,0 \\
\hline $\mathrm{D}$ & 8 & E. saligna & 12 & $2,0 \times 1,5$ & 19,47 & 3,75 & 23,8 \\
\hline $\mathrm{D}$ & 9 & E. saligna & 16 & $2,5 \times 2,0$ & 17,05 & 6,50 & 24,1 \\
\hline $\mathrm{D}$ & 10 & E. saligna & 17 & $2,5 \times 2,0$ & 25,84 & 6,00 & 20,2 \\
\hline $\mathrm{D}$ & 11 & E. saligna & 13 & $2,0 \times 1,5$ & 21,99 & 5,75 & 31,0 \\
\hline $\mathrm{D}$ & 12 & E. saligna & 13 & $2,0 \times 1,5$ & 12,82 & 3,50 & 18,8 \\
\hline $\mathrm{D}$ & 13 & E. saligna & 13 & $2,0 \times 1,5$ & 4,14 & 5,00 & 26,9 \\
\hline $\mathrm{D}$ & 14 & E. saligna & 13 & $2,0 \times 1,5$ & 24,43 & 5,17 & 27,8 \\
\hline $\mathrm{D}$ & 15 & E. saligna & 14 & $2,0 \times 1,5$ & 25,53 & 5,67 & 26,5 \\
\hline $\mathrm{D}$ & 16 & E. saligna & 16 & $2,5 \times 2,0$ & 21,25 & 7,00 & 25,9 \\
\hline $\mathrm{D}$ & 17 & E. saligna & 17 & $2,5 \times 2,0$ & 11,06 & 8,50 & 28,6 \\
\hline $\mathrm{D}$ & 18 & E. saligna & 23 & $2,5 \times 2,0$ & 13,9 & 8,50 & 19,3 \\
\hline $\mathrm{D}$ & 19 & E. saligna & 22 & $2,5 \times 2,0$ & 23,3 & 6,25 & 14,9 \\
\hline $\mathrm{D}$ & 20 & E. saligna & 16 & $2,0 \times 1,5$ & 16,45 & 6,00 & 22,2 \\
\hline $\mathrm{D}$ & 21 & E. saligna & 14 & $2,5 \times 2,0$ & 12,65 & 6,50 & 30,4 \\
\hline $\mathrm{D}$ & 22 & E. saligna & 22 & $2,5 \times 2,0$ & 19,12 & 8,25 & 19,7 \\
\hline $\mathrm{D}$ & 23 & E. saligna & 22 & $2,5 \times 2,0$ & 11,47 & 6,00 & 14,3 \\
\hline $\mathrm{E}$ & 1 & $\mathrm{C} 1$ & 23 & $3,0 \times 3,0$ & 9,99 & 7,83 & 17,7 \\
\hline $\mathrm{E}$ & 2 & $\mathrm{C} 1$ & 22 & $3,0 \times 3,0$ & 7,49 & 7,30 & 17,4 \\
\hline $\mathrm{F}$ & 1 & $\mathrm{C} 2$ & 17 & $3,0 \times 3,0$ & - & 7,30 & 24,6 \\
\hline $\mathrm{F}$ & 2 & $\mathrm{C} 3$ & 23 & $3,0 \times 3,0$ & 31,4 & 10,13 & 22,9 \\
\hline $\mathrm{F}$ & 3 & $\mathrm{C} 4$ & 18 & $3,0 \times 3,0$ & - & 8,62 & 26,7 \\
\hline G & 1 & $\mathrm{C} 1$ & 17 & $3,0 \times 3,0$ & - & 5,83 & 19,6 \\
\hline $\mathrm{G}$ & 2 & E. saligna & 22 & $2,7 \times 2,0$ & - & 8,63 & 20,6 \\
\hline $\mathrm{G}$ & 3 & E. saligna & 20 & $2,7 \times 2,0$ & - & 7,80 & 20,9 \\
\hline $\mathrm{H}$ & 1 & $\mathrm{C} 5$ & 21 & $3,0 \times 3,0$ & 34,85 & 6,35 & 16,0 \\
\hline $\mathrm{H}$ & 2 & C6 & 21 & $3,0 \times 3,0$ & 29,7 & 7,38 & 18,6 \\
\hline Total & 61 & & & & 948 & & \\
\hline
\end{tabular}


Tabela 23. Avaliação da produtividade dos talhões na região de Jacareí.

\begin{tabular}{cccccccc}
\hline Fazenda & Talhão & $\begin{array}{c}\text { Espécie/ } \\
\text { Clone }\end{array}$ & $\begin{array}{c}\text { Idade } \\
(\mathbf{m e s e s})\end{array}$ & $\begin{array}{c}\text { Espaçamento } \\
\left(\mathbf{m}^{\mathbf{2}}\right)\end{array}$ & $\begin{array}{c}\text { Área } \\
(\mathbf{h a})\end{array}$ & $\begin{array}{c}\text { MHDOM } \\
(\mathbf{m})\end{array}$ & $\begin{array}{c}\text { IS } \\
(\mathbf{m})\end{array}$ \\
\hline A & 1 & E. grandis & 20 & $3,0 \times 2,5$ & 13,4 & 10,04 & 26,9 \\
A & 2 & E. grandis & 20 & $3,0 \times 2,5$ & 23,9 & 9,57 & 25,7 \\
B & 1 & E. grandis & 21 & $3,0 \times 2,5$ & 37,74 & 11,98 & 30,2 \\
C & 1 & J1 & 21 & $3,0 \times 3,0$ & 38,8 & 9,10 & 22,9 \\
D & 1 & E. grandis & 20 & $3,0 \times 2,5$ & 47,27 & 8,76 & 23,5 \\
D & 2 & J1 & 20 & $3,0 \times 3,0$ & 29,97 & 9,10 & 24,4 \\
E & 1 & E. grandis & 21 & $3,0 \times 2,5$ & 47,51 & 9,95 & 23,7 \\
E & 2 & E. grandis & 22 & $3,0 \times 2,5$ & 34,66 & 10,03 & 25,3 \\
E & 3 & J2 & 18 & $3,0 \times 3,0$ & - & 8,27 & 25,6 \\
F & 1 & J3 & 24 & $3,0 \times 3,0$ & 30,2 & 12,40 & 26,8 \\
F & 2 & J3 & 19 & $3,0 \times 3,0$ & 71,66 & 13,74 & 39,4 \\
Total & 11 & & & & 375 & & \\
\hline
\end{tabular}


Tabela 24. Avaliação da produtividade dos talhões na região de Lençóis Paulista.

\begin{tabular}{|c|c|c|c|c|c|c|c|}
\hline Fazenda & Talhão & $\begin{array}{l}\text { Espécie/ } \\
\text { Clone }\end{array}$ & $\begin{array}{c}\text { Idade } \\
\text { (meses) }\end{array}$ & $\begin{array}{c}\text { Espaçamento } \\
\left(\mathbf{m}^{2}\right)\end{array}$ & $\begin{array}{c}\text { Área } \\
\text { (ha) }\end{array}$ & $\begin{array}{c}\text { MHDOM } \\
(\mathrm{m})\end{array}$ & $\begin{array}{c}\text { IS } \\
(\mathbf{m})\end{array}$ \\
\hline A & 1 & E. grandis & 44 & $3,25 \times 1,9$ & 26,77 & 19,25 & 25,5 \\
\hline A & 2 & E. grandis & 44 & $3,25 \times 1,9$ & 24,59 & 18,75 & 24,8 \\
\hline A & 3 & E. grandis & 39 & $3,25 \times 1,9$ & 33,55 & 17,17 & 24,5 \\
\hline A & 4 & E. grandis & 45 & $3,0 \times 1,8$ & 30,31 & 16,17 & 21,1 \\
\hline A & 5 & E. grandis & 44 & $3,0 \times 1,8$ & 17,71 & 19,00 & 25,1 \\
\hline A & 6 & E. grandis & 36 & $3,0 \times 1,8$ & 11,40 & 18,00 & 27,2 \\
\hline $\mathrm{B}$ & 1 & E. grandis & 41 & $3,0 \times 1,9$ & 11,00 & 16,50 & 22,8 \\
\hline B & 2 & E. grandis & 41 & $3,0 \times 1,9$ & - & 18,50 & 25,6 \\
\hline $\mathrm{B}$ & 3 & E. grandis & 44 & $3,0 \times 1,9$ & - & 17,00 & 22,5 \\
\hline $\mathrm{C}$ & 1 & E. grandis & 36 & $3,0 \times 1,8$ & 37,73 & 16,33 & 24,6 \\
\hline $\mathrm{C}$ & 2 & E. grandis & 41 & $3,0 \times 1,8$ & 9,98 & 17,00 & 23,5 \\
\hline $\mathrm{C}$ & 3 & E. grandis & 41 & $3,0 \times 1,8$ & 10,78 & 17,50 & 24,2 \\
\hline $\mathrm{C}$ & 4 & E. grandis & 41 & $3,0 \times 1,8$ & 8,62 & 17,00 & 23,5 \\
\hline $\mathrm{D}$ & 1 & E. grandis & 37 & $3,0 \times 1,8$ & 25,53 & 14,50 & 21,5 \\
\hline $\mathrm{E}$ & 1 & E. grandis & 30 & $3,0 \times 1,9$ & 6,63 & 19,50 & 34,0 \\
\hline $\mathrm{E}$ & 2 & E. grandis & 42 & $3,0 \times 1,9$ & 20,00 & 19,25 & 26,2 \\
\hline $\mathrm{E}$ & 3 & E. grandis & 42 & $3,0 \times 1,9$ & 12,00 & 19,50 & 26,5 \\
\hline $\mathrm{E}$ & 4 & E. grandis & 42 & $3,0 \times 1,9$ & 5,00 & 19,00 & 25,9 \\
\hline $\mathrm{E}$ & 5 & E. grandis & 42 & $3,0 \times 1,9$ & 24,00 & 19,25 & 26,2 \\
\hline $\mathrm{E}$ & 6 & E. grandis & 42 & $3,0 \times 1,9$ & 15,00 & 19,50 & 26,5 \\
\hline $\mathrm{E}$ & 7 & E. grandis & 42 & $3,0 \times 1,9$ & 15,26 & 19,50 & 26,5 \\
\hline $\mathrm{E}$ & 8 & E. grandis & 42 & $3,0 \times 1,9$ & 21,00 & 17,75 & 24,2 \\
\hline $\mathrm{E}$ & 9 & E. grandis & 41 & $3,0 \times 1,9$ & 16,50 & 16,00 & 22,1 \\
\hline $\mathrm{E}$ & 10 & E. grandis & 40 & $3,0 \times 1,9$ & 9,20 & 17,00 & 23,9 \\
\hline $\mathrm{E}$ & 11 & E. grandis & 40 & $3,0 \times 1,9$ & 12,99 & 16,00 & 22,5 \\
\hline $\mathrm{E}$ & 12 & E. grandis & 42 & $3,0 \times 1,9$ & 15,80 & 18,00 & 24,5 \\
\hline $\mathrm{E}$ & 13 & E. grandis & 42 & $3,0 \times 1,9$ & 21,76 & 16,75 & 22,8 \\
\hline $\mathrm{E}$ & 14 & E. grandis & 42 & $3,0 \times 1,9$ & 20,00 & 19,00 & 25,9 \\
\hline $\mathrm{E}$ & 15 & E. grandis & 42 & $3,0 \times 1,9$ & 22,93 & 19,00 & 25,9 \\
\hline $\mathrm{E}$ & 16 & E. grandis & 41 & $3,0 \times 1,9$ & 20,85 & 16,50 & 22,8 \\
\hline $\mathrm{E}$ & 17 & E. grandis & 40 & $3,0 \times 1,9$ & 13,72 & 15,00 & 21,1 \\
\hline $\mathrm{E}$ & 18 & E. grandis & 40 & $3,0 \times 1,9$ & 16,00 & 13,50 & 18,9 \\
\hline $\mathrm{E}$ & 19 & E. grandis & 40 & $3,0 \times 1,9$ & 8,00 & 14,50 & 20,4 \\
\hline $\mathrm{E}$ & 20 & E. grandis & 40 & $3,0 \times 1,9$ & 9,20 & 15,50 & 21,8 \\
\hline
\end{tabular}




\begin{tabular}{cccccccc} 
E & 21 & E. grandis & 40 & $3,0 \times 1,9$ & 16,70 & 15,50 & 21,8 \\
E & 22 & E. grandis & 41 & $3,0 \times 1,9$ & 23,69 & 16,75 & 23,1 \\
E & 23 & E. grandis & 41 & $3,0 \times 1,9$ & 27,00 & 16,83 & 23,3 \\
F & 1 & E. grandis & 36 & $3,0 \times 1,8$ & 18,15 & 11,50 & 17,3 \\
F & 2 & E. grandis & 36 & $3,0 \times 1,8$ & 15,04 & 13,50 & 20,4 \\
F & 3 & E. grandis & 36 & $3,0 \times 1,8$ & 15,00 & 12,50 & 18,9 \\
F & 4 & E. grandis & 36 & $3,0 \times 1,8$ & 15,00 & 10,00 & 15,1 \\
G & 1 & E. grandis & 40 & $3,0 \times 1,9$ & 30,81 & 16,67 & 23,4 \\
G & 2 & E. grandis & 40 & $3,0 \times 1,9$ & 23,57 & 16,00 & 22,5 \\
G & 3 & E. grandis & 40 & $3,0 \times 1,9$ & 15,47 & 16,00 & 22,5 \\
G & 4 & E. grandis & 39 & $3,0 \times 1,8$ & 14,43 & 16,50 & 23,5 \\
Total & 45 & & & & 769 & & \\
\hline
\end{tabular}

\subsubsection{Capão Bonito}

De acordo com a Tabela 25, foi possível verificar diferenças significativas dos índices de sítios, entre as fazendas levantadas na região de Capão Bonito. Este resultado já era esperado, a medida que se procurou amostrar talhões que visualmente apresentassem baixa, média e alta produtividade. A ordem de produtividade das fazendas amostradas, na região de Capão Bonito, foi a seguinte: $\mathrm{C}=\mathrm{A}=\mathrm{B}>\mathrm{F}>\mathrm{D}=\mathrm{G}=\mathrm{E}=\mathrm{H}$ (Tabela 26). $\mathrm{O}$ desvio padrão e o coeficiente de variação dos índices de sítio dos talhões, nas diferentes fazendas, variou de 0,21 a 4,39 e de 1,21 a 18,59 , respectivamante.

Tabela 25 - Análise de variância do índice de sítio das diferentes fazendas, na região de Capão Bonito.

\begin{tabular}{cccc}
\hline Causa da Variação & G.L. & S.Q. & F \\
\hline Fazenda & 7 & 488,29 & $7,08 * * *$ \\
Erro & 53 & 521,92 & \\
Total & 60 & 1010,21 & \\
\hline
\end{tabular}

*** significativo ao nível de $0,1 \%$ de probabilidade. 
Tabela 26 - Teste de comparação de médias, desvio e coeficiente de variação do índice de sítio, nas diferentes fazendas da região de Capão Bonito (médias seguidas de mesma letra não diferem entre si, pelo teste Tukey ao nível de $5 \%$ de probabilidade).

\begin{tabular}{ccccc}
\hline Fazenda & IS (m) & IS (\%) & s (m) & CV (\%) \\
\hline A & $27,73 a$ & 98 & 1,39 & 5,03 \\
B & $25,37 \mathrm{a}$ & 90 & 2,66 & 10,48 \\
D & $23,62 \mathrm{~b}$ & 83 & 4,39 & 18,59 \\
C & $28,30 \mathrm{a}$ & 100 & 0,92 & 3,25 \\
E & $17,55 \mathrm{c}$ & 62 & 0,21 & 1,21 \\
F & $24,73 \mathrm{a}$ & 87 & 1,90 & 7,70 \\
G & $20,37 \mathrm{c}$ & 72 & 0,68 & 3,34 \\
H & $17,30 \mathrm{c}$ & 61 & 1,83 & 10,68 \\
\hline
\end{tabular}

\subsubsection{Jacareí}

Na região de Jacareí, por outro lado, não foram observadas diferenças significativas do índice de sítio, entre as fazendas levantadas (Tabela 27). O desvio padrão e o coeficiente de variação variou de 0,64 a 8,91 e de 2,66 a 26,92, respectivamente, entre as fazendas (Tabela 28). Estes resultados indicam que a quantidade de parcelas amostradas, nesta região, foi insuficiente para expressar as diferenças de produtividade existente entre as fazendas.

Tabela 27 - Análise de variância do índice de sítio das diferentes fazendas, na região de Jacareí.

\begin{tabular}{cccc}
\hline Causa da Variação & G.L. & S.Q. & F \\
\hline Fazenda & 5 & 134,09 & 1,62 n.s. \\
Erro & 5 & 82,59 & \\
Total & 10 & 216,68 & \\
\hline
\end{tabular}


Tabela 28 - Teste de comparação de médias, desvio e coeficiente de variação do índice de sítio, nas diferentes fazendas da região de Jacareí (médias seguidas de mesma letra não diferem entre si, pelo teste Tukey ao nível de 5\% de probabilidade).

\begin{tabular}{ccccc}
\hline Fazenda & IS (m) & IS (\%) & S (m) & CV (\%) \\
\hline A & $26,30 \mathrm{a}$ & 79 & 0,85 & 3,23 \\
B & $30,20 \mathrm{a}$ & 91 & - & - \\
C & $22,90 \mathrm{a}$ & 69 & - & - \\
D & $23,95 \mathrm{a}$ & 72 & 0,64 & 2,66 \\
E & $24,87 \mathrm{a}$ & 75 & 1,02 & 4,11 \\
F & $33,10 \mathrm{a}$ & 100 & 8,91 & 26,92 \\
\hline
\end{tabular}

\subsubsection{Lençóis Paulista}

Na região de Lençóis Paulista, assim como em Capão Bonito, foram observadas diferenças significativas do índice de sítio entre as fazendas levantadas (Tabela 29). A ordem de produtividade observada foi a seguinte: $\mathrm{A}=\mathrm{E}=\mathrm{C}>=\mathrm{B}=\mathrm{G}=\mathrm{D}>=\mathrm{F}$ (Tabela 30). $\mathrm{O}$ desvio padrão e o coeficiente de variação dos índice de sítios nas diferentes fazendas variaram de 0,54 a 3,06 e de 2,27 a 12,63, respectivamente.

Tabela 29 - Análise de variância do índice de sítio das diferentes fazendas, na região de Lençóis Paulista.

\begin{tabular}{cccc}
\hline Causa da Variação & G.L. & S.Q. & F \\
\hline Fazenda & 6 & 150,47 & $3,83^{* *}$ \\
Erro & 38 & 248,81 & \\
Total & 44 & 399,28 & \\
\hline
\end{tabular}

** significativo ao nível de $1 \%$ de probabilidade. 
Tabela 30 - Teste de comparação de médias, desvio e coeficiente de variação do índice de sítio, nas diferentes fazendas da região de Lençóis Paulista (médias seguidas de mesma letra não diferem entre si, pelo teste Tukey ao nível de 5\% de probabilidade).

\begin{tabular}{ccccc}
\hline Fazenda & IS (m) & IS (\%) & s (m) & CV (\%) \\
\hline A & $24,70 \mathrm{a}$ & 100 & 2,00 & 8,11 \\
$\mathrm{~B}$ & $23,63 \mathrm{ab}$ & 96 & 1,71 & 7,23 \\
$\mathrm{C}$ & $23,95 \mathrm{a}$ & 97 & 0,54 & 2,27 \\
$\mathrm{D}$ & $21,50 \mathrm{ab}$ & 87 & - & - \\
$\mathrm{E}$ & $24,21 \mathrm{a}$ & 98 & 3,06 & 12,63 \\
$\mathrm{~F}$ & $17,92 \mathrm{~b}$ & 73 & 2,27 & 12,66 \\
$\mathrm{G}$ & $22,97 \mathrm{ab}$ & 93 & 0,55 & 2,39 \\
\hline
\end{tabular}

\subsubsection{Todas as regiões}

Foi possível observar diferenças significativas da produtividade, entre as regiões estudadas (Tabela 31). A produtividade obtida na região de Jacareí foi 14\% superior aquela obtida na região de Lençóis Paulista (Tabela 32). A produtividade obtida na região de Capão Bonito não diferiu daquelas obtidas em Jacareí e em Lençóis Paulista. O desvio padrão e o coeficiente de variação do índice de sítio, dentro de cada região, variaram de 3,01 a 4,65 e de 12,83 a 17,39, respectivamente.

Tabela 31 - Análise de variância do índice de sítio das diferentes regiões.

\begin{tabular}{cccc}
\hline Causa da Variação & G.L. & S.Q. & F \\
\hline Região & 2 & 103,99 & $3,65^{*}$ \\
Erro & 114 & 1626,17 & \\
Total & 116 & 1730,16 & \\
\hline
\end{tabular}

* significativo ao nível de $5 \%$ de probabilidade. 
Tabela 32 - Teste de comparação de médias, desvio e coeficiente de variação do índice de sítio, nas diferentes regiões estudadas (médias seguidas de mesma letra não diferem entre si, pelo teste Tukey ao nível de $5 \%$ de probabilidade).

\begin{tabular}{ccccc}
\hline Região & IS (m) & IS (\%) & S (m) & CV (\%) \\
\hline Capão Bonito & $24,68 \mathrm{ab}$ & 105 & 4,10 & 16,62 \\
Jacareí & $26,76 \mathrm{a}$ & 114 & 4,65 & 17,39 \\
Lençóis Paulista & $23,48 \mathrm{~b}$ & 100 & 3,01 & 12,83 \\
\hline
\end{tabular}

IS (m): Índice de sítio médio; IS (\%): Índice de sítio relativo; s (m): Desvio padrão do IS; CV (\%): Coeficiente de variação do IS.

\subsection{Avaliação do estado nutricional e da fertilidade do solo}

\subsubsection{Capão Bonito}

$\mathrm{Na}$ região de Capão Bonito, foram observadas diferenças significativas para todos os parâmetros químicos do solo entre as fazendas levantadas (Tabela 33). Notou-se, de modo geral, que as fazendas $\mathrm{C}$ e $\mathrm{F}$ apresentaram solos de maior fertilidade, proporcionando produtividades também mais elevadas. (Tabela 26). Na fazenda $\mathrm{C}$, a maior fertilidade do solo atribuiu-se aos elevados níveis de adubação utilizados nos cultivos de tomate e batata, os quais antecederam os plantios de Eucalyptus sp. (Tabela 17). A fazenda F também apresentou solos com elevada fertilidade, devido a grande quantidade de corretivos e fertilizantes utilizados nas rotação anteriores (Tabela 17). 
Tabela 33 - Parâmetros químicos médios dos solos, nas diferentes fazendas da região de Capão Bonito (médias seguidas de mesma letra não diferem entre si pelo teste Tukey ao nível de 5\% de probabilidade).

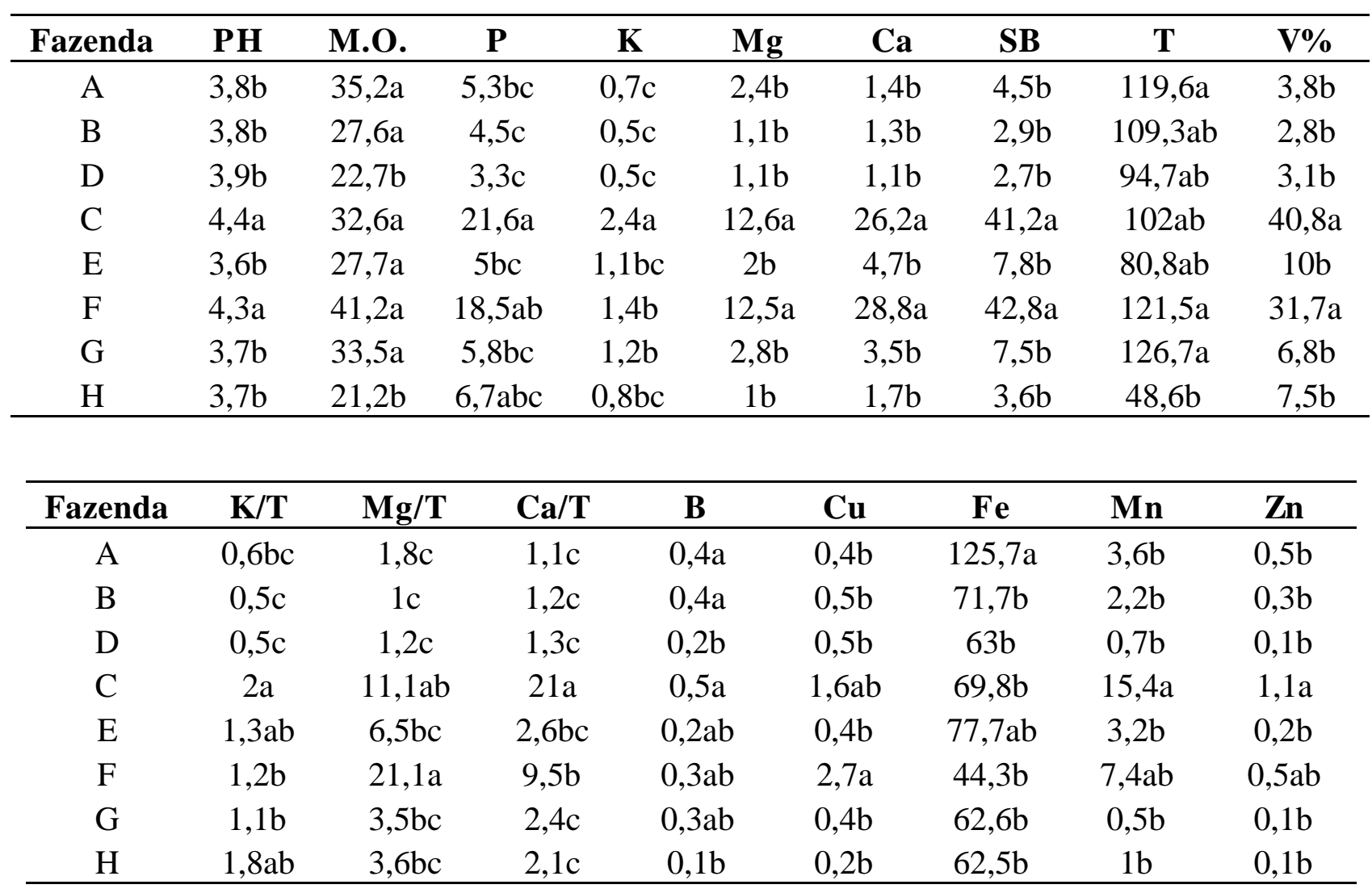

Com exceção do potássio e do ferro, todos os demais nutrientes no tecido foliar apresentaram diferenças significativas entre as fazendas levantadas (Tabela 34). Isso mostra que, assim como verificado para o índice de sítio, o número de fazendas amostradas foi suficiente para representar a variabilidade existente entre os teores dos nutrientes nos tecidos foliares, na região de Capão Bonito. Os maiores teores dos nutrientes, com exceção do boro, cobre, ferro e manganês, foram obtidos nos plantios de Eucalyptus sp., na fazenda C. 
Tabela 34 - Teores foliares médios dos macro e micronutrientes obtidos nas diferentes fazendas da região de Capão Bonito (médias seguidas de mesma letra não diferem entre si pelo teste Tukey ao nível de 5\% de probabilidade).

\begin{tabular}{cccccccccccc}
\hline Fazenda & $\mathbf{N}$ & $\mathbf{P}$ & $\mathbf{K}$ & $\mathbf{C a}$ & $\mathbf{M g}$ & $\mathbf{S}$ & $\mathbf{B}$ & $\mathbf{C u}$ & $\mathbf{F e}$ & $\mathbf{M n}$ & $\mathbf{Z n}$ \\
\hline $\mathrm{A}$ & $18 \mathrm{a}$ & $1,4 \mathrm{a}$ & $8,6 \mathrm{a}$ & $6,9 \mathrm{~b}$ & $2,2 \mathrm{abc}$ & $1,6 \mathrm{ab}$ & $37 \mathrm{a}$ & $5 \mathrm{ab}$ & $131 \mathrm{a}$ & $583 \mathrm{ab}$ & $9 \mathrm{~b}$ \\
$\mathrm{~B}$ & $18,1 \mathrm{a}$ & $1,3 \mathrm{a}$ & $6,8 \mathrm{a}$ & $6,5 \mathrm{~b}$ & $2,6 \mathrm{ab}$ & $1,5 \mathrm{ab}$ & $31 \mathrm{ab}$ & $3 \mathrm{~b}$ & $97 \mathrm{a}$ & $405 \mathrm{~b}$ & $12 \mathrm{ab}$ \\
$\mathrm{D}$ & $22 \mathrm{a}$ & $1,6 \mathrm{a}$ & $8,8 \mathrm{a}$ & $5,9 \mathrm{~b}$ & $2,1 \mathrm{c}$ & $1,5 \mathrm{ab}$ & $29 \mathrm{~b}$ & $5 \mathrm{ab}$ & $107 \mathrm{a}$ & $740 \mathrm{a}$ & $11 \mathrm{~b}$ \\
$\mathrm{C}$ & $22,9 \mathrm{a}$ & $1,9 \mathrm{a}$ & $9,5 \mathrm{a}$ & $9,1 \mathrm{a}$ & $2,7 \mathrm{a}$ & $1,7 \mathrm{a}$ & $32 \mathrm{ab}$ & $5 \mathrm{ab}$ & $98 \mathrm{a}$ & $350 \mathrm{~b}$ & $16 \mathrm{a}$ \\
$\mathrm{E}$ & $11,9 \mathrm{~b}$ & $0,8 \mathrm{~b}$ & $6,9 \mathrm{a}$ & $5,5 \mathrm{~b}$ & $2,2 \mathrm{abc}$ & $0,8 \mathrm{c}$ & $32 \mathrm{ab}$ & $5 \mathrm{ab}$ & $73 \mathrm{a}$ & $581 \mathrm{ab}$ & $11 \mathrm{ab}$ \\
$\mathrm{F}$ & $17,3 \mathrm{a}$ & $0,9 \mathrm{ab}$ & $8 \mathrm{a}$ & $7 \mathrm{ab}$ & $2,3 \mathrm{abc}$ & $0,9 \mathrm{c}$ & $32 \mathrm{ab}$ & $7 \mathrm{a}$ & $191 \mathrm{a}$ & $543 \mathrm{ab}$ & $11 \mathrm{ab}$ \\
$\mathrm{G}$ & $15,5 \mathrm{a}$ & $0,9 \mathrm{ab}$ & $8,4 \mathrm{a}$ & $6,6 \mathrm{~b}$ & $2,7 \mathrm{a}$ & $0,8 \mathrm{c}$ & $30 \mathrm{ab}$ & $5 \mathrm{ab}$ & $77 \mathrm{a}$ & $574 \mathrm{ab}$ & $12 \mathrm{ab}$ \\
$\mathrm{H}$ & $13,3 \mathrm{~b}$ & $0,9 \mathrm{~b}$ & $6 \mathrm{a}$ & $4,8 \mathrm{~b}$ & $2,2 \mathrm{abc}$ & $0,8 \mathrm{c}$ & $26 \mathrm{~b}$ & $5 \mathrm{ab}$ & $101 \mathrm{a}$ & $323 \mathrm{~b}$ & $8 \mathrm{~b}$ \\
\hline
\end{tabular}

De acordo com a Tabela 39, verificou-se que a maior parte das fazendas amostradas na região de Capão Bonito apresentaram baixo pH, baixos teores de fósforo, potássio, magnésio, cálcio, baixa soma de bases (SB) e baixa capacidade de troca catiônica (T). A saturação por bases $(\mathrm{V} \%)$ e as relações $\mathrm{K} / \mathrm{T}, \mathrm{Mg} / \mathrm{T}$ e $\mathrm{Ca} / \mathrm{T}$ também estavam abaixo da faixa considerada adequada para o crescimento do Eucalyptus sp., na maior parte das fazendas levantadas. Os teores de zinco no solo também estavam dentro da faixa considerada deficiente, em grande parte das fazendas.

A baixa fertilidade dos solos nesta região, pode ser explicada pela elevada ocorrência de Latossolos e Argilossolos distróficos (Anexo I).

Entretanto, quando se avaliou os teores dos nutrientes no tecido vegetal, verificou-se que a maior parte das fazendas amostradas apresentaram níveis considerados adequados para o crescimento do Eucalyptus sp. (Tabela 40). Isso se deve a distribuição mais uniforme das chuvas durante o ano (Figuras 5 e 6), o que proporcionou uma maior absorção dos nutrientes pelas plantas. O fósforo e o cobre, por outro lado, estavam acima e abaixo, respectivamente, da faixa adequada na maior parte das fazendas levantadas. 
Através destes resultados, foi possível verificar que as faixas consideradas baixa, média e alta para os parâmetros químicos do solo (Tabela 39), na região de Capão Bonito, não apresentaram boas relações com a produtividade do Eucalyptus sp., nesta região.

\subsubsection{Jacareí}

Nesta região, com exceção dos teores de zinco no solo e de boro e ferro nos tecidos foliares, não foram observadas diferenças significativas destes parâmetros, entre as fazendas avaliadas. Isso se deve ao pequeno número de fazendas amostradas, nesta região (Tabelas 35 e 36).

A fazenda $\mathrm{F}$ foi a que apresentou os maiores teores de boro no tecido foliar (Tabela 36), o que proporciou uma maior produtividade do Eucalyptus sp, nesta região. (Tabela 23).

Tabela 35 - Parâmetros químicos médios dos solos, nas diferentes fazendas da região de Jacareí (médias seguidas de mesma letra não diferem entre si pelo teste Tukey ao nível de 5\% de probabilidade).

\begin{tabular}{cccccccccc}
\hline Fazenda & PH & M.O. & $\mathbf{P}$ & $\mathbf{K}$ & $\mathbf{M g}$ & $\mathbf{C a}$ & $\mathbf{S B}$ & $\mathbf{T}$ & $\mathbf{V} \%$ \\
\hline A & $3,8 \mathrm{a}$ & $26 \mathrm{a}$ & $5,7 \mathrm{a}$ & $2,7 \mathrm{a}$ & $3,5 \mathrm{a}$ & $9,2 \mathrm{a}$ & $15,5 \mathrm{a}$ & $70,7 \mathrm{a}$ & $22,7 \mathrm{a}$ \\
B & $3,6 \mathrm{a}$ & $33,5 \mathrm{a}$ & $7 \mathrm{a}$ & $1,5 \mathrm{a}$ & $1,5 \mathrm{a}$ & $2,5 \mathrm{a}$ & $5,5 \mathrm{a}$ & $110 \mathrm{a}$ & $4,5 \mathrm{a}$ \\
$\mathrm{C}$ & $3,8 \mathrm{a}$ & $28 \mathrm{a}$ & $7 \mathrm{a}$ & $1 \mathrm{a}$ & $3 \mathrm{a}$ & $6 \mathrm{a}$ & $10 \mathrm{a}$ & $74 \mathrm{a}$ & $14 \mathrm{a}$ \\
$\mathrm{D}$ & $3,7 \mathrm{a}$ & $32,5 \mathrm{a}$ & $6 \mathrm{a}$ & $1,4 \mathrm{a}$ & $3,5 \mathrm{a}$ & $6,2 \mathrm{a}$ & $11,1 \mathrm{a}$ & $102,1 \mathrm{a}$ & $12,7 \mathrm{a}$ \\
E & $3,6 \mathrm{a}$ & $29 \mathrm{a}$ & $7,3 \mathrm{a}$ & $1 \mathrm{a}$ & $2,3 \mathrm{a}$ & $2 \mathrm{a}$ & $5,4 \mathrm{a}$ & $105 \mathrm{a}$ & $5 \mathrm{a}$ \\
F & $3,5 \mathrm{a}$ & $27,7 \mathrm{a}$ & $9,5 \mathrm{a}$ & $2,1 \mathrm{a}$ & $4,5 \mathrm{a}$ & $11 \mathrm{a}$ & 17,6 & $147,3 \mathrm{a}$ & $10,7 \mathrm{a}$ \\
\hline
\end{tabular}

\begin{tabular}{ccccccccc}
\hline Fazenda & $\mathbf{K} / \mathbf{T}$ & $\mathbf{M g} / \mathbf{T}$ & $\mathbf{C a} / \mathbf{T}$ & $\mathbf{B}$ & $\mathbf{C u}$ & $\mathbf{F e}$ & $\mathbf{M n}$ & $\mathbf{Z n}$ \\
\hline $\mathrm{A}$ & $4 \mathrm{a}$ & $13,7 \mathrm{a}$ & $5 \mathrm{a}$ & $0,2 \mathrm{a}$ & $0,1 \mathrm{a}$ & $100,7 \mathrm{a}$ & $18,9 \mathrm{a}$ & $1,1 \mathrm{a}$ \\
$\mathrm{B}$ & $1,3 \mathrm{a}$ & $2,3 \mathrm{a}$ & $1,4 \mathrm{a}$ & $0,3 \mathrm{a}$ & $0,4 \mathrm{a}$ & $118,5 \mathrm{a}$ & $5,7 \mathrm{a}$ & $0,8 \mathrm{ab}$ \\
$\mathrm{C}$ & $1,4 \mathrm{a}$ & $8,1 \mathrm{a}$ & $4,1 \mathrm{a}$ & $0,2 \mathrm{a}$ & $0,7 \mathrm{a}$ & $72 \mathrm{a}$ & $17,1 \mathrm{a}$ & $0,6 \mathrm{ab}$ \\
$\mathrm{D}$ & $1,5 \mathrm{a}$ & $7 \mathrm{a}$ & $3,9 \mathrm{a}$ & $0,2 \mathrm{a}$ & $0,5 \mathrm{a}$ & $129 \mathrm{a}$ & $29,5 \mathrm{a}$ & $0,6 \mathrm{ab}$ \\
$\mathrm{E}$ & $1 \mathrm{a}$ & $1,9 \mathrm{a}$ & $2,2 \mathrm{a}$ & $0,2 \mathrm{a}$ & $0,2 \mathrm{a}$ & $80,7 \mathrm{a}$ & $3,1 \mathrm{a}$ & $0,5 \mathrm{~b}$ \\
$\mathrm{~F}$ & $1,4 \mathrm{a}$ & $3,2 \mathrm{a}$ & $6,1 \mathrm{a}$ & $0,2 \mathrm{a}$ & $0,6 \mathrm{a}$ & $99,5 \mathrm{a}$ & $14 \mathrm{a}$ & $0,6 \mathrm{ab}$ \\
\hline
\end{tabular}


Tabela 36 - Teores foliares médios dos macro e micronutrientes obtidos nas diferentes fazendas da região de Jacareí (médias seguidas de mesma letra não diferem entre si pelo teste Tukey ao nível de 5\% de probabilidade).

\begin{tabular}{cccccccccccc}
\hline Fazenda & $\mathbf{N}$ & $\mathbf{P}$ & $\mathbf{K}$ & $\mathbf{C a}$ & $\mathbf{M g}$ & $\mathbf{S}$ & $\mathbf{B}$ & $\mathbf{C u}$ & $\mathbf{F e}$ & $\mathbf{M n}$ & $\mathbf{Z n}$ \\
\hline $\mathrm{A}$ & $21,3 \mathrm{a}$ & $1,1 \mathrm{a}$ & $10,4 \mathrm{a}$ & $8,8 \mathrm{a}$ & $2,2 \mathrm{a}$ & $1,5 \mathrm{a}$ & $19 \mathrm{~b}$ & $7 \mathrm{a}$ & $110 \mathrm{ab}$ & $1416 \mathrm{a}$ & $20 \mathrm{a}$ \\
$\mathrm{B}$ & $21 \mathrm{a}$ & $1 \mathrm{a}$ & $7,4 \mathrm{a}$ & $4 \mathrm{a}$ & $1,8 \mathrm{a}$ & $1,6 \mathrm{a}$ & $15 \mathrm{c}$ & $8 \mathrm{a}$ & $160 \mathrm{a}$ & $494 \mathrm{a}$ & $15 \mathrm{a}$ \\
C & $22,4 \mathrm{a}$ & $1,3 \mathrm{a}$ & $11,3 \mathrm{a}$ & $3,9 \mathrm{a}$ & $2 \mathrm{a}$ & $1,5 \mathrm{a}$ & $11 \mathrm{c}$ & $9 \mathrm{a}$ & $79 \mathrm{~b}$ & $1387 \mathrm{a}$ & $20 \mathrm{a}$ \\
D & $22,7 \mathrm{a}$ & $1,2 \mathrm{a}$ & $9,7 \mathrm{a}$ & $5,4 \mathrm{a}$ & $2,2 \mathrm{a}$ & $1,7 \mathrm{a}$ & $16 \mathrm{c}$ & $9 \mathrm{a}$ & $94 \mathrm{~b}$ & $1288 \mathrm{a}$ & $20 \mathrm{a}$ \\
E & $18,1 \mathrm{a}$ & $1 \mathrm{a}$ & $7,4 \mathrm{a}$ & $4 \mathrm{a}$ & $1,8 \mathrm{a}$ & $1,7 \mathrm{a}$ & $19 \mathrm{bc}$ & $11 \mathrm{a}$ & $123 \mathrm{ab}$ & $1277 \mathrm{a}$ & $14 \mathrm{a}$ \\
F & $15,8 \mathrm{a}$ & $0,8 \mathrm{a}$ & $7,6 \mathrm{a}$ & $5,3 \mathrm{a}$ & $2 \mathrm{a}$ & $1,1 \mathrm{a}$ & $35 \mathrm{a}$ & $7 \mathrm{a}$ & $133 \mathrm{ab}$ & $1698 \mathrm{a}$ & $15 \mathrm{a}$ \\
\hline
\end{tabular}

Observou-se que apenas o $\mathrm{pH}$, os teores de cálcio, a saturação por bases, a capacidade de troca catiônica e as relações $\mathrm{Mg} / \mathrm{T}$ e $\mathrm{Ca} / \mathrm{T}$ estavam, na maioria das fazendas amostradas, abaixo da faixa considerada adequada para o crescimento do Eucalyptus sp. Os teores de cobre, ferro, manganês e zinco no solo, por outro lado, estavam acima da faixa adequada, na maior parte das fazendas amostradas (Tabela 39).

Em relação as análises foliares, verificou-se que apenas o fósforo e principalmente o boro estavam abaixo da faixa adequada, em 57,9\% e 72,1\% respectivamente, dos talhões amostrados. O manganês, por outro lado, estava em níveis bastante elevados em $90 \%$ dos talhões amostrados (Tabela 40).

\subsubsection{Lençóis Paulista}

Na região de Lençóis Paulista, apenas a relação $\mathrm{Mg} / \mathrm{T}$, os teores de boro no solo e os teores foliares de cálcio não apresentaram diferenças significativas entre as fazendas levantadas (Tabelas 37 e 38). Isso mostra que o número de fazendas amostradas foi suficiente para expressar as variações nos teores foliares dos nutrientes e nos parâmetros químicos do solo existentes nesta região. 
Tabela 37 - Parâmetros químicos médios dos solos, nas diferentes fazendas da região de Lençóis Paulista (médias seguidas de mesma letra não diferem entre si pelo teste Tukey ao nível de 5\% de probabilidade).

\begin{tabular}{cccccccccc}
\hline Fazenda & PH & M.O. & $\mathbf{P}$ & $\mathbf{K}$ & $\mathbf{M g}$ & $\mathbf{C a}$ & $\mathbf{S B}$ & $\mathbf{T}$ & $\mathbf{V \%}$ \\
\hline $\mathrm{A}$ & $3,8 \mathrm{~b}$ & $14,6 \mathrm{a}$ & $6 \mathrm{~b}$ & $0,3 \mathrm{ab}$ & $0,5 \mathrm{~b}$ & $5,3 \mathrm{c}$ & $6,3 \mathrm{~b}$ & $43,8 \mathrm{ab}$ & $15,1 \mathrm{~b}$ \\
$\mathrm{~B}$ & $4,7 \mathrm{a}$ & $14,3 \mathrm{a}$ & $10,3 \mathrm{a}$ & $0,7 \mathrm{ab}$ & $1,5 \mathrm{ab}$ & $20,3 \mathrm{ab}$ & $22,8 \mathrm{ab}$ & $51,2 \mathrm{a}$ & $41 \mathrm{ab}$ \\
$\mathrm{C}$ & $4,6 \mathrm{a}$ & $11,8 \mathrm{~b}$ & $5,6 \mathrm{~b}$ & $0,3 \mathrm{ab}$ & $4,7 \mathrm{a}$ & $17,2 \mathrm{ab}$ & $22,3 \mathrm{ab}$ & $45,4 \mathrm{ab}$ & $47,3 \mathrm{a}$ \\
$\mathrm{D}$ & $3,9 \mathrm{~b}$ & $17 \mathrm{a}$ & $6 \mathrm{~b}$ & $0,3 \mathrm{ab}$ & $0 \mathrm{~b}$ & $7 \mathrm{bc}$ & $8 \mathrm{~b}$ & $40,5 \mathrm{ab}$ & $19 \mathrm{~b}$ \\
$\mathrm{E}$ & $4,4 \mathrm{a}$ & $14,2 \mathrm{a}$ & $5,2 \mathrm{~b}$ & $0,4 \mathrm{ab}$ & $0,6 \mathrm{~b}$ & $11,8 \mathrm{~b}$ & $12,9 \mathrm{~b}$ & $33,9 \mathrm{ab}$ & $35,5 \mathrm{~b}$ \\
F & $6 \mathrm{a}$ & $8 \mathrm{~b}$ & $11,1 \mathrm{a}$ & $1,4 \mathrm{a}$ & $2,2 \mathrm{ab}$ & $28,1 \mathrm{a}$ & $31,7 \mathrm{a}$ & $41,4 \mathrm{ab}$ & $73,4 \mathrm{a}$ \\
G & $4 \mathrm{~b}$ & $13,9 \mathrm{~b}$ & $7,4 \mathrm{a}$ & $0,2 \mathrm{~b}$ & $0,4 \mathrm{~b}$ & $5,9 \mathrm{c}$ & $6,8 \mathrm{~b}$ & $33,1 \mathrm{~b}$ & $20,4 \mathrm{~b}$ \\
\hline
\end{tabular}

\begin{tabular}{ccccccccc}
\hline Fazenda & $\mathbf{K} / \mathbf{T}$ & $\mathbf{M g} / \mathbf{T}$ & $\mathbf{C a} / \mathbf{T}$ & $\mathbf{B}$ & $\mathbf{C u}$ & $\mathbf{F e}$ & $\mathbf{M n}$ & $\mathbf{Z n}$ \\
\hline $\mathrm{A}$ & $0,7 \mathrm{abc}$ & $1,2 \mathrm{a}$ & $13,1 \mathrm{c}$ & $0,2 \mathrm{~b}$ & $0,8 \mathrm{~b}$ & $101 \mathrm{a}$ & $1,4 \mathrm{ab}$ & $0,4 \mathrm{ab}$ \\
$\mathrm{B}$ & $1,4 \mathrm{ab}$ & $2,9 \mathrm{a}$ & $36,5 \mathrm{ab}$ & $0,2 \mathrm{~b}$ & $0,6 \mathrm{c}$ & $63 \mathrm{~cd}$ & $1,8 \mathrm{a}$ & $0,3 \mathrm{ab}$ \\
$\mathrm{C}$ & $0,7 \mathrm{abc}$ & $7,5 \mathrm{a}$ & $38,5 \mathrm{ab}$ & $0,1 \mathrm{~b}$ & $0,5 \mathrm{c}$ & $46,1 \mathrm{~cd}$ & $0,6 \mathrm{c}$ & $0,3 \mathrm{ab}$ \\
$\mathrm{D}$ & $0,7 \mathrm{abc}$ & $0 \mathrm{a}$ & $17 \mathrm{c}$ & $0,2 \mathrm{~b}$ & $1,4 \mathrm{a}$ & $79 \mathrm{ab}$ & $0,5 \mathrm{c}$ & $0,3 \mathrm{ab}$ \\
$\mathrm{E}$ & $1,2 \mathrm{ab}$ & $1,7 \mathrm{a}$ & $32,4 \mathrm{~b}$ & $0,1 \mathrm{~b}$ & $0,7 \mathrm{bc}$ & $73,1 \mathrm{c}$ & $0,9 \mathrm{ab}$ & $0,2 \mathrm{~b}$ \\
$\mathrm{~F}$ & $3,8 \mathrm{a}$ & $6,1 \mathrm{a}$ & $64 \mathrm{a}$ & $0,1 \mathrm{~b}$ & $0,3 \mathrm{c}$ & $18,6 \mathrm{~d}$ & $1,7 \mathrm{ab}$ & $0,6 \mathrm{a}$ \\
$\mathrm{G}$ & $0,7 \mathrm{c}$ & $1,3 \mathrm{a}$ & $18,1 \mathrm{c}$ & $0,3 \mathrm{a}$ & $0,6 \mathrm{c}$ & $76,4 \mathrm{~b}$ & $0,6 \mathrm{~b}$ & $0,2 \mathrm{c}$ \\
\hline
\end{tabular}

Tabela 38 - Teores foliares médios dos macro e micronutrientes obtidos nas diferentes fazendas da região de Lençóis Paulista (médias seguidas de mesma letra não diferem entre si pelo teste Tukey ao nível de 5\% de probabilidade).

\begin{tabular}{cccccccccccc}
\hline Fazenda & $\mathbf{N}$ & $\mathbf{P}$ & $\mathbf{K}$ & $\mathbf{C a}$ & $\mathbf{M g}$ & $\mathbf{S}$ & $\mathbf{B}$ & $\mathbf{C u}$ & $\mathbf{F e}$ & $\mathbf{M n}$ & $\mathbf{Z n}$ \\
\hline $\mathrm{A}$ & $22,7^{\mathrm{a}}$ & $1,4 \mathrm{a}$ & $7,1 \mathrm{~b}$ & $8,1 \mathrm{a}$ & $1,9 \mathrm{a}$ & $1,4 \mathrm{~b}$ & $17 \mathrm{~b}$ & $8 \mathrm{c}$ & $102 \mathrm{~b}$ & $438 \mathrm{a}$ & $14 \mathrm{a}$ \\
$\mathrm{B}$ & $24,3^{\mathrm{a}}$ & $1,4 \mathrm{a}$ & $8,8 \mathrm{ab}$ & $6,7 \mathrm{a}$ & $1,9 \mathrm{a}$ & $1,4 \mathrm{~b}$ & $17 \mathrm{~b}$ & $9 \mathrm{ab}$ & $100 \mathrm{~b}$ & $301 \mathrm{c}$ & $14 \mathrm{a}$ \\
$\mathrm{C}$ & $24,2^{\mathrm{a}}$ & $1,4 \mathrm{a}$ & $8,4 \mathrm{~b}$ & $6,7 \mathrm{a}$ & $1,9 \mathrm{a}$ & $1,5 \mathrm{ab}$ & $17 \mathrm{~b}$ & $7 \mathrm{c}$ & $107 \mathrm{ab}$ & $321 \mathrm{bc}$ & $13 \mathrm{a}$ \\
$\mathrm{D}$ & $23,5^{\mathrm{a}}$ & $1,6 \mathrm{a}$ & $6 \mathrm{c}$ & $8 \mathrm{a}$ & $1,8 \mathrm{a}$ & $1,5 \mathrm{ab}$ & $16 \mathrm{~b}$ & $11 \mathrm{a}$ & $89 \mathrm{c}$ & $424 \mathrm{ab}$ & $16 \mathrm{a}$ \\
$\mathrm{E}$ & $23,3^{\mathrm{a}}$ & $1,4 \mathrm{a}$ & $7,5 \mathrm{~b}$ & $7 \mathrm{a}$ & $1,8 \mathrm{a}$ & $1,4 \mathrm{~b}$ & $17 \mathrm{~b}$ & $8 \mathrm{bc}$ & $131 \mathrm{a}$ & $439 \mathrm{a}$ & $14 \mathrm{a}$ \\
$\mathrm{F}$ & $21 \mathrm{~b}$ & $1,5 \mathrm{a}$ & $10,9 \mathrm{a}$ & $7,2 \mathrm{a}$ & $2 \mathrm{a}$ & $1,2 \mathrm{~b}$ & $16 \mathrm{~b}$ & $8 \mathrm{bc}$ & $103 \mathrm{ab}$ & $528 \mathrm{a}$ & $13 \mathrm{a}$ \\
$\mathrm{G}$ & $22,7^{\mathrm{a}}$ & $1,3 \mathrm{~b}$ & $6,3 \mathrm{c}$ & $8,4 \mathrm{a}$ & $1,7 \mathrm{~b}$ & $1,5 \mathrm{a}$ & $18 \mathrm{a}$ & $9 \mathrm{~b}$ & $92 \mathrm{c}$ & $404 \mathrm{~b}$ & $12 \mathrm{~b}$ \\
\hline
\end{tabular}


De acordo com a Tabela 39, verificou-se que os teores de matéria orgânica, potássio, magnésio, os níveis da capacidade de troca catiônica, a relação $\mathrm{Mg} / \mathrm{T}$ e os teores de boro estavam abaixo da faixa considerada adequada para o crescimento do E grandis, na maior parte dos talhões amostrados. A saturação por bases, a relação $\mathrm{Ca} / \mathrm{T}$ e os teores de cobre e ferro, por outro lado, estavam muito acima da faixa considerada adequada, em grande parte dos talhões.

Com relação as análises foliares, verificou-se que apenas os teores de magnésio, enxofre e boro estavam abaixo da faixa considerada adequada, na maior parte dos talhões levantados (Tabela 40).

Tabela 39 - Porcentagem dos talhões com níveis baixos (B), médios (M) e altos (A) dos parâmetros químicos do solo, nas diferentes regiões.

\begin{tabular}{|c|c|c|c|c|c|c|c|c|c|c|c|}
\hline \multirow[t]{2}{*}{ Parâmetro } & \multirow[t]{2}{*}{ Unid. } & \multirow{2}{*}{$\begin{array}{l}\text { Valores } \\
\text { Máx/Min }\end{array}$} & \multicolumn{3}{|c|}{ Capão Bonito } & \multicolumn{3}{|c|}{ Jacareí } & \multicolumn{3}{|c|}{$\begin{array}{l}\text { Lençóis } \\
\text { Paulista }\end{array}$} \\
\hline & & & $\mathrm{B}$ & $\mathrm{M}$ & A & B & M & A & B & M & A \\
\hline $\mathrm{PH}$ & - & $6,8 / 3,5$ & 84,3 & 14,4 & - & 100 & - & - & 21,9 & 69,9 & 8,2 \\
\hline M.O. & $\mathrm{g} \mathrm{dm}^{-3}$ & $49,3 / 7,0$ & - & 90,7 & 8 & - & 100 & - & 96,7 & 3,3 & - \\
\hline $\mathrm{P}$ & $\mathrm{mg} \mathrm{dm}^{-3}$ & $43,5 / 2,0$ & 46,5 & 37,8 & 14,4 & - & 72,2 & 28,3 & - & 89,6 & 10,4 \\
\hline $\mathrm{K}$ & & $3,9 / 0,2$ & 75,1 & 17,2 & 6,4 & 10,8 & 51 & 38,7 & 91,8 & 8,2 & - \\
\hline $\mathrm{Mg}$ & mmolc & $26,5 / 0,0$ & 76,7 & 7,6 & 14,4 & 29,6 & 42,6 & 28,3 & 91,3 & - & 8,7 \\
\hline $\mathrm{Ca}$ & $\mathrm{dm}^{-3}$ & $71,0 / 1,0$ & 84,3 & - & 14,4 & 61,8 & 38,7 & - & 32,8 & 48,2 & 19 \\
\hline SB & & $99,1 / 2,2$ & 84,3 & - & 14,4 & 61,8 & 10,4 & 28,3 & 32,8 & 48,2 & 19 \\
\hline $\mathrm{T}$ & & $226,0 / 23,0$ & 58,9 & 39,8 & - & 72,2 & 28,3 & - & 100 & - & - \\
\hline $\mathrm{V} \%$ & & $87,0 / 2,0$ & 84,3 & - & 14,4 & 29,6 & 70,9 & - & - & 32,8 & 67,2 \\
\hline $\mathrm{K} / \mathrm{T}$ & $\%$ & $6,6 / 0,2$ & 69,1 & 29,5 & - & 19,1 & 71 & 10,4 & 41,5 & 50,4 & 8,2 \\
\hline $\mathrm{Mg} / \mathrm{T}$ & & $50,1 / 0,0$ & 82,7 & 1,6 & 14,4 & 57,9 & 32,2 & 10,4 & 83,2 & 16,8 & - \\
\hline $\mathrm{Ca} / \mathrm{T}$ & & $82,4 / 0,4$ & 84,3 & 8 & 6,4 & 61,8 & 38,7 & - & - & 18,6 & 81,4 \\
\hline $\mathrm{B}$ & & 06/0,1 & 44 & 48,3 & 6,4 & 38,7 & 61,8 & - & 81,4 & 18,6 & - \\
\hline $\mathrm{Cu}$ & & $4,9 / 0,1$ & 6 & 33,4 & 59,2 & 29,4 & 10,5 & 60,5 & - & 16,8 & 83,2 \\
\hline $\mathrm{Fe}$ & $\mathrm{mg} \mathrm{dm}^{-3}$ & $235,0 / 13,0$ & - & - & 98,6 & - & - & 100 & - & 8,2 & 91,8 \\
\hline Mn & & $57,2 / 0,2$ & 7,6 & 76,7 & 14,4 & - & 19,1 & 81,4 & 3,3 & 96,7 & - \\
\hline $\mathrm{Zn}$ & & $2,3 / 0,1$ & 53,2 & 39,1 & 6,4 & - & 19,1 & 81,4 & 10,9 & 81 & 8,2 \\
\hline
\end{tabular}


Tabela 40 - Porcentagem dos talhões com níveis muito baixos (MB), baixos (B), médios (M) e altos (A) dos teores dos nutrientes no tecido foliar, nas diferentes regiões.

\begin{tabular}{ccccccccccccccc}
\hline Nutriente & Unid. & Valores & \multicolumn{4}{c}{ Capão Bonito } & \multicolumn{4}{c}{ Jacareí } & \multicolumn{4}{c}{ Lençóis Paulista } \\
& & Máx/Min & MB & B & M & A & MB & B & M & A & MB & B & M & A \\
\hline $\mathrm{N}$ & & $28,5 / 11,3$ & 7,6 & 7,6 & 83,4 & - & - & 28,3 & 72,2 & - & - & - & 89,1 & 10,9 \\
$\mathrm{P}$ & & $2,3 / 0,4$ & - & 23,1 & 31,1 & 44,4 & - & 57,9 & 42,6 & - & - & - & 88,6 & 11,4 \\
$\mathrm{~K}$ & $\mathrm{~g} \mathrm{~kg}^{-1}$ & $13,6 / 3,6$ & - & 14,5 & 84,1 & - & - & - & 79,3 & 21,1 & - & 14,2 & 77,7 & 8,2 \\
$\mathrm{Ca}$ & & $11,0 / 3,4$ & - & 6 & 92,7 & - & - & 40,3 & 60,1 & - & - & - & 100 & - \\
$\mathrm{Mg}$ & & $3,3 / 1,4$ & - & - & 98,6 & - & - & 40,3 & 60,1 & - & - & 100 & - & - \\
$\mathrm{S}$ & $2,1 / 0,6$ & 7,6 & 15,6 & 75,5 & - & - & 28,3 & 72,2 & - & - & 58,5 & 41,5 & - \\
$\mathrm{B}$ & & $49 / 11$ & - & 6 & 92,7 & - & 42,7 & 29,4 & 28,3 & - & 11,4 & 88,6 & - & - \\
$\mathrm{Cu}$ & & $11 / 1$ & - & 90,7 & 8 & - & - & - & 81,4 & 19,1 & - & - & 96,7 & 3,3 \\
$\mathrm{Fe}$ & $\mathrm{mg} \mathrm{kg}^{-1}$ & $347 / 19$ & - & - & 90,7 & 8 & - & - & 90 & 10,5 & - & - & 100 & - \\
$\mathrm{Mn}$ & & $2008 / 132$ & - & - & 98,6 & - & - & - & 10,5 & 90 & - & - & 100 & - \\
$\mathrm{Zn}$ & & $24 / 5$ & 30,2 & 62,0 & 6,4 & - & - & 57,9 & 42,6 & - & 14,7 & 73,5 & 11,2 & - \\
\hline
\end{tabular}

\subsubsection{Todas as regiões}

Não houve diferenças significativas dos teores de fósforo, potássio, boro, cobre, manganês, da relação $\mathrm{Mg} / \mathrm{T}$ e da soma de bases do solo, entre as regiões estudadas (Tabela 41). Com relação as análises dos nutrientes no tecido foliar, também não foram constatadas diferenças significativas dos teores de potássio, magnésio, enxofre e ferro entre as regiões estudadas (Tabela 42). Isso se deve a maior variação destes parâmetros entre as fazendas de uma mesma região do que entre as regiões, o que provavelmente se deve as diferenças na intensidade de amostragem adotada em cada delas.

Na região de Capão Bonito, verificou-se haver maiores teores de boro no solo e nos tecidos foliares devido aos elevados teores de matéria orgânica e devido a boa uniformidade das precipitações durante o ano (Tabelas 41 e 42 e Figuras 5 e 6). A matéria orgânica, de acordo com Raij, 1991, é a principal fonte de boro nos solos tropicais. A disponibildade do boro é maior nos períodos mais quentes e úmidos do ano, devido as maiores taxas de mineralização da matéria orgânica. 
Embora não significativo, foi possível observar teores de potássio no solo e nos tecidos foliares do Eucalyptus sp., na região de Jacareí, muito superiores aqueles encontrados nas demais regiões (Tabelas 41 e 42). Estes resultados são explicados pela maior ocorrência de Argilossolos com elevada presença de minerais primários como as micas e os feldspatos, os quais apresentam elevadas concentrações de potássio (Anexo II).

$\mathrm{O}$ pH, os teores de cálcio, a soma de bases e a relação $\mathrm{Ca} / \mathrm{T}$ encontrados, na região de Lençóis Paulista (Tabela 41), foram mais elevados quando comparado as demais regiões, o que se deve as elevadas quantidades de lama-cal aplicadas nesta região (Tabela 19). Os elevados teores de cálcio do solo proporcionaram um aumento nos teores foliares deste nutriente e uma redução dos teores de potássio e magnésio, tanto no solo como nas folhas do Eucalyptus sp. (Tabelas 41 e 42). Esse efeito é explicado pelo fato do cálcio preencher grande parte do complexo de troca catiônica do solo, reduzindo desta maneira a participação do potássio e principalmente do magnésio (Tabela 41).

Ainda com relação a região de Lençóis Paulista, verifica-se menores teores de matéria orgânica e consequentemente menor capacidade de troca catiônica no solo, quando comparado as demais regiões. A matéria orgânica, nos solos florestais, apresentam a maior contribuição no complexo de troca de cátions, em função destes solos geralmente apresentarem textura média e/ou arenosa e serem altamente intemperizados, como é o caso dos Neossolos Quartzarênicos e dos Latossolos distróficos. O teor foliar médio de nitrogênio encontrado nesta região, entretanto, foi superior aqueles encontrados na região de Capão Bonito e Jacareí, o que pode ser explicado pelo maior índice de precipitação, uma vez que este nutriente é preferencialmente absorvido pelas plantas, através do mecanismo de fluxo de massa (Malavolta et al. 1997). Os teores de boro no solo e nas folhas, nesta região, foram inferiores aqueles obtidos para as demais fazendas, o que se deve aos menores teores de matéria orgânica encontrados nestas solos. 
Tabela 41 - Parâmetros químicos médios dos solos nas diferentes fazendas da região de Lençóis Paulista (médias seguidas de mesma letra não diferem entre si pelo teste Tukey ao nível de 5\% de probabilidade).

\begin{tabular}{|c|c|c|c|c|c|c|c|c|c|}
\hline Região & pH & M.O. & $\mathbf{P}$ & $\mathbf{K}$ & Mg & $\mathbf{C a}$ & SB & $\mathbf{T}$ & $\mathrm{V} \%$ \\
\hline Capão Bonito & $3,9 b$ & $28,7 \mathrm{a}$ & $6,2 \mathrm{a}$ & $0,8 \mathrm{a}$ & $2,8 \mathrm{ab}$ & $4,5 b$ & $8,1 \mathrm{a}$ & $104,4 a$ & $7,6 b$ \\
\hline Jacareí & $3,7 b$ & $29,2 \mathrm{a}$ & $7,1 \mathrm{a}$ & $1,6 \mathrm{a}$ & $3,1 \mathrm{a}$ & $6,1 \mathrm{ab}$ & $10,9 \mathrm{a}$ & $103,6 \mathrm{a}$ & $11,4 \mathrm{~b}$ \\
\hline Lençóis Paulista & $4,8 \mathrm{a}$ & $13,5 b$ & $6,4 \mathrm{a}$ & $0,4 \mathrm{a}$ & $1,1 \mathrm{~b}$ & $12,8 \mathrm{a}$ & $14,5 \mathrm{a}$ & $38,1 \mathrm{~b}$ & $35,8 \mathrm{a}$ \\
\hline Região & $\mathrm{K} / \mathrm{T}$ & $\mathrm{Mg} / \mathrm{T}$ & $\mathrm{Ca} / \mathrm{T}$ & B & & $\mathbf{C u}$ & $\mathbf{F e}$ & Mn & $\mathbf{Z n}$ \\
\hline Capão Bonito & $0,7 b$ & $3,3 a$ & $3 b$ & $0,3 a$ & & $0,6^{\mathrm{a}}$ & $79,7 \mathrm{ab}$ & $3 a$ & $0,3 b$ \\
\hline Jacareí & $1,8 \mathrm{a}$ & $5,8 \mathrm{a}$ & $3,8 b$ & $0,2 \mathrm{a}$ & & $0,4^{\mathrm{a}}$ & $99,2^{\mathrm{a}}$ & $14,3 \mathrm{a}$ & $0,7 \mathrm{a}$ \\
\hline Lençóis Paulista & $1,2 \mathrm{ab}$ & $2,5 \mathrm{a}$ & $31,8 \mathrm{a}$ & $0,1 \mathrm{a}$ & & $0,6^{\mathrm{a}}$ & $69,3 b$ & $1 \mathrm{a}$ & $0,3 b$ \\
\hline
\end{tabular}

Tabela 42 - Teores foliares médios dos macro e micronutrientes obtidos nas diferentes fazendas da região de Lençóis Paulista (médias seguidas de mesma letra não diferem entre si pelo teste Tukey ao nível de 5\% de probabilidade).

\begin{tabular}{cccccccccccc}
\hline Região & $\mathbf{N}$ & $\mathbf{P}$ & $\mathbf{K}$ & $\mathbf{C a}$ & $\mathbf{M g}$ & $\mathbf{S}$ & $\mathbf{B}$ & $\mathbf{C u}$ & $\mathbf{F e}$ & $\mathbf{M n}$ & $\mathbf{Z n}$ \\
\hline Capão Bonito & $19,3 \mathrm{~b}$ & $1,4 \mathrm{a}$ & $8,3 \mathrm{a}$ & $6,5 \mathrm{a}$ & $2,3 \mathrm{a}$ & $1,4 \mathrm{a}$ & $32 \mathrm{a}$ & $5 \mathrm{~b}$ & $112 \mathrm{a}$ & $590 \mathrm{~b}$ & $11 \mathrm{~b}$ \\
Jacareí & $19,7 \mathrm{~b}$ & $1 \mathrm{~b}$ & $8,7 \mathrm{a}$ & $5,3 \mathrm{~b}$ & $2 \mathrm{a}$ & $1,5 \mathrm{a}$ & $20 \mathrm{~b}$ & $9 \mathrm{a}$ & $117 \mathrm{a}$ & $1320 \mathrm{a}$ & $17 \mathrm{a}$ \\
Lençóis Paulista & $23,1 \mathrm{a}$ & $1,4 \mathrm{a}$ & $7,8 \mathrm{a}$ & $7,3 \mathrm{a}$ & $1,8 \mathrm{a}$ & $1,4 \mathrm{a}$ & $17 \mathrm{~b}$ & $8 \mathrm{a}$ & $116 \mathrm{a}$ & $423 \mathrm{c}$ & $14 \mathrm{a}$ \\
\hline
\end{tabular}

\subsection{Relação do Estado Nutricional e da Fertilidade do Solo com a Produtividade}

\subsubsection{Estado Nutricional e Produtividade}

Verificou-se não haver correlações significativas entre os teores foliares dos nutrientes com o índice de sítio do Eucalyptus sp., na região de Capão Bonito e em todas as regiões analisadas conjuntamente (Tabela 43). A baixa relação entre os teores foliares dos nutrientes com a produtividade, na região de Capão Bonito, deve-se ao fato da maioria das fazendas apresentarem-se com estes parâmetros dentro da faixa adequada para o crescimento do Eucalyptus sp. A falta de variabilidade dos dados, neste caso, impediu a obtenção de boas relações entre os teores dos nutrientes no tecido foliar e a produtividade. 
Na região de Jacareí, observou-se uma correlação positiva do boro e negativa do cobre e do manganês com o índice de sítio do Eucalyptus sp. (Tabela 43). Sgarbi et al. (2000a e b) e Silveira et al. 1995c também encontraram relações positivas do boro com a produtividade do Eucalyptus sp., na maior parte dos plantios do Estado de São Paulo.

Na região de Lençóis Paulista, observou-se uma correlação positiva entre os teores foliares de ferro com o índice de sítio do Eucalyptus sp. (Tabela 43). O aumento do índice de sítio em função do aumento dos teores de ferro ocorreu em função da elevada quantidade de lama-cal aplicada na região de Lençóis Paulista, a qual proporcionou uma elevação do pH e consequentemente uma redução dos teores de ferro nos solos, devido a formação de $\mathrm{FeOH}_{2}$ e $\mathrm{FeOH}_{3}$, conforme apresentado por Marschner, (1995).

Através destes resultados, conclui-se que os elevados teores de cálcio no solo, na região de Lençóis Paulista, limitaram o crescimento do Eucalyptus sp.

Tabela 43 - Correlação (coeficiente de correlação de Pearson) entre o índice de sítio e os teores dos nutrientes do tecido foliar.

\begin{tabular}{|c|c|c|c|c|}
\hline Nutriente & Capão Bonito & Jacareí & Lençóis Paulista & Todas \\
\hline $\mathrm{N}$ & 0,241 n.s. & $-0,487$ n.s. & 0,191 n.s. & 0,045 n.s. \\
\hline $\mathrm{P}$ & $0,267 *$ & $-0,569$ n.s. & $-0,270$ n.s. & 0,038 n.s. \\
\hline $\mathrm{K}$ & 0,199 n.s. & $-0,203$ n.s. & $-0,287$ n.s. & 0,068 n.s. \\
\hline $\mathrm{Ca}$ & $0,383 * *$ & $-0,140$ n.s. & $-0,363 *$ & $-0,018$ n.s. \\
\hline $\mathrm{Mg}$ & 0,015 n.s. & $-0,116$ n.s. & $-0,138$ n.s. & 0,035 n.s. \\
\hline $\mathrm{S}$ & $0,492 * *$ & $-0,517$ n.s. & 0,156 n.s. & $0,332 * *$ \\
\hline $\mathrm{B}$ & 0,233 n.s. & $0,779 * *$ & $0,412 * *$ & $0,289 * *$ \\
\hline $\mathrm{Cu}$ & 0,082 n.s. & $-0,619 *$ & 0,213 n.s. & $-0,031$ n.s. \\
\hline $\mathrm{Fe}$ & 0,073 n.s. & 0,502 n.s. & $0,524 * *$ & 0,169 n.s. \\
\hline Mn & 0,030 n.s. & 0,232 n.s. & $-0,348 *$ & 0,172 n.s. \\
\hline $\mathrm{Zn}$ & 0,059 n.s. & $-0,180$ n.s. & $-0,055$ n.s. & 0,022 n.s. \\
\hline
\end{tabular}

n.s. não significativo; $*$ significativo a $5 \%$ de probabilidade; $* *$ significativo a $1 \%$ de probabilidade. 
Foram obtidos modelos de produtividade, na região de Jacareí (Tabela 44), os quais relacionaram o índice de sítio com os teores foliares de boro (Figura 11), de cobre (Figura 12) e de manganês (Figura 13).

A produtividade do Eucalyptus sp., na região de Jacareí, aumentou linearmente com o aumento dos teores foliares de boro. Observou-se uma diminuição do índice de sítio do Eucalyptus sp., na região de Jacareí, a medida que se elevou os teores foliares de manganês. A menor produtividade $(27,9 \mathrm{~m})$ foi obtida quando os teores foliares deste nutriente estavam na faixa de $1640 \mathrm{mg} \mathrm{kg}^{-1}$ de matéria seca. $\mathrm{O}$ teor foliar médio de manganês, na região de Jacareí, é de $1390 \pm 425 \mathrm{mg} \mathrm{kg}^{-1}$, que inclui a faixa de menor produtividade do Eucalyptus $\mathrm{sp}$.

Também foram observadas reduções lineares no crescimento do Eucalyptus sp. a medida que se elevou os teores foliares de cobre. Houve um aumento dos teores foliares deste nutriente a medida que diminuiu os teores de magnésio no solo (Tabela 47), o qual poderia estar limitando o crescimento do Eucalyptus sp., nesta região. Conclui-se, desta forma, que o crescimento do Eucalyptus sp., na região de Jacareí, está associado positivamente ao boro e ao magnésio e negativamente ao manganês e ao cobre.

Tabela 44 - Relação entre o índice de sítio do Eucalyptus sp. e os teores foliares dos nutrientes, em função das regiões estudadas.

\begin{tabular}{ccc}
\hline Região & Modelo & $\mathbf{r}^{\mathbf{2}}$ \\
\hline Jacareí & $\mathrm{IS}=17,85+0,43 \mathrm{~B}$ & 0,61 \\
Jacareí & $\mathrm{IS}=40,90-1,59 \mathrm{Cu}$ & 0,38 \\
Jacareí & $\mathrm{IS}=36,89-0,02 \mathrm{Mn}+0,000005 \mathrm{Mn}^{2}$ & 0,63 \\
Lençóis Paulista & $\mathrm{IS}=31,93-1,18 \mathrm{Ca}$ & 0,24 \\
Lençóis Paulista & $\mathrm{IS}=32,75-0,04 \mathrm{Mn}+0,00002 \mathrm{Mn}^{2}$ & 0,28 \\
\hline
\end{tabular}

IS: Índice de Sítio; B: $\mathrm{mg}$ de boro $\mathrm{kg}^{-1}$ de MS; Cu: $\mathrm{mg}$ de cobre $\mathrm{kg}^{-1}$ de MS; Mn: mg de manganês $\mathrm{kg}^{-1} \mathrm{de}^{-}$ MS; Ca: $\mathrm{g}$ de cálcio $\mathrm{kg}^{-1}$ de MS; Fe: $\mathrm{mg}$ de ferro $\mathrm{kg}^{-1}$ de MS. 


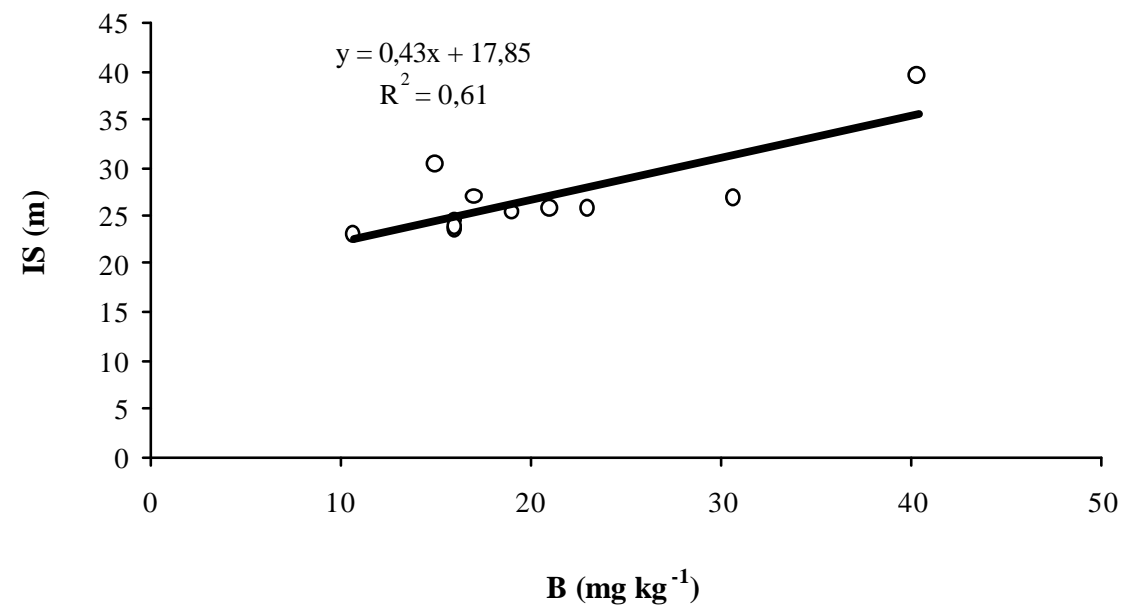

Figura 11 - Relação entre o teor foliar de boro e o índice de sítio do Eucalyptus sp., na região de Jacareí.

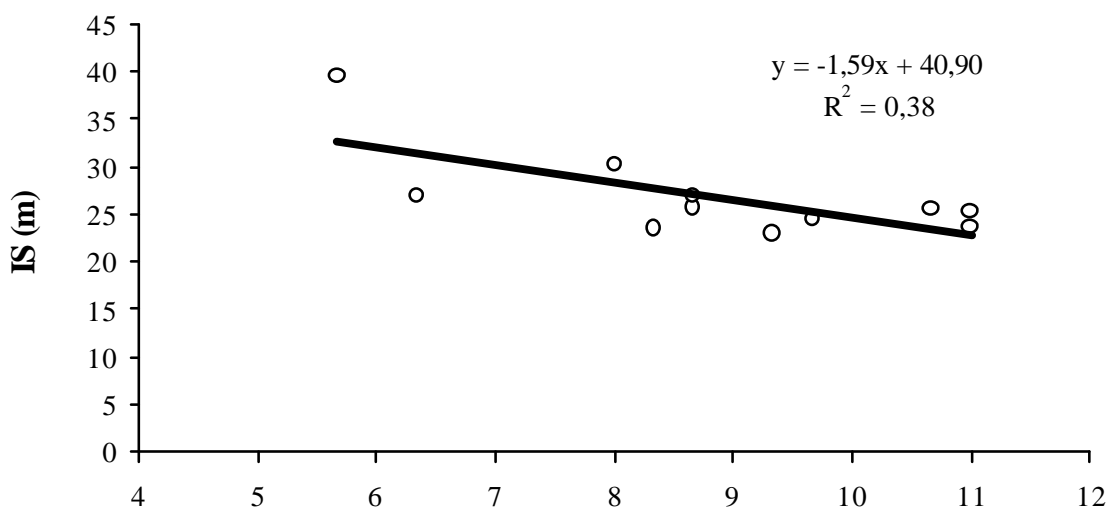

Cu (mg kg-1)

Figura 12 - Relação entre o teor foliar de cobre e o índice de sítio do Eucalyptus sp., na região de Jacareí. 


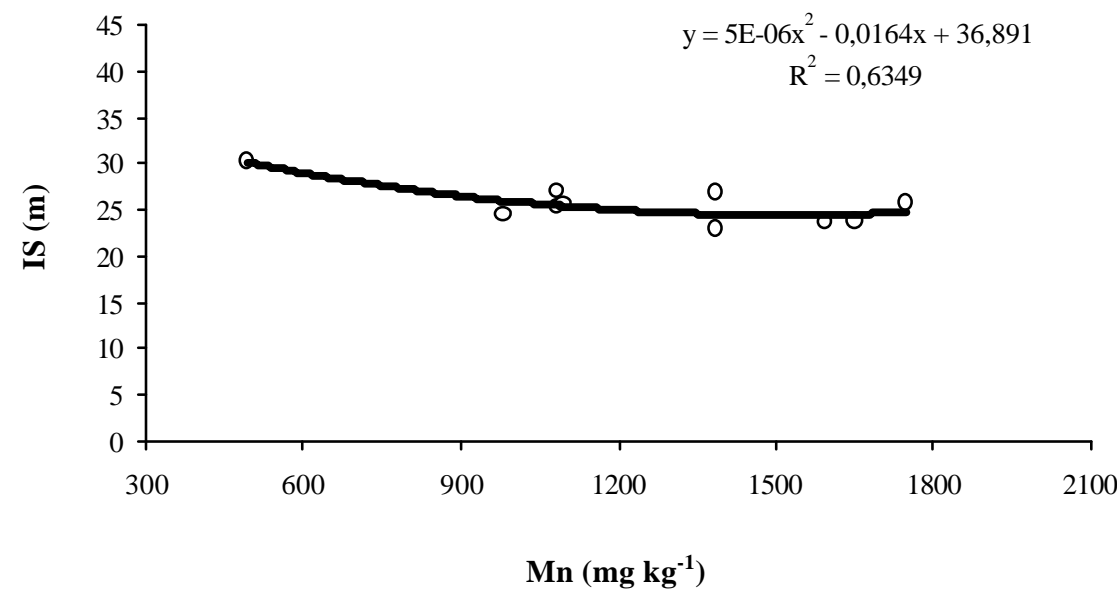

Figura 13 - Relação entre o teor foliar de manganês e o índice de sítio do Eucalyptus sp., na região de Jacareí.

Na região de Lençóis Paulista, também foram obtidos modelos de produtividade (Tabela 44), que relacionam o índice de sítio com os teores de cálcio e manganês.

A medida que se elevou os teores foliares de cálcio e manganês houve redução da produtividade, conforme mostra as Figuras 14 e 15, respectivamente.

Conclui-se, desta forma, que o crescimento do Eucalyptus sp., na região de Lençóis Paulista, estava associado negativamente ao cálcio e ao manganês.

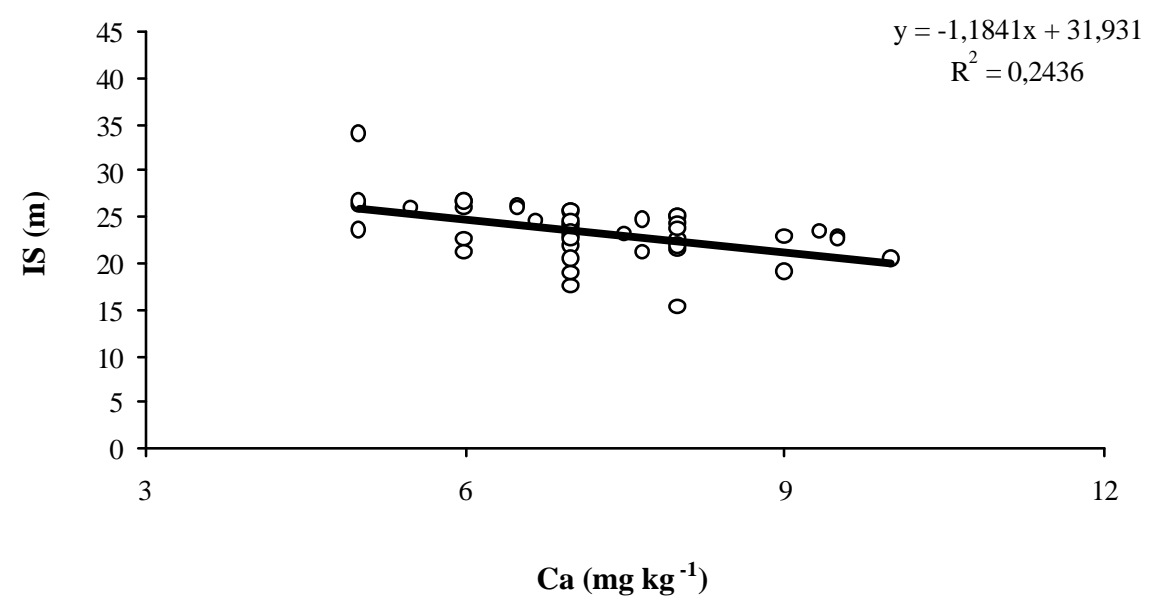


Figura 14 - Relação entre o teor foliar de cálcio e o índice de sítio do Eucalyptus sp., na região de Lençóis Paulista.

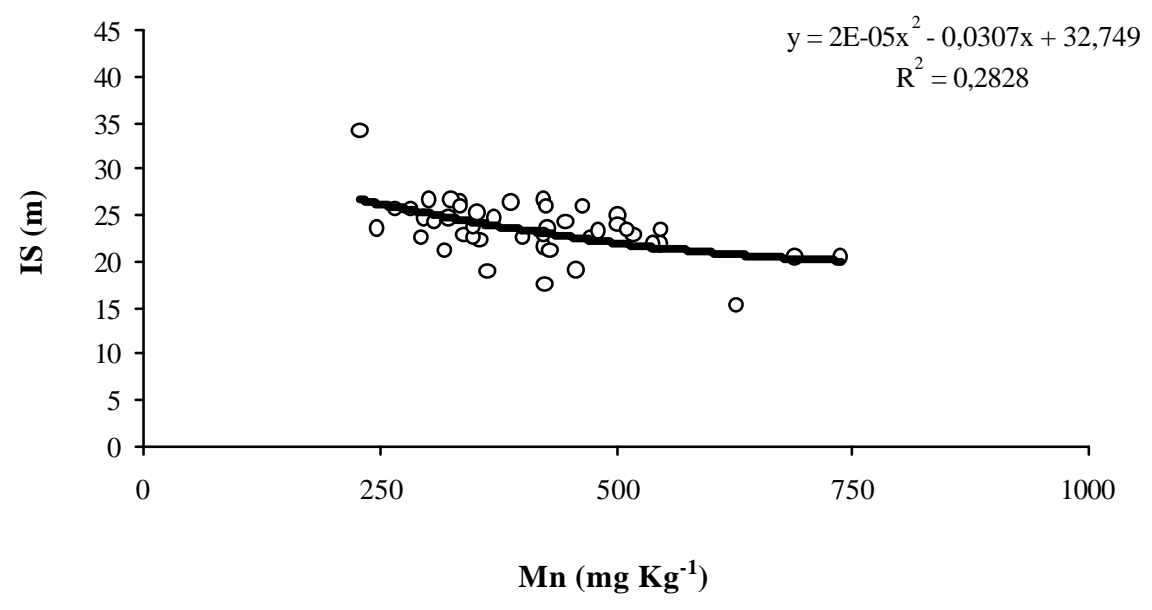

Figura 15 - Relação entre o teor foliar de manganês e o índice de sítio do Eucalyptus sp., na região de Lençóis Paulista.

\subsubsection{Parâmetros químicos do solo e produtividade}

Foram observadas correlações positivas entre os teores de boro no solo e o índice de sítio do Eucalyptus sp., na região de Capão Bonito (Tabela 45), conforme também constatado por Sgarbi et al. 2000a.

Na região de Jacareí, verificou-se que os teores de fósforo, cálcio, a soma de bases, a capacidade de troca de cátions e a relação $\mathrm{Ca} / \mathrm{T}$ apresentaram correlações positivas com o índice de sítio do Eucalyptus sp. (Tabela 45).

Com relação ao fósforo, resultados semelhantes a este foram também obtidos por Zakia et al. (1983), Bellote \& Ferreira (1993), Valeri et al. (1993), Bennett et al. (1996) e Sgarbi et al. (2000a), ao estudarem a relação do teor deste nutriente no solo com a produtividade do Eucalyptus sp.

Com relação a capacidade de troca catiônica do solo, Gonçalves et al. (1990), entretanto, encontraram correlações negativas entre esta variável e a produtividade do $E$. grandis e E. saligna, em alguns solos do Estado de São Paulo. Estes mesmos autores, por 
outro lado, também verificaram que o teores de matéria orgânica, principal fonte de cargas negativas nos solos florestais, encontrados nas camadas mais superficiais (0 a $10 \mathrm{~cm})$, apresentaram correlações positivas com a produtividade de ambas espécies.

O aumento da produtividade do Eucalyptus sp., na região de Jacareí, com o aumento dos teores de cálcio, soma de bases e a relação $\mathrm{Ca} / \mathrm{T}$, ocorreu em decorrência dos elevados teores de potássio no complexo de troca, o que proporcionou uma redução dos teores trocáveis de cálcio, sendo este o nutriente mais limitante para o crescimento do Eucalyptus sp., nesta região.

Não foram observadas correlações significativas entre os parâmetros químicos dos solos da região de Lençóis Paulista e de todas as região conjuntamente com o índice de sítio do Eucalyptus sp. (Tabela 45).

Tabela 45 - Correlação (coeficiente de correlação de Pearson) entre o índice de sítio e os parâmetros químicos do solo, nas diferentes regiões.

\begin{tabular}{|c|c|c|c|c|}
\hline Parâmetro & Capão Bonito & Jacareí & Lençóis Paulista & Todas \\
\hline $\mathrm{PH}$ & 0,218 n.s. & $-0,218$ n.s. & $-0,367 *$ & $-0,210 *$ \\
\hline M.O. & 0,233 n.s. & $-0,324$ n.s. & $0,354 *$ & $0,274 * *$ \\
\hline $\mathrm{P}$ & 0,208 n.s. & $0,674 *$ & $-0,332 *$ & 0,131 n.s. \\
\hline $\mathrm{K}$ & 0,147 n.s. & 0,443 n.s. & $-0,147$ n.s. & $0,232 *$ \\
\hline $\mathrm{Mg}$ & 0,232 n.s. & 0,558 n.s. & $-0,022$ n.s. & $0,223 *$ \\
\hline $\mathrm{Ca}$ & 0,162 n.s. & $0,693 *$ & $-0,308 *$ & $-0,029$ n.s. \\
\hline SB & 0,184 n.s. & $0,667 *$ & $-0,298 *$ & 0,043 n.s. \\
\hline $\mathrm{T}$ & 0,241 n.s. & $0,694 *$ & $-0,034$ n.s. & $0,307 * *$ \\
\hline V & 0,163 n.s. & 0,099 n.s. & $-0,341 *$ & $-0,160$ n.s. \\
\hline $\mathrm{K} / \mathrm{T}$ & $-0,093$ n.s. & $-0,013$ n.s. & $-0,156$ n.s. & $-0,071$ n.s. \\
\hline $\mathrm{Mg} / \mathrm{T}$ & 0,074 n.s. & $-0,155$ n.s. & $-0,032$ n.s. & 0,065 n.s. \\
\hline $\mathrm{Ca} / \mathrm{T}$ & 0,192 n.s. & $0,616^{*}$ & $-0,340 *$ & $-0,203^{*}$ \\
\hline B & $0,538 * *$ & $-0,188$ n.s. & 0,249 n.s. & $0,420 * *$ \\
\hline $\mathrm{Cu}$ & $-0,024$ n.s. & 0,353 n.s. & $0,393 * *$ & 0,014 n.s. \\
\hline $\mathrm{Fe}$ & $0,350 * *$ & $-0,009$ n.s. & $0,412 * *$ & 0,368 n.s. \\
\hline $\mathrm{Mn}$ & $0,297 *$ & 0,035 n.s. & $-0,008$ n.s. & 0,244 n.s. \\
\hline $\mathrm{Zn}$ & $0,373 * *$ & 0,020 n.s. & $-0,238$ n.s. & 0,276 n.s. \\
\hline
\end{tabular}


Não foi possível obter modelos matemáticos que explicassem as variações do índice de sítio do Eucalyptus sp., em função das variações dos parâmetros químicos do solo, em todas as regiões estudadas. Isso mostra a importância da diagnose foliar como ferramenta complementar às análises de solo, nos levantamentos nutricionais em plantios de Eucalyptus sp. Esse efeito se deve a interação dos fatores genéticos (espécie, progênie e clone) e climáticos (precipitação, temperatura e luminosidade) no processo de absorção dos nutrientes e consequentemente na produtividade do Eucalyptus sp.

\subsubsection{Estado nutricional e parâmetros químicos do solo}

Na região de Capão Bonito, observou-se um aumento dos teores foliares de cálcio a medida que se aumentou os teores de potássio e magnésio no solo (Tabela 46). Estes resultados divergem daqueles propostos por Marschner (1995) e Malavolta et al. (1997), os quais explicam o efeito de antagonismo entre estes nutrientes.

$\mathrm{Na}$ região de Jacareí, verificou-se uma correlação negativa entre o teor de fósforo no solo e os teores foliares de nitrogênio no Eucalyptus sp. Essa relação se deve ao efeito de diluição do nitrogênio nos tecidos vegetais em função do maior crescimento das plantas, a medida que se aumentou os teores de fósforo no solo (Tabela 47). Observou-se também um aumento nos teores foliares de cálcio a medida que se aumentou os níveis de zinco no solo (Tabela 47). Estes resultados também divergem daqueles sugeridos por Malavolta et al. (1997), os quais explicam a relação de inibição competitiva existente entre estes dois nutrientes. Foi observado correlações positivas entre o teor foliar de enxofre e o teor de boro no solo e entre o teor foliar de manganês e o teor de magnésio no solo. O teor foliar de cobre apresentou correlações negativas com os teores de potássio e magnésio no solo. Observou-se também uma correlação negativa entre o teor foliar de manganês e o teor de boro no solo.

Na região de Lençóis Paulista, verificou-se haver correlações positivas entre os teores de potássio no solo e nos tecidos foliares (Tabela 48). 
Quando se analisou todas as regiões conjuntamente, foram observadas correlações positivas entre os teores de matéria orgânica e de boro no solo com os teores foliares deste nutriente nas plantas (Tabela 49). 
Tabela 46 - Correlação (coeficiente de correlação de Pearson) entre as características químicas do solo e os teores foliares dos nutrientes na região de Capão Bonito.

\begin{tabular}{|c|c|c|c|c|c|c|c|c|c|c|c|}
\hline \multirow{2}{*}{$\begin{array}{c}\text { Parâmetros } \\
\text { do solo } \\
\end{array}$} & \multicolumn{11}{|c|}{ Teores foliares } \\
\hline & $\mathrm{N}$ & $\mathrm{P}$ & $\mathrm{K}$ & $\mathrm{Ca}$ & $\mathrm{Mg}$ & $\mathrm{S}$ & $\mathrm{B}$ & $\mathrm{Cu}$ & $\mathrm{Fe}$ & Mn & $\mathrm{Zn}$ \\
\hline $\mathrm{Ph}$ & $0,252 *$ & 0,245 n.s. & 0,128 n.s. & $0,474 * *$ & 0,169 n.s. & 0,172 n.s. & $-0,039$ n.s. & $0,282 *$ & $0,475 * *$ & $-0,194$ n.s. & $0,370 * *$ \\
\hline M.O. & $-0,076$ n.s. & $-0,160$ n.s. & 0,096 n.s. & $0,452 * *$ & $0,276 *$ & 0,038 n.s. & $0,293 *$ & $0,371 * *$ & $0,325 *$ & $-0,073$ n.s. & 0,204 n.s. \\
\hline $\mathrm{P}$ & 0,121 n.s. & 0,114 n.s. & 0,064 n.s. & $0,449 * *$ & $0,313 *$ & 0,063 n.s. & 0,006 n.s. & $0,288 *$ & $0,376 * *$ & $-0,336 * *$ & $0,334 * *$ \\
\hline $\mathrm{K}$ & 0,060 n.s. & 0,020 n.s. & 0,241 n.s. & $0,568 * *$ & $0,274 *$ & $-0,022$ n.s. & 0,033 n.s. & $0,313 *$ & 0,046 n.s. & $-0,211$ n.s. & $0,418 * *$ \\
\hline $\mathrm{Ca}$ & 0,093 n.s. & 0,034 n.s. & 0,055 n.s. & $0,463 * *$ & $0,256 *$ & $-0,053$ n.s. & 0,028 n.s. & $0,338 * *$ & $0,415 * *$ & $-0,240$ n.s. & $0,313 *$ \\
\hline $\mathrm{Mg}$ & 0,090 n.s. & 0,048 n.s. & 0,093 n.s. & $0,526 * *$ & $0,274 *$ & $-0,012$ n.s. & $-0,047$ n.s. & $0,322 *$ & $0,441 * *$ & $-0,260 *$ & $0,307 *$ \\
\hline $\mathrm{B}$ & 0,028 n.s. & 0,032 n.s. & 0,105 n.s. & $0,406 * *$ & $0,292 *$ & $0,321 *$ & 0,244 n.s. & 0,007 n.s. & $-0,032$ n.s. & $-0,233$ n.s. & 0,227 n.s. \\
\hline $\mathrm{Cu}$ & 0,085 n.s. & $-0,061$ n.s. & $-0,038$ n.s. & $0,266 *$ & 0,023 n.s. & $-0,115$ n.s. & $-0,017$ n.s. & $0,346 * *$ & 0,205 n.s. & $-0,065$ n.s. & 0,208 n.s. \\
\hline $\mathrm{Fe}$ & $-0,143$ n.s. & $-0,025$ n.s. & $-0,065$ n.s. & 0,071 n.s. & 0,017 n.s. & 0,215 n.s. & $0,424 * *$ & $-0,083$ n.s. & 0,061 n.s. & $-0,099$ n.s. & $-0,322 *$ \\
\hline $\mathrm{Mn}$ & 0,112 n.s. & 0,108 n.s. & 0,159 n.s. & $0,464 * *$ & 0,182 n.s. & 0,147 n.s. & 0,138 n.s. & $0,305 *$ & 0,012 n.s. & $-0,087$ n.s. & $0,350 * *$ \\
\hline $\mathrm{Zn}$ & 0,118 n.s. & 0,251 n.s. & 0,062 n.s. & $0,342 * *$ & 0,249 n.s. & $0,294 *$ & $0,286 *$ & 0,118 n.s. & 0,224 n.s. & $-0,344 * *$ & 0,215 n.s. \\
\hline
\end{tabular}

n.s. não significativo; $*$ significativo a $5 \%$ de probabilidade; $* *$ significativo a $1 \%$ de probabilidade. 
Tabela 47 - Correlação (coeficiente de correlação de Pearson) entre as características químicas do solo e os teores foliares dos nutrientes na região de Jacareí.

\begin{tabular}{|c|c|c|c|c|c|c|c|c|c|c|c|}
\hline \multirow{2}{*}{$\begin{array}{c}\text { Parâmetros } \\
\text { do solo }\end{array}$} & \multicolumn{11}{|c|}{ Teores foliares } \\
\hline & $\mathrm{N}$ & $\mathrm{P}$ & $\mathrm{K}$ & $\mathrm{Ca}$ & $\mathrm{Mg}$ & $\mathrm{S}$ & $\mathrm{B}$ & $\mathrm{Cu}$ & $\mathrm{Fe}$ & Mn & $\mathrm{Zn}$ \\
\hline $\mathrm{PH}$ & 0,532 n.s. & 0,498 n.s. & 0,598 n.s. & 0,408 n.s. & 0,257 n.s. & 0,040 n.s. & $-0,385$ n.s. & $-0,444$ n.s. & $-0,414$ n.s. & $-0,040$ n.s. & 0,511 n.s. \\
\hline M.O. & 0,247 n.s. & 0,344 n.s. & $-0,079$ n.s. & $-0,224$ n.s. & 0,205 n.s. & 0,500 n.s. & $-0,306$ n.s. & 0,469 n.s. & $-0,061$ n.s. & $-0,428$ n.s. & 0,119 n.s. \\
\hline $\mathrm{P}$ & $-0,766 * *$ & $-0,566$ n.s. & $-0,429$ n.s. & $-0,414$ n.s. & $-0,541$ n.s. & $-0,592$ n.s. & 0,544 n.s. & $-0,305$ n.s. & 0,132 n.s. & 0,484 n.s. & $-0,448$ n.s. \\
\hline $\mathrm{K}$ & $-0,188$ n.s. & $-0,185$ n.s. & 0,122 n.s. & 0,575 n.s. & 0,131 n.s. & $-0,501$ n.s. & 0,302 n.s. & $-0,778 * *$ & $-0,038$ n.s. & 0,296 n.s. & 0,152 n.s. \\
\hline $\mathrm{Ca}$ & $-0,253$ n.s. & $-0,191$ n.s. & 0,190 n.s. & 0,211 n.s. & 0,052 n.s. & $-0,533$ n.s. & 0,456 n.s. & $-0,571$ n.s. & $-0,251$ n.s. & $0,766 * *$ & 0,013 n.s. \\
\hline $\mathrm{Mg}$ & $-0,419$ n.s. & $-0,271$ n.s. & $-0,038$ n.s. & 0,112 n.s. & $-0,192$ n.s. & $-0,450$ n.s. & 0,521 n.s. & $-0,801 * *$ & $-0,174$ n.s. & 0,593 n.s. & 0,209 n.s. \\
\hline $\mathrm{B}$ & 0,292 n.s. & 0,317 n.s. & $-0,125$ n.s. & $-0,580$ n.s. & $-0,042$ n.s. & $0,706 *$ & $-0,427$ n.s. & 0,521 n.s. & 0,158 n.s. & $-0,736 * *$ & 0,042 n.s. \\
\hline $\mathrm{Cu}$ & $-0,166$ n.s. & $-0,037$ n.s. & $-0,098$ n.s. & $-0,258$ n.s. & $-0,126$ n.s. & $-0,352$ n.s. & 0,280 n.s. & $-0,355$ n.s. & $-0,090$ n.s. & 0,352 n.s. & $-0,072$ n.s. \\
\hline $\mathrm{Fe}$ & 0,404 n.s. & 0,380 n.s. & 0,290 n.s. & $-0,030$ n.s. & 0,558 n.s. & 0,286 n.s. & $-0,075$ n.s. & 0,046 n.s. & $-0,177$ n.s. & $-0,341$ n.s. & 0,495 n.s. \\
\hline $\mathrm{Mn}$ & 0,062 n.s. & 0,015 n.s. & 0,055 n.s. & 0,421 n.s. & $-0,102$ n.s. & $-0,282$ n.s. & $-0,016$ n.s. & $-0,543$ n.s. & $-0,215$ n.s. & 0,435 n.s. & 0,037 n.s. \\
\hline $\mathrm{Zn}$ & 0,190 n.s. & 0,076 n.s. & 0,249 n.s. & $0,758 * *$ & 0,131n.s. & $-0,143$ n.s. & $-0,192$ n.s. & $-0,582$ n.s. & $-0,129$ n.s. & 0,073 n.s. & 0,273 n.s. \\
\hline
\end{tabular}


Tabela 48 - Correlação (coeficiente de correlação de Pearson) entre as características químicas do solo e os teores foliares dos nutrientes na região de Lençóis Paulista.

\begin{tabular}{|c|c|c|c|c|c|c|c|c|c|c|c|}
\hline \multirow{2}{*}{$\begin{array}{c}\text { Parâmetros } \\
\text { do Solo } \\
\end{array}$} & \multicolumn{11}{|c|}{ Teores foliares } \\
\hline & $\mathrm{N}$ & $\mathrm{P}$ & $\mathrm{K}$ & $\mathrm{Ca}$ & $\mathrm{Mg}$ & S & $\mathrm{B}$ & $\mathrm{Cu}$ & $\mathrm{Fe}$ & Mn & $\mathrm{Zn}$ \\
\hline $\mathrm{PH}$ & $-0,421 * *$ & 0,041 n.s. & $0,444 * *$ & 0,099 n.s. & $-0,002$ n.s. & $-0,188$ n.s. & $-0,130$ n.s. & $-0,065$ n.s. & $-0,043$ n.s. & 0,189 n.s. & $-0,179$ n.s. \\
\hline M.O. & $0,490 * *$ & 0,027 n.s. & $-0,259$ n.s. & $-0,237$ n.s. & $-0,067$ n.s. & 0,213 n.s. & 0,097 n.s. & 0,240 n.s. & 0,217 n.s. & $-0,354 *$ & 0,166 n.s. \\
\hline $\mathrm{P}$ & $-0,141$ n.s. & 0,144 n.s. & 0,294 n.s. & 0,059 n.s. & 0,042 n.s. & 0,013 n.s. & 0,017 n.s. & 0,136 n.s. & $-0,237$ n.s. & $-0,026$ n.s. & $-0,034$ n.s. \\
\hline $\mathrm{K}$ & $-0,279$ n.s. & 0,133 n.s. & $0,660 * *$ & $-0,281$ n.s. & 0,118 n.s. & $-0,276$ n.s. & 0,002 n.s. & $-0,011$ n.s. & 0,101 n.s. & 0,050 n.s. & $-0,135$ n.s. \\
\hline $\mathrm{Ca}$ & $-0,342 *$ & $-0,024$ n.s. & $0,362 *$ & 0,029 n.s. & 0,056 n.s. & $-0,132$ n.s. & 0,018 n.s. & $-0,309 *$ & $-0,031$ n.s. & 0,013 n.s. & $-0,354 *$ \\
\hline $\mathrm{Mg}$ & $-0,073$ n.s. & $-0,254$ n.s. & 0,283 n.s. & $-0,338 *$ & 0,201 n.s. & $-0,101$ n.s. & $-0,122$ n.s. & $-0,054$ n.s. & $-0,017$ n.s. & 0,084 n.s. & $-0,186$ n.s. \\
\hline $\mathrm{B}$ & 0,061 n.s. & 0,074 n.s. & $-0,261$ n.s. & 0,011 n.s. & $-0,013$ n.s. & 0,089 n.s. & 0,261 n.s. & 0,154 n.s. & $-0,144$ n.s. & $-0,192$ n.s. & 0,191 n.s. \\
\hline $\mathrm{Cu}$ & $-0,042$ n.s. & $-0,122$ n.s. & $-0,436 * *$ & 0,014 n.s. & $-0,177$ n.s. & 0,093 n.s. & 0,243 n.s. & $0,496 * *$ & 0,155 n.s. & $-0,186$ n.s. & 0,197 n.s. \\
\hline $\mathrm{Fe}$ & $0,327 *$ & 0,117 n.s. & $-0,317 *$ & $-0,171$ n.s. & 0,099 n.s. & 0,096 n.s. & 0,264 n.s. & 0,095 n.s. & 0,267 n.s. & $-0,247$ n.s. & 0,153 n.s. \\
\hline $\mathrm{Mn}$ & $-0,063$ n.s. & $-0,121$ n.s. & 0,230 n.s. & $-0,097$ n.s. & $-0,088$ n.s. & $-0,102$ n.s. & 0,058 n.s. & 0,081 n.s. & $-0,041$ n.s. & 0,043 n.s. & $-0,206$ n.s. \\
\hline $\mathrm{Zn}$ & 0,015 n.s. & 0,227 n.s. & $0,392 * *$ & $-0,192$ n.s. & 0,122 n.s. & 0,026 n.s. & 0,059 n.s. & $-0,113$ n.s. & $-0,071$ n.s. & $-0,074$ n.s. & $-0,129$ n.s. \\
\hline
\end{tabular}


Tabela 49 - Correlação (coeficiente de correlação de Pearson) entre as características químicas do solo e os teores foliares dos nutrientes em todas as região estudadas.

\begin{tabular}{|c|c|c|c|c|c|c|c|c|c|c|c|}
\hline \multirow{2}{*}{$\begin{array}{c}\text { Parâmetros } \\
\text { do Solo } \\
\end{array}$} & \multicolumn{11}{|c|}{ Teores foliares } \\
\hline & $\mathrm{N}$ & $\mathrm{P}$ & $\mathrm{K}$ & $\mathrm{Ca}$ & $\mathrm{Mg}$ & S & B & $\mathrm{Cu}$ & $\mathrm{Fe}$ & Mn & $\mathrm{Zn}$ \\
\hline $\mathrm{PH}$ & $0,208 *$ & $0,186 *$ & 0,136 n.s. & $0,321 * *$ & $-0,166$ n.s. & $-0,030$ n.s. & $-0,332 * *$ & $0,269 * *$ & 0,130 n.s. & $-0,264 * *$ & 0,138 n.s. \\
\hline M.O. & $-0,341 * *$ & $-0,184 *$ & 0,126 n.s. & $-0,097$ n.s. & $0,461 * *$ & 0,086 n.s. & $0,585 * *$ & $-0,299 * *$ & 0,170 n.s. & $0,229 *$ & $-0,128$ n.s. \\
\hline $\mathrm{P}$ & 0,065 n.s. & 0,083 n.s. & 0,082 n.s. & $0,256 * *$ & $0,206 *$ & 0,042 n.s. & $-0,001$ n.s. & 0,165 n.s. & $0,302 * *$ & $-0,128$ n.s. & $0,216 *$ \\
\hline $\mathrm{K}$ & $-0,168$ n.s. & $-0,152$ n.s. & $0,348 * *$ & 0,084 n.s. & $0,260 * *$ & $-0,038$ n.s. & 0,152 n.s. & 0,007 n.s. & 0,037 n.s. & $0,333 * *$ & $0,277 * *$ \\
\hline $\mathrm{Ca}$ & 0,158 n.s. & 0,051 n.s. & 0,095 n.s. & $0,330 * *$ & $-0,020$ n.s. & $-0,084$ n.s. & $0,184 *$ & $-0,049$ n.s. & $0,308 * *$ & 0,034 n.s. & 0,069 n.s. \\
\hline $\mathrm{Mg}$ & $-0,071$ n.s. & $-0,039$ n.s. & 0,161 n.s. & 0,140 n.s. & $0,311 * *$ & $-0,030$ n.s. & $-0,270 * *$ & $0,316 * *$ & $0,292 * *$ & $-0,173$ n.s. & $0,254 * *$ \\
\hline $\mathrm{B}$ & $-0,231 *$ & 0,003 n.s. & 0,085 n.s. & 0,037 n.s. & $0,437 * *$ & $0,240 * *$ & $0,528 * *$ & $-0,377 * *$ & $-0,063$ n.s. & $-0,014$ n.s. & $-0,123$ n.s. \\
\hline $\mathrm{Cu}$ & 0,070 n.s. & $-0,020$ n.s. & $-0,093$ n.s. & $0,189 *$ & 0,006 n.s. & $-0,121$ n.s. & 0,027 n.s. & 0,149 n.s. & $0,188 *$ & $-0,111$ n.s. & 0,091 n.s. \\
\hline $\mathrm{Fe}$ & $-0,088$ n.s. & $-0,054$ n.s. & $-0,067$ n.s. & $-0,111$ n.s. & 0,113 n.s. & $0,206 *$ & $0,267 * *$ & $-0,047$ n.s. & 0,086 n.s. & 0,059 n.s. & $-0,067$ n.s. \\
\hline Mn & $-0,051$ n.s. & $-0,124$ n.s. & 0,155 n.s. & 0,090 n.s. & 0,091 n.s. & 0,077 n.s. & 0,056 n.s. & 0,059 n.s. & $-0,017$ n.s. & $0,457 * *$ & $0,282 * *$ \\
\hline $\mathrm{Zn}$ & 0,040 n.s. & 0,089 n.s. & 0,171 n.s. & 0,113 n.s. & 0,178 n.s. & $0,258 * *$ & 0,097 n.s. & 0,085 n.s. & 0,161 n.s. & 0,100 n.s. & $0,261 * *$ \\
\hline
\end{tabular}

n.s. não significativo; * significativo a $5 \%$ de probabilidade; ** significativo a $1 \%$ de probabilidade. 
Não foram obtidos modelos matemáticos entre os teores foliares dos nutrientes e os parâmetros químicos do solo, na região de Capão Bonito e Lençóis Paulista. Na região de Jacareí, determinou-se modelos entre os teores foliares de cobre e os teores de potássio e magnésio no solo (Tabela 50). A medida que se elevou os teores de potássio e magnésio no solo, houve uma redução linear nos teores foliares de cobre no Eucalyptus sp. (Figuras 16 e 17).

Quando se avaliou todas as regiões conjuntamente, verificou-se um aumento linear nos teores foliares de boro a medida que se aumentou os teores de matéria orgânica no solo (Figura 18).

Conclui-se, desta forma, que a redução nos teores foliares de cobre, na região de Jacareí, estavam associados aos aumentos dos teores de potássio e magnésio no solo e que os aumentos dos teores foliares de boro, nas diferentes regiões estudadas, estavam associados ao aumento dos teores de matéria orgânica.

Tabela 50 - Relação entre os parâmetros químicos do solo e os teores foliares dos nutrientes no Eucalyptus sp., em função das regiões estudadas.

\begin{tabular}{ccc}
\hline Região & Modelo & $\mathbf{r}^{\mathbf{2}}$ \\
\hline Jacareí & $\mathrm{CuF}=11,88-1,80 \mathrm{KS}$ & 0,60 \\
Jacareí & $\mathrm{CuF}=10,62-0,28 \mathrm{MgS}$ & 0,64 \\
Todas regiões & $\mathrm{BF}=12,93+0,53 \mathrm{M} . \mathrm{O}$. & 0,34 \\
\hline
\end{tabular}

$\mathrm{CuF}$ : teor foliar de cobre ( $\mathrm{mg} \mathrm{kg}^{-1}$ de MS); BF: teor foliar de boro ( $\mathrm{mg} \mathrm{kg}^{-1}$ de MS); KS: teor de potássio no solo $\left(\mathrm{mmol}_{c} \mathrm{dm}^{-3}\right) ; \mathrm{MgS}$ : teor de magnésio no solo $\left(\mathrm{mmol}_{\mathrm{c}} \mathrm{dm}^{-3}\right)$; M.O.: teor de matéria orgânica no solo (mg $\left.\mathrm{dm}^{-3}\right)$. 


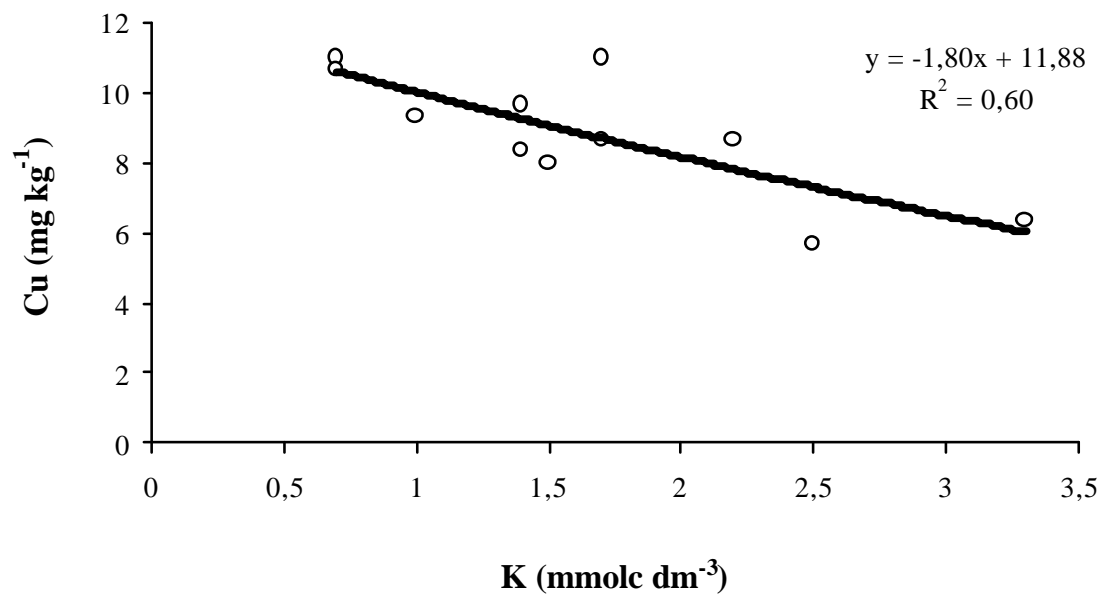

Figura 16 - Relação entre o teor de potássio no solo e o teor foliar de cobre no Eucalyptus sp., na região de Jacareí.

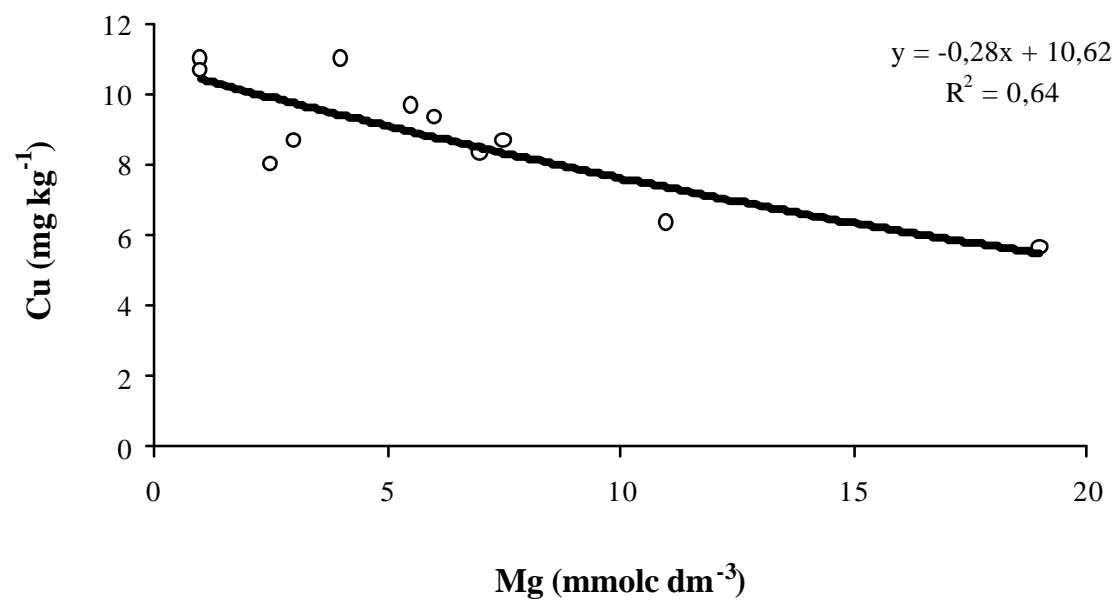

Figura 17 - Relação entre o teor de magnésio no solo e o teor foliar de cobre no Eucalyptus sp., na região de Jacareí. 


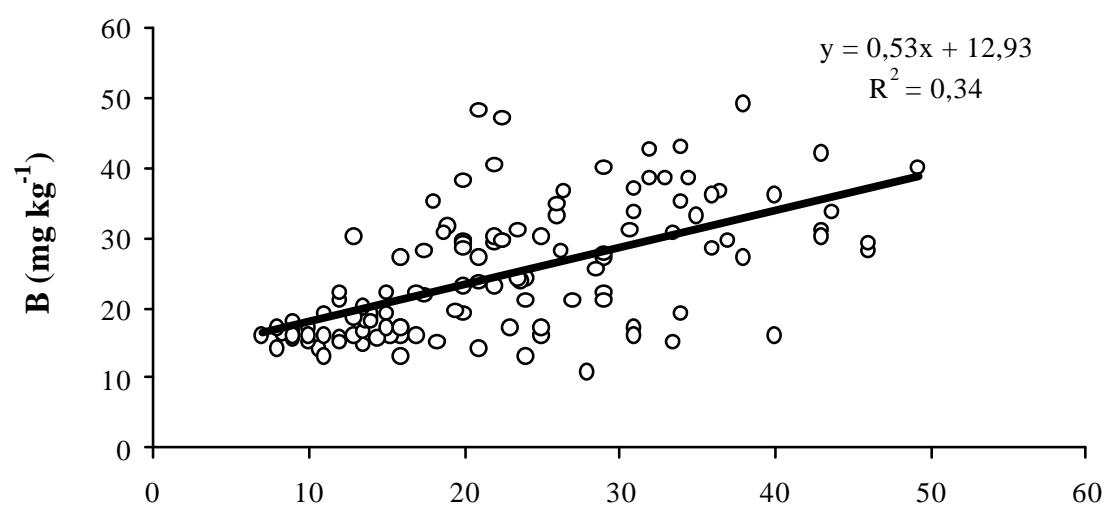

M.O. (mmolc $\left.\mathbf{d m}^{-3}\right)$

Figura 18 - Relação entre o teor de matéria orgânica no solo e o teor foliar de boro no Eucalyptus sp., em todas as região estudadas.

\subsection{Sistema integrado de diagnose e recomendação (DRIS)}

Com o auxílio do software DRIS, foram obtidos os índices primários para cada um dos nutrientes, nas regiões de Capão Bonito, Jacareí, Lençóis Paulista e em todas as regiões, conforme mostra as Tabelas 51, 52, 53 e 54 .

Tabela 51 - Índices primários dos nutrientes obtidos para os plantios de Eucalyptus sp., na região de Capão Bonito.

\begin{tabular}{cccccccccccc}
\hline Fazenda & & \multicolumn{10}{c}{ Índices Primários } \\
\hline & $\mathrm{N}$ & $\mathrm{P}$ & $\mathrm{K}$ & $\mathrm{Ca}$ & $\mathrm{Mg}$ & $\mathrm{S}$ & $\mathrm{B}$ & $\mathrm{Cu}$ & $\mathrm{Fe}$ & $\mathrm{Mn}$ & $\mathrm{Zn}$ \\
$\mathrm{A}$ & $-1,4$ & $-0,3$ & $-1,1$ & 0,0 & $-1,0$ & 0,5 & $-1,6$ & $-2,0$ & $-0,3$ & 3,4 & $-3,5$ \\
$\mathrm{~B}$ & $-6,3$ & $-59,6$ & $-3,4$ & $-0,8$ & $-0,1$ & 0,6 & $-201,2$ & 47,5 & 7,8 & 2,3 & 79,9 \\
$\mathrm{D}$ & $-0,7$ & 0,7 & $-0,8$ & 0,4 & $-0,7$ & 0,6 & $-3,2$ & $-0,6$ & $-0,6$ & 0,4 & $-0,6$ \\
$\mathrm{C}$ & $-1,4$ & $-0,1$ & $-2,9$ & $-0,5$ & $-0,9$ & 0,5 & $-84,4$ & 259,1 & $-430,2$ & $-5,0$ & $-6,8$ \\
$\mathrm{E}$ & $-2,6$ & $-1,9$ & $-1,1$ & 0,0 & $-0,1$ & 0,3 & $-1,3$ & 0,1 & $-0,5$ & 4,3 & $-0,8$ \\
$\mathrm{~F}$ & $-1,9$ & $-7,6$ & $-1,2$ & 0,2 & $-0,7$ & 0,0 & $-2,3$ & 1,0 & 4,1 & 3,0 & $-1,9$ \\
$\mathrm{G}$ & $-1,3$ & $-1,9$ & $-0,7$ & 0,2 & 0,1 & 0,2 & $-2,0$ & $-0,2$ & $-0,5$ & 3,3 & $-0,6$ \\
$\mathrm{H}$ & $-1,1$ & $-0,5$ & $-1,1$ & 0,0 & $-0,1$ & 0,3 & $-1,8$ & 0,5 & 0,7 & 1,6 & $-1,6$ \\
Média & $-2,1$ & $-8,9$ & $-1,5$ & 0,0 & $-0,4$ & 0,4 & $-37,2$ & 38,2 & $-52,4$ & 1,7 & 8,0 \\
\hline
\end{tabular}


Tabela 52 - Índices primários dos nutrientes obtidos para os plantios de Eucalyptus sp., na região de Jacareí.

\begin{tabular}{cccccccccccc}
\hline $\begin{array}{c}\text { Fazend } \\
\text { a }\end{array}$ & \multicolumn{110}{c}{ Índices Primários } \\
\hline & $\mathrm{N}$ & $\mathrm{P}$ & $\mathrm{K}$ & $\mathrm{Ca}$ & $\mathrm{Mg}$ & $\mathrm{S}$ & $\mathrm{B}$ & $\mathrm{Cu}$ & $\mathrm{Fe}$ & $\mathrm{Mn}$ & $\mathrm{Zn}$ \\
$\mathrm{A}$ & $-2,1$ & $-3,8$ & $-1,5$ & $-0,1$ & $-1,2$ & 0,4 & $-11,0$ & $-0,2$ & $-0,4$ & 10,1 & 1,8 \\
$\mathrm{~B}$ & $-0,4$ & $-2,0$ & $-1,4$ & $-1,1$ & $-1,2$ & 0,5 & $-10,2$ & 1,8 & 2,7 & 3,3 & 1,3 \\
$\mathrm{D}$ & $-1,6$ & $-1,7$ & $-1,1$ & $-2,4$ & $-0,9$ & 0,4 & $-27,0$ & 1,6 & $-1,2$ & 19,3 & 7,2 \\
$\mathrm{C}$ & $-1,6$ & $-2,2$ & $-1,7$ & $-1,4$ & $-1,0$ & 0,5 & $-14,5$ & 1,0 & $-0,9$ & 12,1 & 3,1 \\
$\mathrm{E}$ & $-2,5$ & $-4,0$ & $-2,6$ & $-1,9$ & $-1,1$ & 0,4 & $-8,9$ & 3,6 & 0,6 & 15,8 & $-0,5$ \\
$\mathrm{~F}$ & $-3,9$ & $-5,9$ & $-2,6$ & $-1,6$ & $-0,9$ & 0,3 & $-3,2$ & $-1,1$ & 0,5 & 22,5 & $-0,9$ \\
Média & $-2,0$ & $-3,3$ & $-1,8$ & $-1,4$ & $-1,0$ & 0,4 & $-12,5$ & 1,1 & 0,2 & 13,9 & 2,0 \\
\hline
\end{tabular}

Tabela 53 - Índices primários dos nutrientes obtidos para os plantios de E. grandis, na região de Lençóis Paulista.

\begin{tabular}{cccccccccccc}
\hline $\begin{array}{c}\text { Fazend } \\
\text { a }\end{array}$ & \multicolumn{10}{c}{ Índices Primários } \\
\hline & $\mathrm{N}$ & $\mathrm{P}$ & $\mathrm{K}$ & $\mathrm{Ca}$ & $\mathrm{Mg}$ & $\mathrm{S}$ & $\mathrm{B}$ & $\mathrm{Cu}$ & $\mathrm{Fe}$ & $\mathrm{Mn}$ & $\mathrm{Zn}$ \\
$\mathrm{A}$ & $-0,4$ & 0,0 & $-1,6$ & 0,3 & $-1,2$ & 0,5 & $-9,0$ & 1,2 & 0,2 & 2,0 & 0,0 \\
$\mathrm{~B}$ & 0,1 & 0,2 & $-0,8$ & 0,0 & $-1,2$ & 0,4 & $-8,0$ & 2,3 & 0,2 & 0,9 & 0,1 \\
$\mathrm{D}$ & 0,2 & 0,3 & $-0,8$ & 0,0 & $-1,2$ & 0,5 & $-8,2$ & 1,2 & 0,5 & 1,2 & $-0,4$ \\
$\mathrm{C}$ & $-0,5$ & 0,2 & $-2,2$ & 0,2 & $-1,5$ & 0,4 & $-11,3$ & 3,1 & $-0,4$ & 1,9 & 1,2 \\
$\mathrm{E}$ & $-0,3$ & $-0,1$ & $-1,4$ & 0,0 & $-1,4$ & 0,4 & $-9,7$ & 1,7 & 1,1 & 2,0 & 0,4 \\
$\mathrm{~F}$ & $-0,8$ & 0,4 & $-0,5$ & 0,1 & $-1,1$ & 0,3 & $-10,9$ & 1,3 & 0,3 & 2,8 & $-0,4$ \\
$\mathrm{G}$ & $-0,5$ & 0,1 & $-2,0$ & 0,3 & $-1,5$ & 0,5 & $-8,3$ & 2,1 & $-0,2$ & 1,7 & 0,2 \\
Média & $-0,3$ & 0,1 & $-1,3$ & 0,1 & $-1,3$ & 0,4 & $-9,3$ & 1,8 & 0,2 & 1,8 & 0,2 \\
\hline
\end{tabular}


Tabela 54 - Índices primários dos nutrientes obtidos para os plantios de Eucalyptus sp. em todas as regiões do Estado de São Paulo.

\begin{tabular}{ccccccccccc}
\hline \multicolumn{11}{c}{ Índices Primários } \\
\hline $\mathrm{N}$ & $\mathrm{P}$ & $\mathrm{K}$ & $\mathrm{Ca}$ & $\mathrm{Mg}$ & $\mathrm{S}$ & $\mathrm{B}$ & $\mathrm{Cu}$ & $\mathrm{Fe}$ & $\mathrm{Mn}$ & $\mathrm{Zn}$ \\
$-1,5$ & $-4,3$ & $-1,5$ & $-0,4$ & $-0,9$ & 0,4 & $-20,9$ & 15,5 & $-19,8$ & 5,2 & 3,7 \\
\hline
\end{tabular}

A partir destes índices, estabeleceu-se a ordem de limitação dos nutrientes para cada uma das fazendas e regiões, conforme apresentado nas Tabelas 59, 60, 61 e 62.

Tabela 55 - Ordem de limitação dos nutrientes para os plantios de Eucalyptus sp. na região de Capão Bonito.

\begin{tabular}{cc}
\hline $\begin{array}{c}\text { Fazend } \\
\text { a }\end{array}$ & Ordem de Limitação \\
\hline $\mathrm{A}$ & $\mathrm{Mn}<\mathrm{S}<\mathrm{Ca}<\mathrm{Fe}=\mathrm{P}<\mathrm{Mg}<\mathrm{K}<\mathrm{N}<\mathrm{B}<\mathrm{Cu}<\mathrm{Zn}$ \\
$\mathrm{B}$ & $\mathrm{Zn}<\mathrm{Cu}<\mathrm{Fe}<\mathrm{Mn}<\mathrm{S}<\mathrm{Mg}<\mathrm{Ca}<\mathrm{K}<\mathrm{N}<\mathrm{P}<\mathrm{B}$ \\
$\mathrm{D}$ & $\mathrm{P}<\mathrm{S}<\mathrm{Mn}=\mathrm{Ca}<\mathrm{Cu}=\mathrm{Fe}=\mathrm{Zn}<\mathrm{N}=\mathrm{Mg}<\mathrm{K}<\mathrm{B}$ \\
$\mathrm{C}$ & $\mathrm{Cu}<\mathrm{S}<\mathrm{P}<\mathrm{Ca}<\mathrm{Mg}<\mathrm{N}<\mathrm{K}<\mathrm{Mn}<\mathrm{Zn}<\mathrm{B}<\mathrm{Fe}$ \\
$\mathrm{E}$ & $\mathrm{Mn}<\mathrm{S}<\mathrm{Cu}<\mathrm{Ca}<\mathrm{Mg}<\mathrm{Fe}<\mathrm{Zn}<\mathrm{K}<\mathrm{B}<\mathrm{P}<\mathrm{N}$ \\
$\mathrm{F}$ & $\mathrm{Fe}<\mathrm{Mn}<\mathrm{Cu}<\mathrm{Ca}<\mathrm{S}<\mathrm{Mg}<\mathrm{K}<\mathrm{Zn}=\mathrm{N}<\mathrm{B}<\mathrm{P}$ \\
$\mathrm{G}$ & $\mathrm{Mn}<\mathrm{Ca}=\mathrm{S}<\mathrm{Mg}<\mathrm{Cu}<\mathrm{Fe}<\mathrm{Zn}<\mathrm{K}<\mathrm{N}<\mathrm{P}<\mathrm{B}$ \\
$\mathrm{H}$ & $\mathrm{Mn}<\mathrm{Fe}<\mathrm{Cu}<\mathrm{S}<\mathrm{Ca}<\mathrm{Mg}<\mathrm{P}<\mathrm{N}=\mathrm{K}<\mathrm{Zn}<\mathrm{B}$ \\
Média & $\mathrm{Cu}<\mathrm{Zn}<\mathrm{Mn}<\mathrm{S}<\mathrm{Ca}<\mathrm{Mg}<\mathrm{K}<\mathrm{N}<\mathrm{P}<\mathrm{B}<\mathrm{Fe}$ \\
\hline
\end{tabular}

Tabela 56 - Ordem de limitação dos nutrientes para os plantios de Eucalyptus sp. na região de Jacareí.

\begin{tabular}{cc}
\hline $\begin{array}{c}\text { Fazend } \\
\text { a }\end{array}$ & Ordem de Limitação \\
\hline $\mathrm{A}$ & $\mathrm{Mn}<\mathrm{Zn}<\mathrm{S}<\mathrm{Ca}<\mathrm{Cu}<\mathrm{Fe}<\mathrm{Mg}<\mathrm{K}<\mathrm{N}<\mathrm{P}<\mathrm{B}$ \\
$\mathrm{B}$ & $\mathrm{Mn}<\mathrm{Fe}<\mathrm{Cu}<\mathrm{Zn}<\mathrm{S}<\mathrm{N}<\mathrm{Ca}<\mathrm{Mg}<\mathrm{K}<\mathrm{P}<\mathrm{B}$ \\
$\mathrm{D}$ & $\mathrm{Mn}<\mathrm{Zn}<\mathrm{Cu}<\mathrm{S}<\mathrm{Mg}<\mathrm{K}<\mathrm{Fe}<\mathrm{N}<\mathrm{P}<\mathrm{Ca}<\mathrm{B}$ \\
$\mathrm{C}$ & $\mathrm{Mn}<\mathrm{Zn}<\mathrm{Cu}<\mathrm{S}<\mathrm{Fe}<\mathrm{Mg}<\mathrm{Ca}<\mathrm{N}<\mathrm{K}<\mathrm{P}<\mathrm{B}$ \\
$\mathrm{E}$ & $\mathrm{Mn}<\mathrm{Cu}<\mathrm{Fe}<\mathrm{S}<\mathrm{Zn}<\mathrm{Mg}<\mathrm{Ca}<\mathrm{N}<\mathrm{K}<\mathrm{P}<\mathrm{B}$ \\
$\mathrm{F}$ & $\mathrm{Mn}<\mathrm{Fe}<\mathrm{S}<\mathrm{Zn}=\mathrm{Mg}<\mathrm{Cu}<\mathrm{Ca}<\mathrm{K}<\mathrm{B}<\mathrm{N}<\mathrm{P}$ \\
Média & $\mathrm{Mn}<\mathrm{Zn}<\mathrm{Cu}<\mathrm{S}<\mathrm{Fe}<\mathrm{Mg}<\mathrm{Ca}<\mathrm{K}<\mathrm{N}<\mathrm{P}<\mathrm{B}$ \\
\hline
\end{tabular}


Tabela 57 - Ordem de limitação dos nutrientes para os plantios de Eucalyptus sp. na região de Lençóis Paulista.

\begin{tabular}{cc}
\hline $\begin{array}{c}\text { Fazend } \\
\text { a }\end{array}$ & Ordem de Limitação \\
\hline $\mathrm{A}$ & $\mathrm{Mn}<\mathrm{Cu}<\mathrm{S}<\mathrm{Ca}<\mathrm{Fe}<\mathrm{P}=\mathrm{Zn}<\mathrm{N}<\mathrm{Mg}<\mathrm{K}<\mathrm{B}$ \\
$\mathrm{B}$ & $\mathrm{Cu}<\mathrm{Mn}<\mathrm{S}<\mathrm{P}=\mathrm{Fe}<\mathrm{Zn}=\mathrm{N}<\mathrm{Ca}<\mathrm{K}<\mathrm{Mg}<\mathrm{B}$ \\
$\mathrm{D}$ & $\mathrm{Cu}=\mathrm{Mn}<\mathrm{S}=\mathrm{Fe}<\mathrm{P}<\mathrm{N}<\mathrm{Ca}<\mathrm{Zn}<\mathrm{K}<\mathrm{Mg}<\mathrm{B}$ \\
$\mathrm{C}$ & $\mathrm{Cu}<\mathrm{Mn}<\mathrm{Zn}<\mathrm{S}<\mathrm{P}<\mathrm{Ca}<\mathrm{Fe}<\mathrm{N}<\mathrm{Mg}<\mathrm{K}<\mathrm{B}$ \\
$\mathrm{E}$ & $\mathrm{Mn}<\mathrm{Cu}<\mathrm{Fe}<\mathrm{S}=\mathrm{Zn}<\mathrm{Ca}<\mathrm{P}<\mathrm{N}<\mathrm{K}=\mathrm{Mg}<\mathrm{B}$ \\
$\mathrm{F}$ & $\mathrm{Mn}<\mathrm{Cu}<\mathrm{P}<\mathrm{S}=\mathrm{Fe}<\mathrm{Ca}<\mathrm{Zn}<\mathrm{K}<\mathrm{N}<\mathrm{Mg}<\mathrm{B}$ \\
$\mathrm{G}$ & $\mathrm{Cu}<\mathrm{Mn}<\mathrm{S}<\mathrm{Ca}<\mathrm{Zn}<\mathrm{P}<\mathrm{Fe}<\mathrm{N}<\mathrm{Mg}<\mathrm{K}<\mathrm{B}$ \\
Média & $\mathrm{Cu}=\mathrm{Mn}<\mathrm{S}<\mathrm{Fe}=\mathrm{Zn}<\mathrm{P}=\mathrm{Ca}<\mathrm{N}<\mathrm{Mg}=\mathrm{K}<\mathrm{B}$ \\
\hline
\end{tabular}

Tabela 58 - Ordem de limitação dos nutrientes para os plantios de Eucalyptus sp. em todas as regiões do Estado de São Paulo.

$\frac{\text { Ordem de Limitação }}{\mathrm{Cu}<\mathrm{Mn}<\mathrm{Zn}<\mathrm{S}<\mathrm{Ca}<\mathrm{Mg}<\mathrm{N}=\mathrm{K}<\mathrm{P}<\mathrm{Fe}<\mathrm{B}}$

De acordo com os índices primários obtidos através do software DRIS verificou-se que o boro, o fósforo e o nitrogênio foram os nutrientes mais limitantes para o crescimento do Eucalyptus sp., nas regiões de Capão Bonito e Jacareí. Na região de Capão Bonito, verificou-se que o ferro foi o nutriente mais limitante apenas na fazenda $\mathrm{C}$, como indicado na Tabela 55.

Sgarbi et al. (2000a e b) e Silveira et al. 1995c também encontraram relações positivas do boro com a produtividade, mostrando ser este nutriente um dos mais limitantes para o crescimento do Eucalyptus sp., na maior parte dos plantios do Estado de São Paulo.

Em relação ao fósforo e ao nitrogênio, Zakia et al. (1983), Bellote e Ferreira (1993), Louw (1997) e Silveira et al. (2000c) também constataram que estes nutrientes estavam sendo limitantes para o crescimento do Eucalyptus sp.

Na região de Lençóis Paulista, os índices primários mostraram que o boro, o magnésio e o potássio foram os nutrientes mais limitantes para o crescimento do Eucalyptus sp. A 
limitação proporcionada pelo magnésio e pelo potássio, na região de Lençóis Paulista, estava associada as elevadas quantidades de lama-cal aplicadas nestas áreas, as quais são ricas em cálcio, o que certamente reduziu a disponibilidade de magnésio e potássio às plantas. 


\section{CONCLUSÕES}

De acordo com os resultados obtidos, no presente trabalho, concluiu-se que:

Nas regiões de Capão Bonito e Jacareí, os nutrientes mais limitantes para o crescimento do Eucalyptus sp. foram o boro, o fósforo e o nitrogênio.

Os elevados teores de cobre no solo, nas regiões de Capão Bonito e de Jacareí, proporcionaram uma redução no crescimento do Eucalyptus sp.

Nas regiões de Jacareí e Lençóis Paulista, o manganês foi responsável pelo menor crescimento do Eucalyptus sp.

Os elevados teores de cálcio, na região de Lençóis Paulista, limitaram o crescimento do E. grandis.

$\mathrm{Na}$ região de Lençóis Paulista, a baixa participação do magnésio e do potássio no complexo de troca catiônica do solo proporcionaram um menor crescimento do E. grandis.

O boro foi o nutriente mais limitante para o crescimento do Eucalyptus sp., em todas as regiões avaliadas. 
ANEXOS 
Anexo I. Classificação dos principais tipos de solos encontrados na região de Capão Bonito.

\begin{tabular}{|c|c|c|c|c|}
\hline Código & Ordem & Subordem & Nome & $\operatorname{AR}(\%)^{1}$ \\
\hline LV 64 & Latossolos & Latossolos Vermelhos & $\begin{array}{l}\text { Distróficos, textura argilosa, relevo suave ondulado + } \\
\text { Argilossolos Vermelho-Amarelos distróficos, abrúpticos } \\
\text { ou não, textura média/argilosa e arenosa/média, relevo } \\
\text { ondulado, ambos A moderado }\end{array}$ & 36 \\
\hline CX1 & Cambissolos & Cambissolos Háplicos & $\begin{array}{l}\text { Distróficos, A moderado, textura argilosa, relevo forte } \\
\text { ondulado }\end{array}$ & 13 \\
\hline LVA 35 & Latossolos & Latossolos Vermelho-Amarelos & $\begin{array}{c}\text { Distróficos, textura argilosa, relevo ondulado + } \\
\text { Argilossolos Vermelho-Amarelos distróficos, textura } \\
\text { média/argilosa, relevo ondulado e forte ondulado, ambos } \\
\text { A moderado }\end{array}$ & 10 \\
\hline PVA 47 & Argissolos & Argissolos Vermelho-Amarelos & $\begin{array}{l}\text { Distróficos, abrúpticos, A moderado e proeminente, } \\
\text { textura média/argilosa com cascalhos + Cambissolos } \\
\text { Háplicos distróficos e eutróficos, A moderado e textura } \\
\text { argilosa, com cascalhos e média, relevo forte ondulado e } \\
\text { ondulado }\end{array}$ & 5 \\
\hline LV 41 & Latossolos & Latossolos Vermelhos & $\begin{array}{l}\text { Distróficos, A moderado, textura argilosa, relevo suave } \\
\text { ondulado }\end{array}$ & 5 \\
\hline LV 40 & Latossolos & Latossolos Vermelhos & $\begin{array}{c}\text { Distróficos, A moderado, textura argilosa, relevo suave } \\
\text { ondulado e plano }\end{array}$ & 4 \\
\hline
\end{tabular}


PV3 Argissolos

CX9 Cambissolos

LVA 37 Latossolos

RL13 Neossolos

PVA 64 Argissolos

Argissolos Vermelho-Amarelos

CX29

Argissolos Vermelhos

Cambissolos Háplicos

Latossolos Vermelho-Amarelos

Neossolos Litólicos
Cambissolos

Eutróficos + Argilossolos Vermelho-Amarelos

Eutróficos, ambos abrúptos, A moderado, textura arenosa/média, relevo suave ondulado e ondulado

Tb Distróficos + Latossolos Vermelho-Amarelos, distróficos, ambos A moderado, textura argilosa, relevo

forte ondulado

Distróficos, textura argilosa, relevo ondulado + Argilossolos Vermelho-Amarelos distróficos, A moderado, textura argilosa e média/argilosa, ambos relevo suave ondulado

Distróficos, textura arenosa + Cambissolos Háplicos, Tb, distróficos, textura média e argilosa, ambos relevo forte ondulado + Argilossolos Vermelho-Amarelos distróficos, textura média/argilosa e arenosa/média, relevo ondulado

$$
\text { e forte ondulado }
$$

Distróficos, textura arenosa/média e média/argilosa, relevo ondulado + Argilossolos Vermelho-Amarelos

distróficos, abrúpticos, textura arenosa/argilosa e arenosa/média, relevo ondulado e forte ondulado, ambos

$$
\text { A moderado. }
$$

Ta, eutróficos, A moderado, textura argilosa + Chernossolos Argilúvicos órticos, textura argilosa + Neossolos Litólicos eutróficos, Ta, A moderado, textura média e argilosa, todos fase rochosa, relevo montanhoso 
ou escapado

CX25 Cambissolos Cambissolos Háplicos

CX6 Cambissolos
Cambissolos Háplicos
Tb, distróficos, textura argilosa + Neossolos Litólicos distróficos, $\mathrm{Tb}$, ambos relevo montanhoso ou escarpado + Latossolos Vermelho-Amarelos distróficos, pouco profundos ou não, ambos textura argilosa, relevo forte ondulado, todos A moderado

Tb distróficos + Cambissolos Háplicos, Tb, distróficos latossólicos, ambos A moderado, textura argilosa e argilosa, com cascalhos relevo montanhoso 
Anexo II. Classificação dos principais tipos de solos encontrados na região de Jacareí.

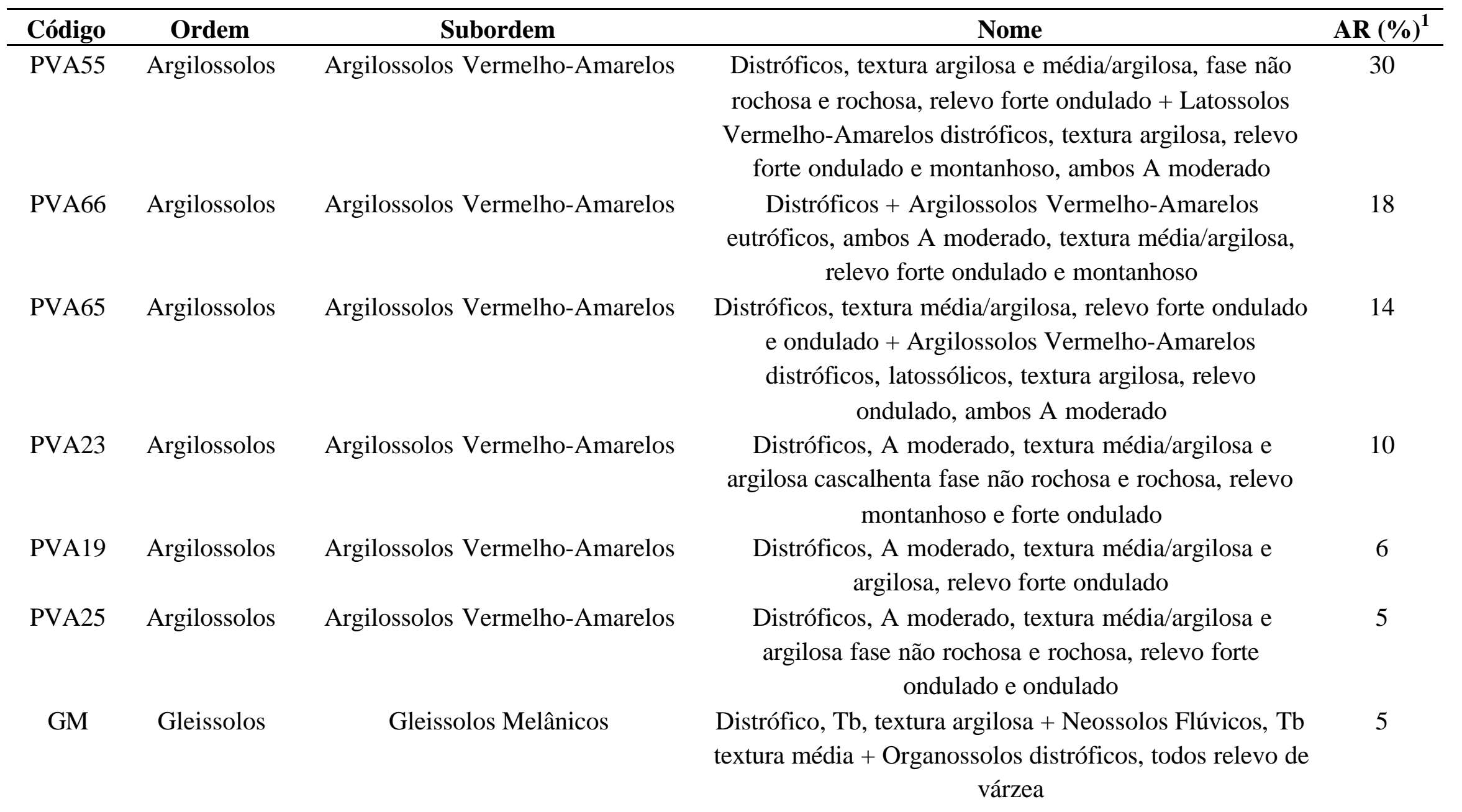


LV 16 Latossolos Latossolos Vermelhos

PVA45 Argilossolos Argilossolos Vermelho-Amarelos

LVA1 Latossolos Latossolos Vermelho-Amarelos

OY1 Organossolos Organossolos Mésicos ou Háplicos

LVA32 Latossolos Latossolos Vermelho-Amarelos

LV $40 \quad$ Latossolos

Latossolos Vermelhos

LVA15 Latossolos Latossolos Vermelho-Amarelos
Distroférricos, textura argilosa + Latossolos Vermelho-

Amarelos distróficos, textura média, ambos A moderado, relevo suave ondulado

Distróficos, textura argilosa e média/argilosa, relevo forte ondulado e montanhoso + Cambissolos Háplicos distróficos, textura argilosa, relevo montanhoso, ambos A moderado

Distróficos, A moderado, textura argilosa, relevo forte ondulado

Distróficos + Gleissolos Melanozêmicos, A proeminente

+ Gleissolos Háplicos, ambos distróficos, Tb, textura argilosa, todos relevo plano de várzea

Distróficos, relevo suave ondulado e plano +

Argilossolos Vermelho-Amarelos distróficos,

latossólicos, relevo suave ondulado, ambos A moderado textura argilosa

Distróficos, A moderado, textura argilosa, relevo suave ondulado e plano

Distróficos, textura argilosa + Cambissolos Háplicos distróficos, textura argilosa e média, ambos A moderado e proeminente, relevo forte ondulado 
Anexo III. Classificação dos principais tipos de solos encontrados na região de Lençóis Paulista.

\begin{tabular}{|c|c|c|c|c|}
\hline Código & Ordem & Subordem & Nome & $\operatorname{AR}(\%)^{1}$ \\
\hline LV56 & Latossolos & Latossolos Vermelhos & $\begin{array}{c}\text { Distróficos + Latossolos Vermelho-Amarelos distróficos, } \\
\text { ambos A moderado, textura média, relevo plano e suave } \\
\text { ondulado e ondulado }\end{array}$ & 47 \\
\hline LV1 & Latossolos & Latossolos Vermelhos & $\begin{array}{c}\text { Eutroférricos e distroférricos, A moderado, textura } \\
\text { argilosa, relevo plano e suave ondulado }\end{array}$ & 29 \\
\hline PVA2 & Argilossolos & Argilossolos Vermelho-Amarelos & $\begin{array}{c}\text { Eutróficos, abrúpticos ou não, A moderado textura } \\
\text { arenosa/média e média, relevo suave ondulado e } \\
\text { ondulado }\end{array}$ & 7 \\
\hline LV45 & Latossolos & Latossolos Vermelhos & $\begin{array}{c}\text { Distróficos, A moderado, textura média, relevo plano e } \\
\text { suave ondulado }\end{array}$ & 5 \\
\hline NV1 & Nitossolos & Nitossolos Vermelhos & $\begin{array}{c}\text { Eutroférricos + Latossolos Vermelhos eutroférricos, } \\
\text { ambos A moderado, textura argilosa, relevo suave } \\
\text { ondulado e ondulado }\end{array}$ & 4 \\
\hline LV6 & Latossolos & Latossolos Vermelhos & $\begin{array}{c}\text { Eutroférricos e distroférricos, relevo plano e suave } \\
\text { ondulado + Nitossolos Vermelhos eutroférricos, relevo } \\
\text { suave ondulado e ondulado, ambos A moderado e } \\
\text { chernozêmico, textura argilosa }\end{array}$ & 3 \\
\hline LV54 & Latossolos & Latossolos Vermelhos & $\begin{array}{l}\text { Distróficos, textura argilosa e média + Latossolos } \\
\text { Vermelhos eutroférricos e distroférricos, textura argilosa, }\end{array}$ & 1 \\
\hline
\end{tabular}


ambos A moderado, relevo plano e suave ondulado

LV52 Latossolos Latossolos Vermelhos

NV6 Nitossolos

Nitossolos Vermelhos
Distróficos, textura argilosa e média + Latossolos Vermelhos distroférricos, textura argilosa, ambos A moderado, relevo suave ondulado

Eutróficos, A chernozêmico + Argilossolos VermelhoAmarelos eutróficos e distróficos, A moderado, ambos textura argilosa, relevo ondulado e forte ondulado + Neossolos Litólicos eutróficos e distróficos, A chernozêmico e moderado, textura média e argilosa, relevo forte ondulado

\footnotetext{
1. Área Relativa
} 


\section{REFERÊNCIAS BIBLIOGRÁFICAS}

BARNES, R. L; RALSTON, C.W. Soil factors related to growth and yield of slash pine plantation. Gainesville: Florida Agriculture Experimental Stations, 1955. 23p. (Bulletin 559).

BARROS, N.F.; NOVAIS, R.F.; NEVES, J.C.L. Fertilização e correção do solo para o plantio de eucalipto. In: BARROS, N.F.; NOVAIS, R.F.(Ed.) Relação solo eucalipto. Viçosa: Ed. Folha de Viçosa, 1990. cap.4, p.127-186.

BARROS, N. F.; NOVAIS, R.F.; CARMO, D.N.; NEVES, J.C.L. Classificação nutricional de sítios florestais - descrição de uma metodologia. Revista Árvore, v.10, p.106-112, 1986.

BEAUFILS, E.R. Pesquisa de uma exploração racional de Hévea após um diagnóstico fisiológico demorado sobre a análise mineral de diversas partes da planta. Fertilité, v.3, p.27-38, 1958.

BEAUFILS, E.R. Diagnosis and Recommendation Integrated System (DRIS). Pietermaritzburg: University of Natal, 1973. 132p. (Soil Science Bulletin, 1)

BELLOTE, A.F.J.; FERREIRA, C.A. Nutrientes minerais e crescimento de árvores adubadas de Eucalyptus grandis, na região do cerrado, no Estado de São Paulo. Boletim de Pesquisa Florestal . n.26/27, p. 17-28, 1993. 
BELLOTE,A.F.J.; SILVA, H.D. Técnicas de amostragem e avaliações nutricionais em plantios de Eucalyptus spp. In: GONÇALVES,J.L.M.; BENEDETTI,V. Nutrição e fertilização florestal. Piracicaba: IPEF, 2000. p.106-133.

BENNETT, L.T.; WESTON, C.J.; JUDD, T.S.; ATTIWILL, P. M.; WHITEMAN, P.H. The effects of fertilizers on early growth and foliar nutrient concentration of three plantation eucalypts on high quality sites in Gippsland, southeastern Australia. Forest Ecology and Management, v.89, p.213-226, 1996.

BHARGAVA, B.S.; CHADA, K. L. Leaf nutrient guide for fruit and plantation crops. Fertility News, v.33, n.7, p.21-29, 1988.

CAMPOS, J. C; TURNBULL, K. J. Um método de estimar índice de local utilizando a análise de tronco. Revista Árvore, v.4, n.1, p.47-61, 1980.

CARDENAS, A, C. Exportação de nutrientes e produtividade de povoamentos de Eucalipto no litoral norte do Espírito Santo. Viçosa, 1987. 113p. Dissertação (Mestrado) - Universidade Federal de Viçosa.

CASTANÕS, M. L. Evaluation de la calidad de estacion de Pino patula en el norte de Oaxaca. Boletim Técnico INIE, v.2, p. 1-32, 1962.

CLUTTER, J. L. Timber management: a quantitative approach. New York: John Wiley, 1983. 333p.

COILE, T.S. Soil and growth of forests. Advances in Agronomy, v.4, p.329-359, 1952. 
GOLFARI, L. Coníferas aptas para reflorestamento nos Estados do Paraná, Santa Catarina e e Rio Grande do Sul. Boletim Técnico IBDF, v.1, p. 1-71, 1971.

GONÇALVES, J.L.M.; DEMATÊ, J.L.I.; COUTO, H.T.Z do. Relações entre a produtividade de sítios florestais de Eucalyptus grandis e Eucalyptus saligna com as propriedades de alguns solos de textura arenosa e média do Estado de São Paulo. IPEF, v.43 44, p.24-39, 1990.

HAGGLUND, B. Evaluation of forest site produtivity. Forestry Abstract, v.42, n.11, p.515-527, 1981.

LOUW, J. H. A site - growth study of Eucalyptus grandis in the Mpumalanga Escarpment area. Southern African Forestry Journal , n.180, p. 1-13, 1997.

MALAVOLTA, E.; VITTI, G.C.; OLIVEIRA, S.A. Avaliação do estado nutricional das plantas: princípios e aplicações. 2.ed. Piracicaba: Associação Brasileira para a Pesquisa da Potassa e do Fosfato, 1997. 319p.

MARSCHNER, H. Mineral nutrition of higher plants. 2. ed. New York: Academic Press, 1995. 889p.

MELO, V.F. Relação entre a reserva mineral dos solos e a produção de nutrientes em povoamentos puros de Eucalyptus saligna Smith no Rio Grande do Sul. Viçosa, 1994. 145p. Dissertação (Mestrado) - Universidade Federal de Viçosa.

MUSHAKA, A. Relationship between growth, mineral nutrition and site factors for Eucalyptus camaldulensis (Dehnh) planted in some communal areas of Zimbabwe. Southern African Forestry Journal, n.183, p. 59-65, 1998. 
OLIVEIRA, J.B de; CAMARGO, M.N.; ROSSI FILHO, M B.C. Mapa pedológico do Estado de São Paulo: legenda expandida. Campinas: Instituto Agronômico; Rio de Janeiro: Embrapa Solos, 1999. 64p.

PHILIP, M. S. Measuring trees and forests. 2. ed. Wallingford: CAB International. 1994. 310p.

RAIJ, B. van. Fertilidade do solo e adubação. Piracicaba: Associação Brasileira para a Pesquisa da Potassa e do Fosfato, 1991. 343p.

QUADROS, R.M.B. Avaliação nutricional em plantios de Eucalyptus grandis, em diferentes solos, no Estado de São Paulo. Curitiba, 1996. 158p. Dissertação (Mestrado) - Universidade Federal do Paraná.

SENTELHAS, P. C.; PEREIRA, A. R.; MARIN, F. R.; ANGELOCCI, L. R.; ALFONSI, R. R.; CARAMORI, P. H.; SWART, S. Balanços hídricos climatológicos do brasil (compact disc). Piracicaba: ESALQ, Depto. Ciências Exatas, 1999.

SGARBI, F.; SILVEIRA, R. L.V. A.; HIGASHI, E.N.; GONÇALVES, N.A. Avaliação do estado nutricional e da fertilidade do solo em plantios de Eucalyptus grandis e Eucalyptus saligna na região de Capão Bonito/SP (compact disc). In: REUNIÃO BRASILEIRA DE FERTILIDADE DO SOLO E NUTRICÃO DE PLANTAS, 25.; REUNIÃO BRASILEIRA SOBRE MICORRIZAS, 8.; SIMPÓSIO BRASILIERO DE MICROBILOGIA DO SOLO, 6; REUNIÃO BRASILEIRA DE BIOLOGIA DO SOLO, 3., Santa Maria, 2000. FERTIBIO 2000: trabalhos. Santa Maria: SBCS; SBM, 2000a. 
SGARBI, F.; SILVEIRA, R. L.V. A.; HIGASHI, E.N.; NETO, C.B.L. Avaliação do estado nutricional e da fertilidade do solo em plantios de Eucalyptus grandis na região de Lençóis Paulista/SP. (compact disc). In: REUNIÃO BRASILEIRA DE FERTILIDADE DO SOLO E NUTRICÃO DE PLANTAS, 25.; REUNIÃO BRASILEIRA SOBRE MICORRIZAS, 8.; SIMPÓSIO BRASILIERO DE MICROBILOGIA DO SOLO, 6; REUNIÃO BRASILEIRA DE BIOLOGIA DO SOLO, 3., Santa Maria, 2000. FERTIBIO 2000: trabalhos. Santa Maria: SBCS; SBM, 2000b.

SILVEIRA, R.L.V.A.; GONÇALVES， A.N.; SILVEIRA， R.I.; BRANCO, E.F. Levantamento do estado nutricional de florestas de Eucalyptus grandis da região de Itatinga-SP. I - Macronutrientes. In: CONGRESSO BRASILEIRO DE CIÊNCIA DO SOLO, Viçosa. 1995. Resumos expandidos. Campinas: SBCS, 1995a. v.2, p. 896-898.

SILVEIRA, R.L.V.A.; GONÇALVES, A.N.; SILVEIRA, R.I.; BRANCO, E.F. Levantamento do estado nutricional de florestas de Eucalyptus grandis da região de Itatinga-SP. II - Micronutrientes. In: CONGRESSO BRASILEIRO DE CIÊNCIA DO SOLO, Viçosa. 1995. Resumos expandidos. Campinas. SBCS, 1995b. v.2, 899-901.

SILVEIRA, R.L.V.A.; HIGASHI, E.N.; POMPERMAYER, P.N. Monitoramento nutricional na Siderúrgica Barra Mansa: relatório de assessoria e pesquisa. Local: Editora, 1998. 92p.

SILVEIRA, R.L.V.A.; HIGASHI, E.N.; MOREIRA, A. Monitoramento nutricional na Lwarcel : relatório de assessoria e pesquisa. Local: Editora, 1999. 62p. 
SILVEIRA, R. L.V.A.; HIGASHI, E. N.; GONÇALVES, A. N.; MOREIRA, A. Avaliação do estado nutricional do Eucalyptus: diagnose visual, foliar e suas interpretações. In: GONÇALVES, J.L.M.; BENEDETTI,V. Nutrição e fertilização florestal, Piracicaba: IPEF, 2000b. cap. 1, p.80-104.

SILVEIRA, R.L.V.A.; ARAÚJO, E.F.; SOUZA, A.J. Avaliação do estado nutricional de clones de Eucalyptus na região sul da Bahia. (compact disc). In: REUNIÃO BRASILEIRA DE FERTILIDADE DO SOLO E NUTRICÃO DE PLANTAS, 25.; REUNIÃO BRASILEIRA SOBRE MICORRIZAS, 8; SIMPÓSIO BRASILIERO DE MICROBILOGIA DO SOLO, 6.; REUNIÃO BRASILEIRA DE BIOLOGIA DO SOLO, 3., Santa Maria, 2000. FERTIBIO 2000: trabalhos. Santa Maria: SBCS.,SBM, 2000c.

SPURR, S.H. Forest ecology. New York: Ronald Press, 1964. 354p.

SPURR, S. H; BARNES, B. V. Forest ecology. New York: Ronald Press, 1973. 572p.

TOME Jr, J. B. Manual para interpretação de análise de solo. Guaíba: Agropecuária, 1997. 247p.

VALERI, S.V.; AGUIAR, I.B.; CORRADINI, L.; Composição química foliar e crescimento volumétrico de Eucalyptus grandis Hill ex Maiden cultivado em areia quartzosa, em resposta à aplicação de fósforo e calcário dolomítico. IPEF, n. 46, p.63-75, 1993. 
WADT, P.G.S. Os métodos da chance matemática e do sistema integrado de diagnose e recomendação (DRIS) na avaliação nutricional de plantios de eucalipto. Viçosa, 1996. 123p. Tese (Doutorado) - Universidade Federal de Viçosa.

ZAKIA, M.J.B.; POGGIANI, F.; COUTO, H.T.Z. do. Correlação entre a concentração de nutrientes nas copas e a altura das árvores de eucalipto plantadas em povoamentos puros. IPEF, n.25, p. 29-32, 1983.

ZIMBACK, C.R.L.; MORAES, M.H.; LIMA, S. L. de.; CARVALHO, A. M. de. Correlações entre propriedades químicas e físicas dos solos com a produtividade de Eucalyptus spp. em Latossolos Vermelho Amarelos em São Paulo. In: CONGRESSO LATINO AMERICANO DE CIÊNCIA DO SOLO, 12., Águas de Lindóia, 1996. SOLO SUELO 1996. Local: Editora, 1996. 